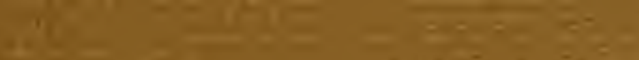

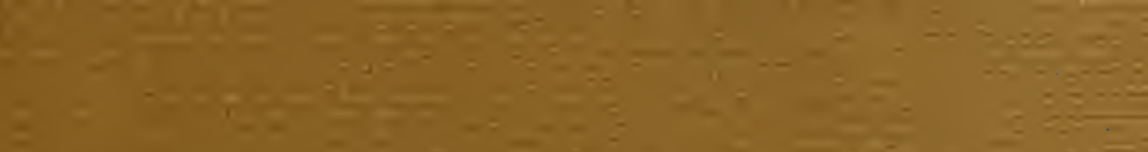

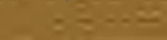

$=0$

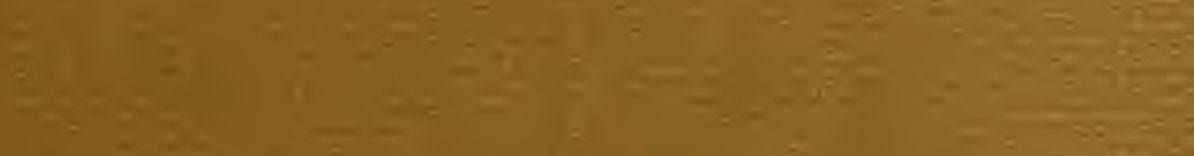

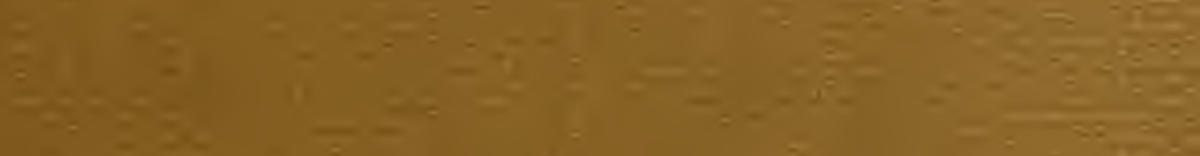

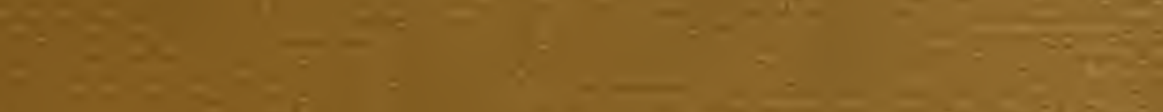
(1)

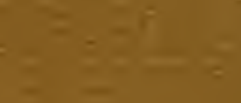

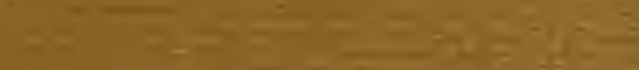

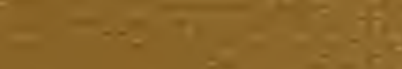

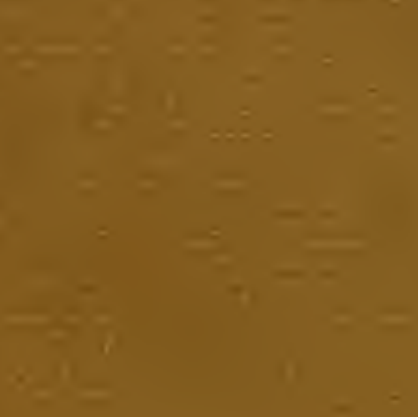

$=$

(11)

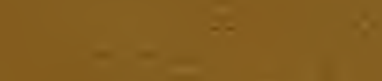

(1)

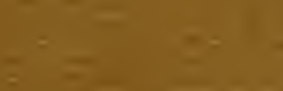

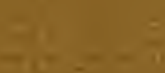

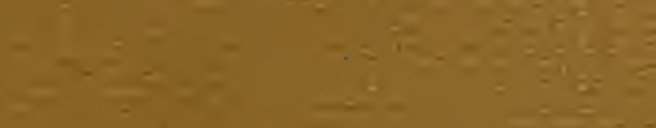

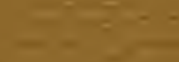

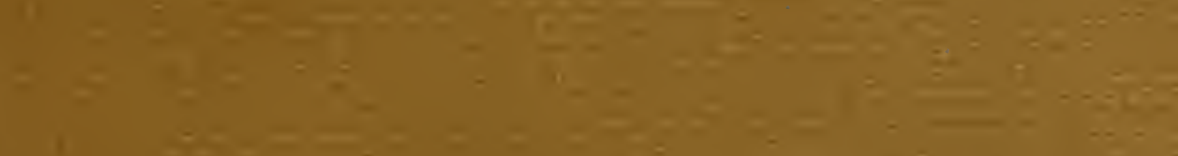
1

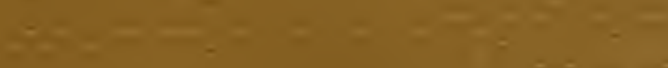

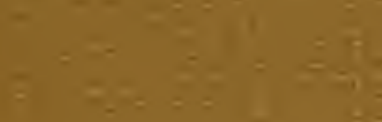
$=0+\frac{1}{2}=0$

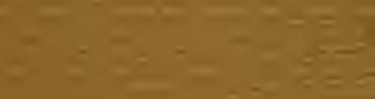

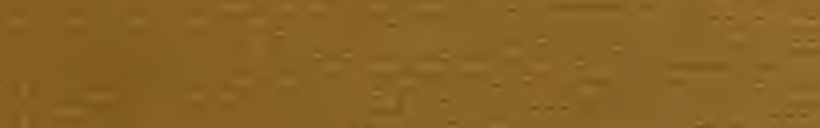
7 18

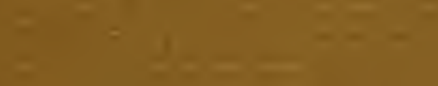

11.

it. $1 \leq \pm 1 \leq 1 \leq-$

$=$

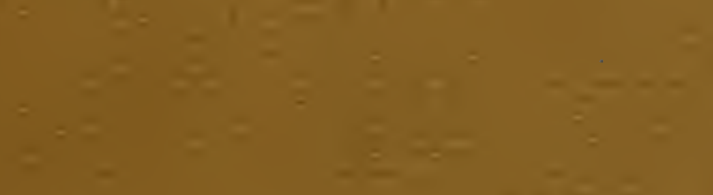

$8=$

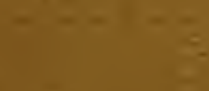

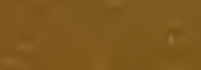

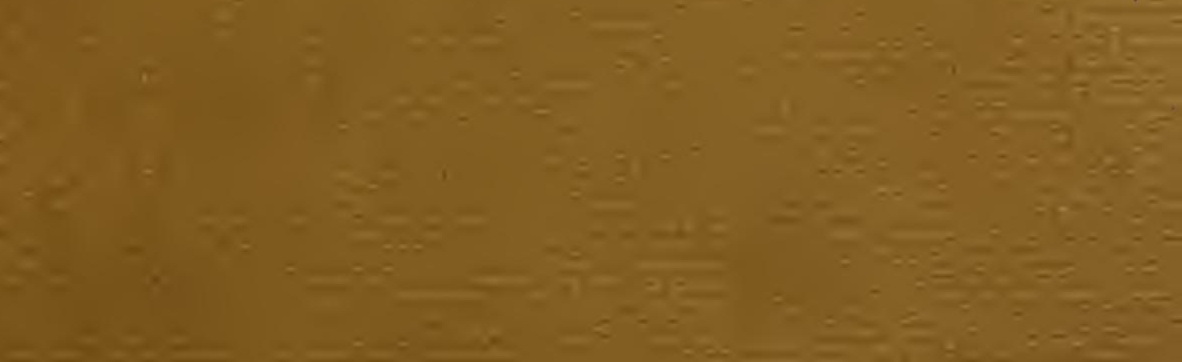

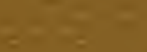

$+9$ 


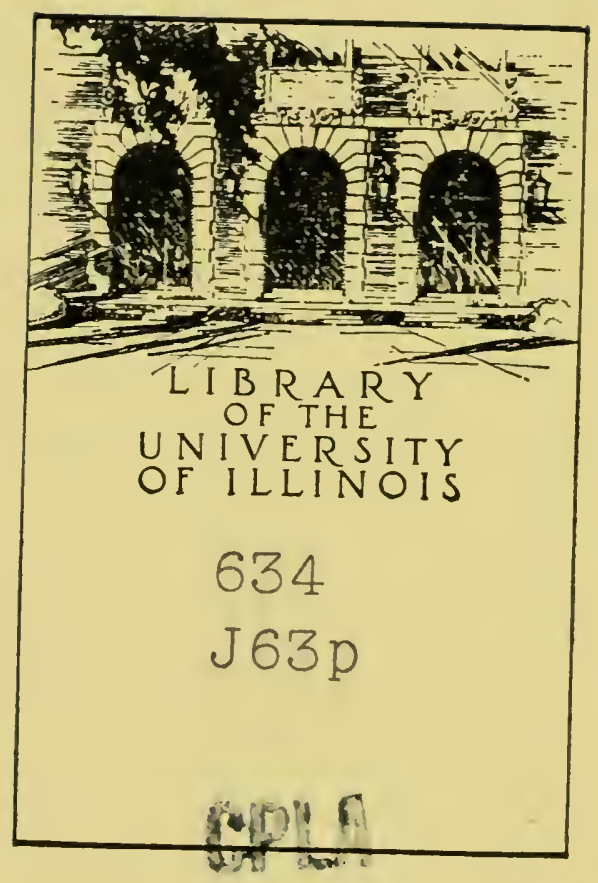






\section{SCIENCE AND PRACTICE}

$$
\text { or }
$$

GARDENING. 

THE

\section{PRINCIPLES}

OF

\section{PRACTICAL GARDENING.}

BY

GEORGE W. JOHNSON, ESQ.

FELLOW OF THE AGRI-HORTICLLTLRAL SOCIFTY OF INDIA: COREESPNDING MEMBER OF THE RUYAL CALEDONIAN AND MARYLAND HORTICULTLRAL SUCIETIES, ETC. ETC.

\section{LONDON :}

ROBERT BALDWIN, 47, PATERNOSTER ROW. 



\section{4 \\ $363 p$}

\section{PREFACE.}

For nearly twenty years the Author of these pages has laboured to make the gardeners of England more generally aware than they are, even at present, of the principles on which their practices are, or ought to be, founded. The results of his early researches have, from time to time, been made public, and those, together with more that are new, he now offers to his readers in a collected and orderly form.

$\mathrm{He}$ has thus laboured to impart the reasons for horticultural practice, because it is certain that gardening is no exception to the rule, that the worst of ignorance is an ignorance of the reasons for our conduct; and if this volume aids in some degree to remove such ignorance from the gardener, the Author will be happy in the consciousness that he has helped the advance of plant-culture from mere empiricism into the class of the rational sciences. 
w

가

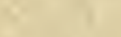

-

(8) 


\section{CONTENTS.}

\begin{tabular}{|c|c|c|c|c|c|c|c|}
\hline & & & & & & & PAGE \\
\hline IXTRODCCTION . & . & - & - & - & - & . & 1 \\
\hline Chapter I.-Sowing & - & . & - & - & - & - & S \\
\hline Chapter II.-The Root & - & - & - & . & - & - & 49 \\
\hline Chapter III.-The Stem & and & Branch & & . & - & - & 125 \\
\hline Chapter IV.-The Leave & & - & - & - & - & - & 135 \\
\hline Chapter V.-The Sap & $\cdot$ & - & - & - & - & - & 152 \\
\hline CHAPTER VI.-The Flowe & & - & - & - & - & - & 185 \\
\hline CHAPTER VII. - The Fruit & t and & Seed & . & 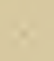 & 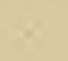 & . & 212 \\
\hline CaAfEer VIII, - The Dis & eases & of Plar & & . & $\cdot$ & - & 243 \\
\hline Crapter IX.-Death and & Deco & omposit & & . & $\because$ & $\because$ & 303 \\
\hline
\end{tabular}





\section{THE}

\section{PRINCIPLES OF GARDENING.}

\section{INTRODUCTION.}

GaRDening or Horticulture has for its objects, the production of the fruits, flowers, and culinary vegetables of any climate, in any habitable place, in the greatest perfection, and at the least possible expense.

Like all other human occupations, gardening is divisible into the science which teaches the principles and circumstances on which the attainment of the desired objects is founded; and the art or practical skill which enables the practitioner to secure those circumstances, and effectuate those principles.

It is to the first of these departments of knowledge that the following pages are devoted: their prime subject being the guidance afforded to the gardener in the practice of his art by chemistry, vegetable physiology, and other sciences.

If any one asks what those sciences have done for 
gardening, I point to the discoveries of the late Mr. Knight. The opinion of that most scienced horticulturist is also recorded in a letter from him now in my possession,- - the words should be engraved over the portal of every garden: "Physiological kxowLEDGE CAN ALONE NOW DIRECT THE GARDENER TO IMPROVEMENT, FOR HE POSSESSES ALL THAT MERE PRACTICE IS LIKELY to GIVE." Science, it is true, can never supersede the necessity for a practical acquaintance with the operations of the spade, the knife, and the hoe; but it is their best guide,-a pilot needed even by the most experienced, and let it be remembered, that to botanists we owe nearly the whole of our flowers, as well as our knowledge of their habits; and that to information drawn from their discoveries, we are indebted for the majority of our numerous varieties of fruits and culinary vegetables, as well as for a knowledge of their anatomy and functions. Botany also affords the best nomenclature for our plants; and thus, to it we are indebted for an enlightened practice, and a language universally intelligible. But for another science, chemistry, the true nature of 'soils, of manures, of the food and functions of plants, would be unknown to us, and many of our simplest garden operations would be inexplicable.

The growth of horticultural science has been slow; for, although its dawn was in the Elizabethan age, 
yet it never afforded any distinct light to gardening until the beginning of the present century.

It is undoubtedly true, that in much earlier ages there were surmises born of inquiring minds, that are startlingly in accordance with the results afforded by modern regetable chemistry and physiology; but they were no more than surmises; fortunate guesses that, among many totally erroneous, happened to savour of truth. Thus Pythagoras forbade the use of beans as food, because he thought that they and human flesh were created from the same substances, and modern research has rendered it certain that that pulse has among its constituents more animo-vegetable matter than most other seeds. Empedocles maintained that plants are sexual; that they possess life and sensation; and that he remembered when he was a plant himself, previously to being Empédocles.

Theophrastus and Pliny wrote more roluminously upon plants, but not with more knowledge of their physiology; and little or no improved progress is really visible until the sixteenth century was well advanced; for this branch of science was no bright exception from the darkness enveloping all human knowledge during the middle ages, and it was not until that period in which Bacon lived, that the human mind threw off the trammels of the schoolmen, and instead of arguing as to what must be, 
proceeded to examine and search out what is. The Reformation, the spirit of the age, was then not confined to religion. By delivering the human mind from thraldom, and teaching man to search all things, but to retain only that which is good because true, it gave an impetus to improvement which no tyrant opposition has ever since been enabled to check.

Such men as Bacon, Peiresc, Evelyn, Grew and Malpighi arose. Bacon was the first to teach aloud that man can discover truth in no way but by observing and imitating the operations of nature; that truth is born of fact, not of speculation; and that systems of knowledge are to be founded not upon ancient authority, not upon metaphysical theories, but upon experiments and observations in the world around us.

Peiresc was a munificent man of letters, whose house, whose advice, and whose purse were opened to the students of every art and science. His library was stored with the literature of every age, and his garden with exotics from every clime, from whence lie delighted to spread them over Europe ${ }^{\text {. }}$

Grew in England, and Malpighi in Italy, deroted themselves to the anatomical examination of plauts, and these were followed by Linnæus, Gærtner, and others, who, trusting only to the dissecting linife and the microscope, soon precipitated into ruins all

a History of English Gardening. 
the fanciful fabrics of the Aristotelians. They were the founders of that science of regetable physiology, which, enlarged and carried into practice by the late Mr. Knight and others, has advanced horticulture to a degree of improvement, undreamed of by their immediate predecessor, Heresbach, when he informed the world that, if the powder of rams' horns is sown, and well watered, "it will come to be good asparagus."

The researches of Hales upon the circulatory power of the sap-ressels, of Bonnet upon the functions of the leares, and of Du Hamel, Priestley, Ingenhousz, Sennebier, Saussure, and others, upon the action of light, and the nature of the gases dereloped during the respiration of plants, imparted still more useful knowledge to the gardener, and rendered his art still less empirical.

The same philosophers directed their attention also to the food of plants imbibed by their roots, and to the examination of their various secretions; but here they were joined by another band of nature's students, and no one conversant with the philosophy of plant-culture but will remember the debt he owes to Vauquelin, Lavoisier, Johns, Davy, Liebig, Lindley, Johnston, and Low.

It thas been my endeavour to concentrate and arrange the results of the researches of the above-named disciples of nature in the following pages,-_adding such rays, 
derived from lesser lights, as aid to render the whole more luminous, and such links of experiments and observations from similar sources as make the work more connected than it would be without their aid.

In the arrangement of this work I might have followed the more obvious plan of commencing with a description of the seed, and the promotion of its production; but I found that the order adopted enabled me to pursue more readily, and more progressively, the phenomena and practices to be explained and illustrated.

A few gardeners may still exist who renture to think science useless-as there once existed a derotee of fashion who wondered why it was not always candle-light; but the great majority of gardeners are now men of science, endeavouring thoroughly to understand the reason of every practice, and the supposed cause of each effect. To those differing from them I might name, if it would not be invidious, nearly all the most successful of our modern gardeners. To a man, these are well acquainted with gardening's relative sciences. I forbear from mentioning names, but I may remind my readers, without fearing to offend, of two departed savans, M. Lavoisier, and our fellow-countryman, Mr. Kinight. Lavoisier, the Linnæus of chemistry, cultivated his grounds in La Vendée on scientific principles, and in a few years their amnual produce doubled that from 
equal spaces of his' neighbours' soil. Mr. Knight has scarcely left a department of our horticulture unimproved, by that combination of scientific with practical knowledge which he, perhaps more than any other man, had united in his orn mind.

It behores every gardener to follow in their steps, for though the great men who have gone before have done much for gardening, yet still more remains to be accomplished. We still, on most points, do and must ever see through a glass darkly; but that is no reason why any one should refrain from the effort to elicit a ray towards diminishing the obscurity - and we may all, without fear of misspending our labour, continue to act as if botany could still furnish something new, and as if chemistry and physiology had still some secret to reveal to the enquirer. 


\section{CHAPTER I.}

SOIVING.

That the seed should have a perfectly developed embryo, and have arrived to nearly perfect ripeness, is essential to its being able to germinate. The reason for this is obvious: the young plant requires for its earliest nourishment a peculiar compound, usually saccharine matter; and this compound, in accordance with that universal fitness of things which demonstrates the wisdom of God, is always generated by the combined agency of heat, moisture, and oxygen gas, from the substances most abundant in the fully ripened seed. Let barley be the example. Saccharine matter is essential for the first nourishment of the radicle and plumule, ${ }^{\mathrm{a}}$ and into such saccharine matter is starch converted, by the combined agency I have named. It is starch, therefore, that is the chief constituent of the seed. But if barley be gathered immature, and dried, the chief ingredient is mucilage or gum; and this, if exposed to the essentials for germination, heat, moisture and oxygen gas, in-

a The thread-like sprouts, becoming afterwards the root and stem, are so named. 
stead of passing into saccharine matter, is converted into acetic acid.

As it is imperative that every seed should have nearly attained to ripeness before it acquires the power of germinating, and that the more perfect the ripeness the more perfect and the more healthy that germination, so is it equally certain, that the length of time it retains the power of germination differs in almost every plant. The seed of the coffee shrub loses all regetative power, unless sown within a few weeks after it has been gathered, whilst that of the melon improres by being stored for one or two years, and celery remains capable of germinating for five times the lastnamed period a. These and all other instances within my knowledge demonstrate, that the more starchy and other matters into which nitrogen ${ }^{b}$ does not enter as a constituent, which a seed contains, the longer will it retain vitality ; and two familiar instances are common rice and the kidney bean. Rice contains 85 per cent. of starch, and will retain its vegetative powers for many years; whilst kidney beans, which contain

a Melon seeds, by keeping, improve only in the sense in which gardeners consider the plant improved, viz. less of stem is produced, and the fruit is matured earlier. Whaterer checks the development of the early organs, the radicle and plumule, produces this effect, and this is effected by age in the melon seed; its starchy component diminishes in quantity, being gradually converted into albumen. This is less easily transmuted to the soluble matters necessary for the nourishment of the parts first developed.

b Nitrogen, a gas present in most animal matters. 
one-third their weight of animo-vegetable matter and other constituents, of which nitrogen is a component, will not vegetate healthily a second season.

\section{Carolina Rice.}

Water

Starch . . . . . . 85.07

Parenchyma . . . . . . 4.80

Gluten . . . . . . . 3.60

Uncrystallizable sugar $\quad \cdot \quad \cdot \quad \cdot 0.29$

Gummy matter, approaching starch . . . . . . 0.71

Oil . . . . . . . 0.13

Phosphate of lime . . . 0.13

$$
99.73^{\mathrm{a}}
$$

Kidney Beans.

Skins . . . . . . . . 288

Starchy fibrous matter . . 425

Starch . . . . . . . 1380

Animo-vegetable matter . . . 799

Extractive . . . . . . 131

Albumen and vegeto-animal matter. . . . . . . 52

Mucilage. . . . . . . . 744

Loss . . . . . . . . 21

$3840^{b}$

a M. Braconnot, in Ann. de Chym. iv. 370.

b Einhof in Gehlen's Journ. vi. 545. 
This speedy loss of vitality in seeds abounding in nitrogenous matter, is just what the chemist would predict; for all bodies so constituted are most prone to decomposition and decay.

The following list, furnished by the late Mr. Loudon, shows the greatest age at which some of our common garden seeds germinate freely; and this result of experience is quite concurrent with our knowledge of their chemical constitution :-

One year. Peas, beans, kidney beans, carrot, parsnip, oraches, herb-patience, rhubarb, elm, poplar, and willow.

Tu'o years. Radish, salsafy, scorzonera, purslane, the alliums, cardoon, rampion, alisander, love apple, capsicum, egg-plant.

Three years. Sea-kale, artichoke, lettuce, marigold, rue, rosemary.

Four years. Brassicas, skirret, spinach, asparagus, endive, mustard, tarragon, borage.

Five and six years. Burnet, sorrel, parsley, dill, femel, chervil, hyssop.

Ten years. Beet, celery, pompion, cucumber, melon. Now in this list generally, as already observed, those with the most of nitrogenous matters among their component parts, are the first to decompose, and consequently lose their vitality; and those with the greatest amount of starch and lignin, or more carbonaceous constituents, retain their germinating 
power the longest, and for the evident reason, that such are less prone to decay.

At the same time, let me guard myself from being misconceived to say, that such are the only chemical causes for a seed's curtailed or protracted vitality. On the contrary, I am well aware there are others, and for example may be taken many seeds abounding with expressed oil. These, exposed to the free operation of the air, gradually lose their vitality, as the oil they contain becomes rancid. Preserved from the action of the air, no seeds are more retentive of vitality, apparently because when so preserved, the oil they contain will remain sweet and unchanged for ages. This is the reason that in earth excarated from great depths below the surface, charlock, mustard, and such like plants, having oleaginous seeds, are found to have retained their embryo vitality.

In considering this subject, let it ever be kept in mind, that almost every species of seed has a peculiar degree of heat, and a peculiar amount of moisture, at or approaching to which its ritality will be excited into action. Therefore, in all observations on the life-retaining power of seeds, and in conclusions deduced from experiment, it must be carefully secured that they have not been excited to those initiatory steps of germination, which being taken and then checked, invariably cause the destruction of a seed's vital powers. 
This brings me to the consideration of the contingencies necessary to cause a seed's germination.

A certain degree of warmth is essential, for no known plant has seeds that will germinate below or at the freezing point of water. A temperature above $32^{\circ}$ of Fahrenheit's thermometer, therefore, is requisite; and the plants whose seeds will germinate nearest to that low degree of temperature, in this country, are the winter weeds. For example, I have found the seeds of the Poa annua, the commonest grass of our gravel walks, germinate at $35^{7}$, and the seeds of groundsel (Senecio vulgaris) would probably require no higher temperature. But, on the other hand, the temperature must not be excessirely high. Even no tropical seed, probably, will germinate at a temperature much above $120^{\circ} \mathrm{F}$., and we know from the experiments of MM. Edwards and Colin, that neither wheat, oats, nor barley will regetate in a temperature of $113^{\circ}$.

Every seed differing in its degree of excitability, consequently has a temperature without which it will not regetate, and from which cause arise the consequences that different plants require to be somn at different seasons, and that they germinate with various degrees of rapidity.

For example, two varieties of early pea, somn on a south border on the same day, and treated strictly

a Jour. de Pharmacie, xxii. 210. 
alike throughout their growth, were about a fortnight differing in all their stages of regetation.

Sown In bloom Gathered from

Cormack's Prince

Albert . Jan. 4. April 1. May 14.

Warwick . Jan.4. April 13. May 28.

Adanson found that, under the most favourable circumstances, various garden seeds might be made to germinate in the following very different spaces of time.

Spinach, Beans, Mustard . 3 days.

Lettuce, Aniseed . . . . 4 ,

Melon, Cucumber, Cress . 5 ,"

Radish, Beet . . . . . 6 ,

Orache . . . . . 8 ,

Purslain . . . . . 9 ,

Cabbage . . . . . 10 ,

Hyssop . . . . . . 30 ,

Parsley . . . . . 40 or 50 do.

Almond, Chesnut, Peach . 1 year.

Rose, Hawthorn, Filbert $\quad 2 \quad$ do. $^{a}$

In one instance M. Adanson certainly must have experimented with old seed, for I have found good new parsley seed, sown on fresh fertile soil in May, had germinated in two days, and its leaves were above the surface within a week from the diay of

a Familles des Plantes, i. $\$ 5$. 
sowing. Then again in the case of rose seed, - at all erents, in the case of that of the dog rose,-if the hips be allowed to endure the frosts of winter before they are gathered, their seed will germinate in much less time than is named by M. Adanson. This lesson was probably taught the gardener by nature, for the hips of roses never shed their seed in this country until they have been frosted.

The gardener should always bear in mind, that it would be a very erroneous conclusion, because a seed does not germinate at the accustomed time, that therefore its regetating powers are departed. No two seeds taken from the same seed-vessel germinate precisely at the same time: but, on the contrary, one will often do so promptly, while its companion seed will remain dormant until another vear. M. De Candolle relates an instance where fresh tobacco seedlings continued to appear annually for ten years on the same plot, though no seed was sown after the first sowing ; and the same phenomenon usually occurs for two or three years, when the seed of either the peony or hawthorn are sown. Why one seed is more easily excited than another is as ret unexplained, but the wisdom of this one of many provisions for aroiding the accidental extinction of a species in any given locality is readily discemed. In ungenial spring may destroy the plants from those seeds which first germinated, but this could 
scarcely occur also to those of the second and third year, or even to those which were only a few weeks later in their regetation.

It is not possible to enunciate a general rule relative to germinating temperatures requiring no exceptions, but in general, for the seeds of plants natives of temperate latitudes, the best germinating temperature is about $60^{\circ} ;^{\text {a }}$ for those of half-hardy plants $\tilde{r} 0^{\circ}$; and for those of tropical plants about $80^{\circ}$; and the necessity for such temperatures depends upon the same causes that prevent the incubation of eggs unless they be kept for a certain period at a temperature of about $100^{\circ}$. The requisite changes are not produced either in the seed or in the egg, unless it be submitted to the propitious temperature-but why this is requisite to develope the forms, and effect the changes, without which there is no vitality, is a secret at present withheld from man's understanding by the Almighty architect, and we must rest satisfied with the approximate knowledge that heat is the vast and all pervading agent he employs to call life into existence.

Although temperatures ranging between $60^{\circ}$ and $80^{2}$, are those most usually propitious to germination, yet a much higher temperature can be endured by seed without its vitality being destroyed, and

a Except where otherwise stated, Fahrenheit's thermometer is referred to in the temperatures particularized. 
indeed may be employed with great advantage, when the seed from age or other cause germinates with difficulty. Dr. Lindley found the seeds of a raspberry germinate, though they must have endured a temperature of $230^{\circ}$ in the boiling syrup of the jam, whence they were taken; and other instances are known where peas submitted to a temperature of $200^{\circ}$, and, left in the water for twenty-four hours until cool, germinated more readily than other peas not so treated. The seeds of Acacia lophantha also produced seedlings after being boiled in water for five minutes. The effects produced by this high temperature, are to permanently soften the cuticle of the seed, and render it more readily permeable by the air; also aiding the conversion of the starchy components of the seed into saccharine matter; but if the boiling be continued until the composition of the germen is altered, the germinating power of the seed is destroyed.

These facts lead to the very important inquiry, whether the soil has any influence over the temperature occurring to the seed, and to the roots of plants placed beneath its surface. The researches of $\mathrm{M}$. Schluber answer this query in the affirmative. This distinguished German chemist found that when the temperature of the upper surface of the earth was $77^{\circ}$ in the shade, various soils, exposed to the sun from 
eleven to three, in ressels four inches square and half an inch deep, attained the temperatures shewn in this table.

Siliceous Sand, bright yellowish gray

Wet. Dry.

$\begin{array}{lllll}\text { Calcareous Sand, whitish gray } & \text { • } & 9 & 99.3 & 112.1\end{array}$

Gypsum, bright white gray * • . $\quad 97.3 \quad 11.0 .5$

Sandy Clay, yellowish . . . . . $98.2 \quad 111.4$

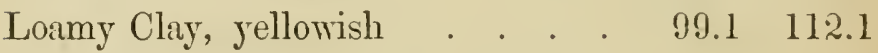

Stiff Clay, or Brick Earth, yellowish

$\begin{array}{lllllllll}\text { gray . . . . . . . . . } & 99.3 & 112.3\end{array}$

Fine bluish gray Clay . . . . . $\quad 99.5113 .0$

Lime, white . . . . . . . . $96.1 \quad 109.4$

Magnesia, pure white . . . . . $95.2 \quad 108.6$

Garden Mould, blackish gray . $\quad 99.5 \quad 113.5$

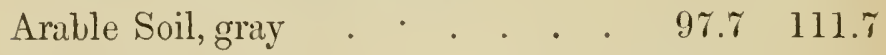

Slaty Marl, brownish red . . . . $101.8 \quad 115.3$

The results of M. Schluber's experiments demonstrate that which our knowledge of the laws of caloric would have induced us to pre-suppose, namely, that light coloured earths by reason of their reflecting most rays of heat, are warmed much more turdily than dark coloured earths. It was this conclusion which induced me, some years now past, to try the effect of sprinkling coal ashes over rows of autumn sown peas. The peas invariably appeared above the soil some days before those in rows not similarly 
treated. This acceleration of vegetation continued equally marked throughout their growth, and is further explained by other experiments of MI. Schluber, which testify that those soils in the above table which absorbed the heat most readily, retained it most tenaciously, and consequently were longest cooling. Magnesia cooled in one hour and twenty minutes as much as the garden mould did in two hours and sixteen minutes, and the slaty marl in three hours and twenty-six minutes.

From more recent experiments made in the Horticultural Society's garden at Chiswick, and in other parts of England, we have the following results, confirming M. Schluber's experiments.

In the Chiswick garden,

1844.
Temp. of air. $\quad \begin{gathered}\text { Earth } \\ \text { foot deep. }\end{gathered} \quad \begin{gathered}\text { Earth } \\ \text { feet deep. }\end{gathered}$

\begin{tabular}{|c|c|c|c|c|c|c|c|c|}
\hline Dec. 4 & . & . & 22 & . & . & 40 & . & . \\
\hline 5 & . & . & 14 & . & . & 38 & . & . \\
\hline 6 & . & . & 14 & . & . & 37 & . & . \\
\hline$\tau$ & . & . & 20 & . & . & 37 & . & . \\
\hline 8 & . & . & 26 & . & . & 36 & . & . \\
\hline 9 & . & . & 28 & . & . & 36 & . & . \\
\hline 10 & . & . & 28 & . & . & 36 & . & . \\
\hline 11 & . & . & 22 & & . & 36 & . & . \\
\hline
\end{tabular}

In a stiffish loam on a gravelly subsoil near Sheffield, after a fortnight's exposure to a minimum 
temperature, varying between $21^{\circ}$ and $31^{\circ}$, the soil had frozen to a depth of $4 \frac{1}{2}$ inches, but at lower deptlis the temperatures were as follow:-

$$
\begin{array}{llll}
\text { At } 6 \text { inches } & \cdot & \cdot & 34^{\circ} \\
-12, " & \cdot & \cdot & 36 \frac{1}{2} \\
-24 \quad, & . & . & 39
\end{array}
$$

In every instance the lighter soils were frozen to a less depth than the more tenacious. The former in no case haring the frost penetrate lower than six inches, but in heary soils two inches deeper. ${ }^{a}$

The following table, kept by Mr. Sharp, the scientific manager of the Winchester gas works, shows the lowest temperature of the air at night, and its highest temperature by day during the January of the present year, as well as the temperature of the soil at six inches and at twelve inches below its surface. The soil is black, rich, and siliceous, resting on a chalky subsoil :-

a Gardeners' Chronicle. 


\begin{tabular}{|c|c|c|c|c|c|}
\hline \multirow[b]{2}{*}{ Jan. } & \multirow[b]{2}{*}{ Night. } & \multirow[b]{2}{*}{ Day. } & \multicolumn{2}{|c|}{ Ground. } & \multirow{2}{*}{ Jan. } \\
\hline & & & 6 in. & $12 \mathrm{in.}$ & \\
\hline 1 & 35 & 44 & 39 & 39 & 1 \\
\hline 2 & 34 & 38 & $37 \frac{1}{2}$ & 39 & 2 \\
\hline 3 & 25 & 40 & $34^{\circ}$ & 37 & 3 \\
\hline 4 & 32 & 47 & 35 & 36 & 4 \\
\hline 5 & 39 & 51 & 38 & $38 \frac{1}{2}$ & 5 \\
\hline 6 & 42 & 52 & $\$ 1$ & $40^{\circ}$ & 6 \\
\hline$T$ & 45 & 50 & $42 \frac{1}{2}$ & $41 \frac{1}{2}$ & 7 \\
\hline 8 & 35 & 42 & $40^{\circ}$ & $41^{2}$ & 8 \\
\hline 9 & 32 & 39 & $37 \frac{1}{2}$ & 40 & 9 \\
\hline 10 & 35 & 39 & $37 \frac{1}{2}$ & $39 \frac{1}{2}$ & 10 \\
\hline 11 & 43 & 50 & $42^{2}$ & $41 \frac{1}{2}$ & 11 \\
\hline 12 & 39 & 45 & 42 & $42^{2}$ & 12 \\
\hline 13 & 38 & 45 & 41 & $41 \frac{1}{2}$ & 13 \\
\hline 14 & $36 \frac{1}{2}$ & 49 & 40 & $41 \frac{1}{2}$ & 14 \\
\hline 15 & $35^{\circ}$ & 46 & 40 & $41^{2}$ & 15 \\
\hline 16 & 38 & 46 & 40 & 41 & 16 \\
\hline 17 & 39 & 45 & 40 & 11 & 17 \\
\hline 18 & 38 & 48 & 40 & 41 & 18 \\
\hline 19 & 32 & 46 & 38 & $40 \frac{1}{2}$ & 19 \\
\hline 20 & , 34 & 45 & 38 & $40^{2}$ & 20 \\
\hline 21 & 30 & 42 & 36 & 39 & 21 \\
\hline 22 & 25 & $4 \pi$ & 35 & 39 & 22 \\
\hline 23 & 35 & 49 & 40 & $39 \frac{1}{2}$ & 23 \\
\hline 21 & 36 & 49 & 40 & $40 \frac{1}{2}$ & 24 \\
\hline 25 & 29 & 51 & 37 & $39^{2}$ & 25 \\
\hline 26 & 42 & 47 & 41 & 41 & 26 \\
\hline 27 & 34 & 46 & 38 & 39 & 27 \\
\hline 29 & $28 \frac{1}{2}$ & 40 & 35 & $37 \frac{1}{2}$ & 28 \\
\hline 29 & 27 & 39 & 34 & $3 T^{2}$ & 29 \\
\hline 30 & 31 & 39 & 38 & 37 & 30 \\
\hline 31 & 25 & 35 & 33 & 36 & 31 \\
\hline
\end{tabular}

These facts, and the frequent failure of our potato crops have led Dr. Lindley to the very judicious suggestion of planting these crops in autumn, which must be the best time, if practicaljle, for it is pursuing the dictate of nature. That it is practicable, I have no 
doubt, for no frost would injure the sets if a little coal ashes were put orer them in each hole, for coal ashes are an excellent non-conductor of heat, and consequently opposed to the admission of cold, and are, at the same time, a good preservative from excessive moisture.

The fact that the earth, in regions not eternally ice-bound, never is reduced in temperature, at a few inches from the surface, so low as the exterior air in winter, nor is elerated at a similar depth to an equal degree of warmth in summer, suggests the necessity for more attention to the temperature of the soil in our horticultural houses than it has hitherto obtained.

Attention is more awakened to it now than formerly, and by bottom-heat our gardeners now intend something more than a mass of fermenting matter for forcing cucumbers or pine-apples.

It is quite certain, that every plant, when groming in a farourite soil in its native climate, has its roots growing in the temperature which is best accordant with that in which its branches are delighting. Under no circumstances, if the plant is flourishing, will the temperature in summer, at 12 inches from the surface, be formd to be less than $2^{2}$, nor more than $5^{\circ}$ lower than the average temperature of the atmosphere; and in winter, that temperature at the same 
depth will be found to range similarly abore the atmospheric temperature. There is no doubt that in tropical climates, the bare exposed soil becomes heated, for a few inches in depth, to a degree higher than that of the air incumbent upon it. But this is not the case about the roots of plants; for their foliage, and the herbage naturally clothing the soil, preserve this from such a pernicious elevation of temperature. That such an excessive elevation is injurious, is known to erery observer of plants, whether the plants are growing in the tropics or in a stove. The roots are stimulated to imbibe moisture faster than the foliage can digest sufficiently the sap thus forced to them, and that foliage is expanded wider and more weakly in the vain effort to keep pace with the supply. This is only one among many instances of that property, so wisely given to organised beings by their Creator, of adapting themselves to circumstances; and it is only when the ricissitudes of those circumstances are too violent, or too long continued, that they fail in their effort at conformity.

If the temperature of the soil be unnaturally below that in which the branches are regetating, the effects are equally, though differently, disastrous. The supply of sap is too much diminished in quantity, and the edges of the leaves consequently die, or the blossoms fall, or disease attacks some part of the fruit, according to the nature of the plant, or the stage of 
growth in which it occurs. The shanking in grapes appears traceable to this cause.

Then again, a soil abounding in superfluous water is always colder than a soil of similar constitution that has been well drained. The reason for this is obviously that the same quantity of caloric which will heat the earth four degrees will only heat water one degree; or, to use the language of the chemist, the capacity for heat of water is four times greater than that of the earth's. In every day experience, we see the low lying and consequently the wettest portions of a field, are always those on which the erening mist or fog first appears; for at one season of the year it becomes colder than the air, and the atmospheric moisture always precipitates first on the coldest surface. At other seasons of the year, evaporation from the wettest portion of a field is the most abundant; and, at those seasons, mists are formed by the temperature of the air being much below that of the earth, and consequently condensing its watery exhalations. The greater the difference of temperature, the denser is the mist, the condensation being more complete.

I will observe, as on a former occasion, that the time will probably arrive when greater precision will be attained as to the time when our virious seeds may best be committed to the soil. We shall owe that advance to a more complete hiowledge of what 
may be termed the coincidences or synchronisms of nature.

The attempt to attain knowledge on this subject is not new, for nearly a century since Harald Barck and Alexander Berger, in Sweden, made many observations directed to this object, and in later years, Stillingfleet and Martyn have done the same in England.

The first named of these botanists thus expresses himself upon the subject: "If botanists noted the time of the foliation and blossoming of trees and herbs, and the days on which the seed is sown, flowers, and ripens, and if they continued these observations for many years, there can be no doubt but that we might find some rule from which we might conclude at what time grains and culinary plants, according to the nature of each soil, ought to be sown; nor should we be at a loss to guess at the approach of winter; nor ignorant whether we ought to make our autumn sowing later or earlier."

M. Barck would derive his intimations from the regetable tribes alone, but I think the other kingdoms of organic nature might be included-as the appearances of certain migratory birds, and the birth of certain insects. For example, in the east of England, it is a common saying among gardenersconfirmed by practice-When you hare seen two swallows together, sow kidney beans. 
This synchronical mode of regulating the operations of the cultivator of the soil is no modern suggestion, but the efforts of Barck and his successors have only been to find such indications in our northern clime that would be of the same utility, and similarly admonitory as others adopted by the ancients in more sumny latitudes. Thus Hesiod says, If it rain three days together when the Cuctioo sings, then late sowing will be as good as early sowing; and in another place, when snails begin to move and climb up plants, cease from digging about vines, and take to pruning.

That our operations may be made justly synchronical with certain appearances in nature is supported even by our present limited knowledge. " It is wonderful," says Mr. Stillingfleet, " to observe the conformity between vegetation and the arrival of certain birds of passage. I will give one instance as marked down in a diary kept by me in Norfolk, in the year 175\%. 'April 16th. Ioung Figs appear; the 1ith of the same month the Cuckoo sings.' Now the word xox:u $\xi$ signifies a Cuckoo and the young Fig, and the reason given for it is, that in Greece they appeared together. I will just add, that the same year I first found the Cuckoo flower in blossom the 19th of April."

"Limmæus says, that the Wood Anemone blows when the Swallow arrires. In my diary for the year 
1755, I find the swallow appeared April 6th, and the Wood Anemone was in blow on the 10th of the same month. He says that the Marsh Marygold blows when the Cuclioo sings. Accordingly in my diary that flower was in blow April $\boldsymbol{i t h}$, and the same day the Cuckoo sang."

Then, again, whatever may be the character of the season. whether it be unusually cold or preternaturally mild, the same order prevails in the leafing of plants.

1. Honeysuckle.

2. Gooseberry.

3. Currant.

4. Elder.

5. Birch.

6. Weeping Willow.

๘. Raspberry.

8. Bramble.

9. Briar.

10. Plum.

11. Apricot.

12. Peach.

13. Filbert.

14. Sallow.

15. Alder.

16. Sycamore.

17. Elm.

18. Quince.
19. Marsh Elder.

20. Wych Elm.

21. Quicken Tree.

22. Hornbean.

23. Apple.

24. Abele.

25. Chestnut.

26. Willow.

2\%. Oak.

28. Lime.

29. Maple.

30. Walnut.

31. Plane.

32. Black Poplar.

33. Beech.

34. Acacia Robinia.

35. Ash.

36. Carolina Poplar. 
This invariable simultaneous change, this consistent adherence to the same order of time, seems to demonstrate that the same circumstances, the same variations of cold and moisture endured, produce this general similar effect; they make all plants delay or accelerate their leafing to the most farourable time for vegetating. It seems to follow, therefore, that if it be found one year that the best potato crop was obtained by planting on the 15th of March, being the first day the gooseberry-leares opened, and that the following year the leaves of the same tree did not open until the 7 th of April, that in such case the potato planting ought until then to be delayed, for, as M. Barck observes, "No one can deny but that the same influences which bring forth the leares of trees, will also make grain regetate; and no one can justly assert that a premature sowing will always and everywhere accelerate a ripe harvest."

I beg leave to explain that my illustration by potato planting is a mere assumption, and that $I$ do not intend to advance that the leafing of the gooseberry and potato planting ought to be simultaneous. I only throw out the suggestion for others to confirm or to refute by observation and experiment, adding only thus much, that Mr. Stillingfleet, one of the most careful of Nature's observers says, that in his time "the prudent gardener never ventured to put 
his house-plants out until the mulberry leaf was of a certain growth."

As no seed will germinate unless a certain degree of heat is present, so also does it require that a certain quantity of water is in contact with its outer skin or integument, and this is required not only to soften this covering, and thus permit the enlargement of the cotyledons (seed lobes) always preceding germination, but also to afford that water to the internal components of the seed, without which the chemical changes necessary for the nutriment of the embryo plant will not take place.

Pure water, or some other liquid of which it is a large constituent, is absolutely necessary ; no other fluid will advance germination a single stage. The quantity of water, necessary to be present before germination will proceed, varies much. The seeds of aquatic plants require to be completely and constantly submerged in water; others, natives of dry soils and warm climates, will germinate if merely exposed to a damp atmosphere, of which the Spanish and Horse chestnut afford ready examples; but the far larger majority of seeds require and germinate most healthily in contact with that degree of moisture which a fertile soil retains only by its chemical and capillary attraction. If the soil be inefficiently drained, and there be, consequently, a superfluity of 
stagnant water, the seeds either decay without germinating or germinate unhealthily. This arises neither merely from its keeping them in an ungenial temperature, nor only from the usual tendency of excessive moisture to promote putrefaction; but also because the vegetable decomposing matters in a soil, where water is superabundant, give out carburettedhydrogen with acetic and gallic acids-compounds unfavourable to the regetation of most cultivated plants, whilst the evolution of carbonic acid and ammonia is prevented, which two bodies are beneficial to the embryo plant.

As water is essential to germination, and only a certain quantity is required for its healthy progress, so is it by no means a matter of indifference what matters it holds in solution. Until germination hins commenced, no liquid but water at common temperatures will pass through the integuments of a seed. So soon as germination has commenced, this power to exclude foreign fluids ceases, but the organs starting into activity, the radicle and the plumule, are so delicate, that the weakest saline solutions are too acrid and offensive for them. So utterly incapable are the infant roots of imbibing such solutions, that at first they are absolutely dependent, themselves, for their very existence, upon the seed-leaves; and if these be removed, the plant either makes no further advance, or altogether perishes. Many years since I 
tried various menstrua, to facilitate the germination of seeds; but, with the exception of those which promoted the decomposition of water, and the consequent more abundant erolution of oxygen, I found none of any efficiency. As to keeping the seeds in saline solutions until they germinated, I never, certainly, carried $\mathrm{my}$ experiments so far as that; and shall be most astonished, if any other effect than injury or death to the plant is the consequence. Such has been the result in the Horticultural Society's gardens, where the seeds of Lupinus Harturegii were made to germinate in a weak solution of phosphate of ammonia.

No liquid in which water does not preponderate will enable a seed moistened with it to germinate; for I have treated broad beans, lidney beans, and peas with pure alcohol, (spirit of wine), olive oil, alcohol and water, in equal proportions by measure, and with a solution of carbonate of ammonia, but in no instance did they germinate.

It may be noted as a warning to those who employ steeps for seed, with the hope of promoting the vigour of the future plant, that they must keep the seed in those steeps a rery few hours. In forty-eight hours, if the temperature be $60^{\circ}$ or more, putrefaction commences, and germination is weakened, or entirely destroyed.

M. Vogel, of Munich, has published an extended 
course of experiments upon this subject; and they fully confirm my opinion, that salts, innoxious when the plant is of robust and advanced growth, are fatal to it at the time of germination; for he found that seeds germinate without injury in carbonate of lime, (chalk), carbonate of strontian, litharge, red oxide of lead, phosphate of lead, black oxide of manganese, calomel, and cimnabar. That they germinate feebly in carbonate of magnesia, copper filings, sulphuret of antimony, red oxide of mercury, and aqueous solution of iodine. Lastly, that they refused to germinate at all in carbonate of barytes, hydrate of barytes, iodine pulverised and moistened, kermes mineral, golden sulphur of antimony, oxide of bismuth, arseniate of lead, and green oxide of chromium a. These are facts which explain the result of practice, that saline manures are generally injurious if applied with the seed, though they may be beneficial if applied long before the seed time, or subsequently, when the plants are of advanced growth.

Nothing is so injurious to a germinating seed as vicissitudes of temperature and moisture, or a lengthened exposure to excess of the latter; in either case, the awakening vitality is frequently entirely extinguished. Nothing is more dreaded by the maltster than a sudden check to his germinating barley; and, as a chill to the incubating egg effectually prevents the

a Journ. de Pharmacie. xri. 406. 
formation of the chick. To preserve the seeds of our winter crops from such vicissitudes, they should invariably be sown upon and covered with a thin stratum of coal ashes-these are an excellent drainage, as well as a good non-conductor of heat.

The preceding facts afford a warming to those who have to pack seeds for lengthened transport in tropical regions. They cannot be kept too dry-for heat alone will have no influence over their germination; and they should, therefore, be put into small, open, canvas bags, and suspended from the beams of the upper cabins, where a current of air will keep the seeds as free as possible from damp. Close packing in paper, in boxes, and in tin cases, stowed away in the hot hold of a ship, causes such a heating of the seeds, such an extrication of moisture from them, as is just enough to commence their germination; and which, only carried through its first stage, ceases, and then decomposition ensues, which effectually destroys the arousing vitality.

Water being such an essential application to the seed as well as to the growing plant, it may be at once observed, that the source from whence it comes is by no means immaterial. The best for the gardener's purpose is rain water, preserved in tanks sunk in the earth, and rendered tight either by puddling, or bricks, covered with Parker's cement. To keep these tanks replenished, gutters should run 
round the eaves of every structure in the garden, and communicate with them. Every 100 cubic inches of rain water contains more than 4 cubic inches of air, of which more than half are carbonic acid gas, and the remainder nitrogen and oxygen, in the proportion of 62 of the former to 38 of the last named. Liebig, from actual experiment on a large scale, states that both rain and snow contain ammonia; and its importance appears from the fact that, if there be only one-fourth of a grain in each pint of water, the annual deposition from the atmosphere would be more than sufficient, on half an acre of ground, to give all the nitrogen contained in the regetable albumen of 150 cwt. of beet root. Rain water also contains a peculiar substance, analogous to the extractive matter and gluten of plants, though differing from them chemically. To this substance Dr. Daubeny has given the name of Pyrrhine. Traces of salts and oxides have also been found in rain water; but compared with all other naturally produced, it is so pure, and so abounds with the gases beneficial to plants, that none other can equal it for their service. That obtained from ponds or springs invariably contains matters offensive or deleterious to plants. That known as hard water, containing in excess salts of lime or magnesia, is invariably prejudicial, and pond water is scarcely less so. If it be stagnant and loaded with vegetable extract, it is even worse than hard 
spring water, for it then contains carburetted hydrogen and other matters noxious to regetables. These last named waters, if obliged to be employed to tender plants, should have a pint of the ammoniacal water of the gas-rorks, mixed thoroughly with every sixty gallons, an hour or two before they are used.

The presence of one of the constituent gases of the atmosphere, oxygen, is also essential to germination. Ray proved that lettuce seeds would not germinate in the exhausted receiver of an air pump, though they did so when the air was re-admitted ${ }^{a}$; and though the experiments of Homberg throw some doubt upon this conclusion ${ }^{b}$, yet it was fully confirmed by the researches of Boyle, Muschenbroek, Boerhaare and Saussure, for they showed that Homberg must have employed an imperfect apparatus, and their experiments embraced many other seeds than those of the lettuce. So soon as pneumatic chemistry demonstrated that the atmospheric air is composed of sereral gases, riz. :

$$
\begin{array}{llllll}
\text { Oxygen . } & \cdot & \cdot & \cdot & 21 \\
\text { Nitrogen } & \cdot & \cdot & \cdot & 79 \\
\hline & & & & \\
100
\end{array}
$$

with about one per cent. of aqueous vapour in the driest weather, and about one part in every thousand of carbonic acid gas, the question then arose which

a Phil. Trans. No. xiii.

b Hem. French Acad. for 1693. 
of these gases is necessary for germination, and Scheele was the first to demonstrate that it is the oxygen. Achard afterwards proved that seeds will not germinate in nitrogen, carbonic acid, or hydrogen gases, unless mixed with oxygen; and though Carradori doubted the correctness of his experiments, his doubt was shown to be groundless by the more accurate researches of Gough, Cruickshank, Saussure and othersa. Senebier carried his experiments still further, and has determined that although seeds will germinate in an atmosphere not containing at least one-eighth of its bulk of oxygen, yet that the proportion most farourable to the process is one-fourth. Germination will proceed in an atmosphere of pure oxygen, but not so readily as when it is mixed with other gases. The same phenomena attend the incubation of eggs-they will not hatch in the vacuum of an air pump, nor will the process proceed so satisfactorily in any other mixture of gases than atmospheric air.

It is necessary that the oxygen should penetrate

a Although seeds will not germinate in an atmosphere of nitrogen, yet they all absorb a small quantity of this gas when germinating. It is a constituent of most roung roots, especially of their spongioles, or extreme points. There is reason to believe that by its aid ammonia is formed during germination, and that this acts as a stimulant and food to the young plant. Seeds containing nitrogen germinate more rapidly than seeds of the same genus which do not contain this gas. 
to the cotrledonous parts of the seed, as is evident by the changes which talie place during germination: and it is further proved by experiment. When healthy seed is moistened and exposed in a suitable temperature to atmospheric air, it absorbs the oxygen only. This porrer of separating one gas from the others, appears to reside in the integuments of the seed, for old seeds lose the power of absorbing the oxygen and consequently of germinating; yet they will frequently germinate if soaked in an aqueous solution of chlorine-a gas which has the power of attracting hydrogen from water, and others of its compounds, and releasing the oxygen, doing so in the case of seeds within their integuments as well as withoutside. Humboldt and Saussure have also shewn that the application of chlorine to seed accelerates its germination, and cress seed, which, under ordinary circumstances, requires some days to complete the process, they found effected it in no more than three hours. The late Mr. George Sinclair, author of the excellent Hortus Gramineus $\mathrm{Wo}_{0}$ burnensis, also informed me that he employed chlorine with singular success. He obtained it by mixing a tablespoonful of muriatic acid with a similar quantity of black oxide of manganese, and half a pint of water. After allowing the mixture to remain two or three hours, the seed is to be immersed in the liquid for a similar period, and then sown. Another, 
and I consider the most eligible mode of applying the chlorine, was also suggested to me by the same distinguished horticulturist. In this way he said he made tropical seeds vegetate, which refused to germinate by other modes of treatment. He placed the mixed ingredients mentioned above in a glass retort, inserting its bulb in the hotbed, and bringing its beak under the pot in which the seeds were sown connecting it with the draining aperture of the pot. The chlorine gas is gradually evolved, passing through the earth of the pot to the seeds, with more or less rapidity according to the heat employed.

This absolute necessity for the presence of oxygen is a reason why seeds will not germinate if buried beyond a certain distance from the earth's surface; and why clayey soils often fail of having a good plant, an impervious coat of the clay enveloping the seed, and preventing the air's access.

M. Burger found that seeds of rye buried one inch below the surface had their leares above it in eight days and a half, whereas those at a depth of six inches, had only just sprouted at the end of twenty-two days.

But too deep sowing inflicts another injury; though it be not at such a depth as entirely to prevent germination, yet it so consumes the matter of the seed in forming the useless elongation of stalk necessary to bring the leaves above the surface, that all further progress in vegetation has been prevented. M. 
Burger found that rye seeds sown five inches and a half deep, forced their blades to the surface in serenteen days and a half, but these remained green only for six days and then withered; and that in every instance, the most shallow sown seeds produced the most stalks. I have observed the same in the case of kidney beans, Windsor beans, and peas of various rarieties; those seeds, buried one and a half inch below the surface, invariably grew higher and were more prolific than those buried at greater depths.

From Saussure's experiments we leam that, weight for weight, wheat and barley during germination absorb less oxygen than peas, whilst these consume less than beans and kidney beans. This explains why, in proportion to their size, the two first may be sown at a greater depth below the soil's surface than the three last named, without regetation being prerented.

Seeds deposited at great depths, or similarly excluded from the air within the Egyptian mummy cerements, will often retain their regetative power for an apparently unlimited time. Hence, earth taken from far below the surface will often become corèred with charlock. This is an oleaginous-seeded plant, and such, when thus excluded from the air, retain their ritality most pertinaciously for reasons already assigned.

The atmosphere contains rather more than one- 
fifth of its weight of oxrgen gas, and this is the proportion most favourable to the germination of the majority of fresh seeds. Indeed few seeds will germinate when this proportion is much reduced. Radish seed refuses to do so when it amounts to no more than one-fortieth part, and lettuce seeds require in it at the least one-sixth, when it amounts to only one-eighth, they refuse to germinate. This is a reason why of all kitchen garden seeds the lettuce requires the most shallow sowing.

So far are plants at their first germination from being benefited by the application of stimulants, as is supposed by the advocates of those menstrua, that if the air supplied to them during that process is contaminated by stimulating vapours, such as that of sulphuric æther, camphor, spirits of turpentine, or ammonia, germination is always in some degree retarded and injured.

Old seeds are alone those which require the additional stimulus of more oxygen to enable them to germinate, and this as just stated is most readily afforded by moistening them with a solution of chlorine, which slowly extracts the hydrogen from water, and sets at liberty its oxygen within the integuments of the seeds.

How oxygen operates in aiding the seed to develope the parts of the embryo plant we camnot even guess -we only know that most seeds have more carbon (pure charcoal) in their composition than other parts 
of their parent plant, that the oxygen absorbed by the seeds combines with a portion of that extra carbon, and is emitted in the form of carbonic acid. These are the attendant phenomena, but we can penetrate the mystery no farther.

I have never been able to discover that light has any injurious influence over germination, and in those experiments apparently proving the contrary, due care was not taken to prevent the seed being exposed to a greater degree of dryness as well as to light. If seed be placed on the surface of a soil, and other seed just below that surface, and care be taken to keep the former constantly moist, it will germinate just as speedily as the buried seed, and if exposed to the blue rays only of the spectrum, by being kept under a glass of that colour, even more rapidly.

M. Saussure found that when the direct rays of the sun were intercepted, though light was admitted, seeds germinated as fast as when kept in the darka.

Therefore the object of sowing the seed below the surface, is for the purposes of keeping it in a state of equable and salutary moisture, as well as to place the radicle in the medium necessary for its growth into a root, immediately it emerges from the integument of the seed.

A seed placed in a situation where it is supplied with the desirable degrees of heat, moisture, and air,

${ }^{a}$ Recherches sur la Vegetation, 23. 
begins immediately to enlarge in size. This is occasioned by its absorbing moisture, which, passing into the Cotyledons, causes their immediate increase in size. The rapidity of this process is remarkable, and warns the gardener from disturbing the seed after it is once committed to the ground. A few choice peas, from which to raise stock, being sown accidentally in ground devoted to another crop, were remored after twenty-four hours, and were not again committed to the ground for some dars. Not one of them produced a fruitful plant, and only two or three regetated.

This is in no degree surprising, because in the majority of healthy seeds cultivated in our open ground departments, the embryo will be found swollen within three hours; within six hours the radicle will be preceptible; in from one to six dars the radicle will have burst the integuments of the seed; within from two to seven days the plantlet will have similarly escaped; and in from four to twentr-four days perfect roots will have been developed, and the leaves appear above the surface.

Moisture, as already stated, is absorbed and causes the immediate enlargement of the parts of the seed, and this moisture though it will and does penetrate through the surface of the integuments, yet is chiefly imbibed through the hilum or scar. It passes to the cotyledons, causing their enlargement, and setting in 
motion their elaborating powers for the nutriment of the radicle and plantlet, for if they are remored, or if they have been injured by insects, the seed does not germinate, and if they are removed even after the radicle is developed into a root, the plant's regetation ceases.

No sooner has the radicle escaped from the seed's integument, than it immediately proceeds to elongate in the direction of the matters most promotive of the future plant's growth. If the seeds of carrots, pars-1 nips, beets, and other fusiform-rooted plants are sown in a soil with its surface richly manured, and its subsoil deficient in decomposing organic matters, the plants will have forked and abundant lateral roots, keeping within the fertile surface soil. On the other hand, if the surface stratum is only moderately rich, but some manure is trenched in with the bottom spit so as to be about sixteen inches below the seed, the roots will strike down straight to this superior source of nutriment.

From the same cause the roots of orchidaceous plants, grown upon wood only partially charred, will be found to have their roots clamber up, and around, and along the wood, but always directing their course most numerously towards the charred portion. Again, the seeds of the misletoe placed upon the under surface of a bough, always have their radicles grow upwards to penetrate the bark, and thus secure to 
themselves the moisture without which they could not exist. Lastly, if seeds of plants loving a fertile soil be sown along the partition, dividing a ressel into two portions, of which one portion is filled with rich earth, and the other with sand, though both portions are equally moist, equally loose, and equally warm, all the radicles will direct their course into the fertile soil.

These facts, with many others, all demonstrating that roots travel in the direction where the most acceptable food is presented, overturn, beyond all controversy, Mr. Knight's hypothesis, that the descent of the root is a consequence of the laws of gravitation, for these laws will not explain why roots will grow sidewise, and even upwards, if their best source of nourishment is so placed as to require it-Gravitation could only influence them to a downward direction, and in a fluid medium. To maintain that the laws of gravitation will make the tender radicle of a seed pierce the hardest soil, appears to be a selfevident absurdity.

As the radicle always advances in the direction most suited to its nourishment, and in which it can best exercise its functions, so does the plantlet as invariably direct itself towards the surface of the soil, where its leaves and stem and other superior organs can alone develope themselves and perform the functions bestowed upon them at their creation. 
The necessaries in search of which their upward course is directed, are air and light, but especially the first, for the plantlet rises above the surface though the seed is germinated in a totally dark room, but if the seed of an aquatic plant be germinated in water under a double glass receiver, one compartment of which is filled with hydrogen or nitrogen, and the other compartment with atmospheric air, the plantlet invariably directs its growth into the latter. We also

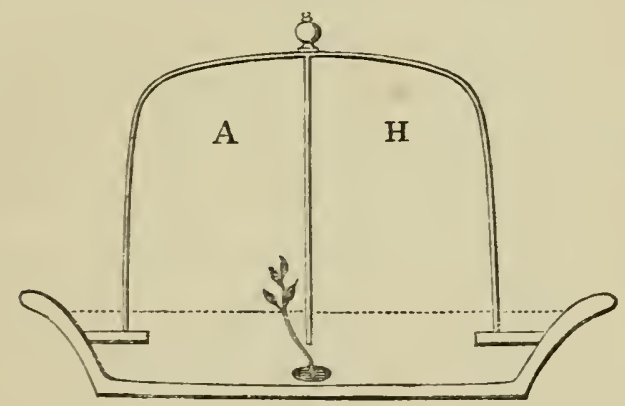

know that germinated seeds placed in racuo refuse to advance any further in vegetation.

The absorption of moisture and the consequent enlargement of the cotyledons is followed by another change in them. Oxygen gas is absorbed and carbonic acid is evolved, the farinaceous nature of the seed being completely changed-it usually becoming saccharine, though sometimes it attains acidity-but in every case its components become soluble in water, more liquid, and adapted to the nutriment of the embryo 
plant. The quantity of oxygen absorbed by seeds differs in every species, but they entirely agree in emitting it all again in the form of carbonic acid; it is absorbed therefore for the purpose of diminishing the seed's carbon.

The seeds of beans and lettuce absorb one-hundredth part of their weight of oxygen to enable them to germinate; purslain, onion, and radish seed onethousandth only, and the weight absorbed is always proportionate to the weight of the cotyledon.

The fact of carbonic acid being extricated aids to explain why germination proceeds more slowly in clay soils, and in soils rolled firm, even under otherwise favourable contingencies, than it does in porous, well pulverized soils; not only does the atmospheric air get to the seed in the former soils with more difficulty, but in these the carbonic acid emitted during germination is confined in immediate contact with the seed, and M. Saussure found that carbonic acid, almost in any proportion, retards the commencement of germination.

That the atmospheric air is that mixture of oxygen and nitrogen gases which is most favourable to the due progress of germination, is proved by the experiments of M. Saussure, for he found that seeds germinating in it always absorbed a portion of the nitrogen, but which they did not do if the proportion of oxygen was increased. 
These facts hold out some beacons worthy of being attended to, as guides for the operation of sowing. They point out that every lind of seed has a particular depth below the surface, at which it germinates most vigorously, as securing to it the most appropriate degree of moisture, of oxygen gas, and of warmth. From a quarter of an inch to two inches beneath the surface, appear to be the limits for the seeds of plan.s usually the objects of cultivation; these, however, must vary for the same seeds in different grounds and countries. It must be the least in aluminous soils and dry climates. In general, sowing should be performed in dry weather, especially on heary soils, nut only because of the greater saving of labour, but lecause it prevents the seed being enveloped with a coat of earth impermeable by the air, "which," say's Sir H. Davy, " is one cause of the unproductireness of cold, clayey soils." Perhaps the time at which any ground may be raked with the greatest facility, is as good a practical criterion as any, to judge when it is most fit for sowing. In general, if clay does not predominate in its constitution, a soil rakes best just after it has been turned up with the siarle. If clay does predominate, it usually rakes with most facility after it has been dug two or three days, and then immediately after a gentle rain. But it is certain that the sooner seed is sown after the soil is dug for its reception, the earlier it 
germinates. In the droughts of summer, water is often required to newly sown beds. Such application must not be very limited or transitory; for, if the soil is only moistened at the immediate time of sowing, it induces the projection of the radicle, which in very parching weather, and in clayey caking soil, I have known wither away, and the crop be consequently lost from the want of a continued supply of moisture. 


\section{CHAPTER II.}

THE ROOT.

The root is present in all cultivated plants. The truffle, which, however, can scarcely be considered as belonging to cultivated regetables, having hitherto defied all attempts to subjugate it, may be considered as consisting of nothing but roota.

A root is annual, biennial, or perennial. In the two former instances, if the individuals to which they belong be allowed to perfect their seed, no care can protract their existence beyond the ensuing winter, however genial the temperature, \&c., in which they are made to vegetate; but, if the ripening of seed be prevented, it is undetermined how long in most instances they may be sustained in life. I have known mignionette continued in healthy vegetation for four years by this precaution. In all roots, and under any mode of management, the fibrous parts (radiculæ) are strictly annual; they decay as winter approaches, and are produced with the returning vigour of their parent

${ }^{2}$ In Prussia it is said the gardeners succeed in cultivating this subterraneous fungus, but their mode of treatment is a secret. 
in the spring. Hence the reason that plants are transplanted with most success during the season of their decay: for, as the root almost exclusively imbibes nourishment by the mouths of these fibres, in proportion as they are injured by the removal, so is the plant deprived of the means of support; that sap which is employed in the formation of new fibres, would have served to increase the size of other parts.

The quantity of root I have always observed to increase with the poverty of the soil in which it is growing. Duhamel found the roots of some young oaks in a poor soil to be nearly four feet long, though the stem was not more than six inches. Every one may have noticed this familiarly instanced in $\mathrm{Poa}$ annua growing on a gravel walk, its stem minute, its root a mass of widely extending fibres. The cause of this is evident: the nourishment which is required for the growth of the plant, can only be obtained by an increased, widely extending surface of root, and, to form this, more sap is often required than the plant, owing to the poverty of the earth, can obtain for itself; in that case, a soil is sterile, for the plant must evidently perish.

A root always proceeds in that direction where food is most abundant, and, from a knowledge of this fact, we should be circumspect in our mode of applying manures, according to the crop and object 
we have in riew. The soil in my own garden being shallow, never produced a carrot or a parsnip of any size; but almost every root consisted of numerous forks thickly coated with fibres: digging two spades deep produced no material advantage, the gardener applying as usual manure to the surface; but, by trenching as before, and turning in a small quantity of manure at the bottom, the roots always spindled well, grew clean, and had few lateral fibres. For late crops of peas, which mildew chiefly from a deficiency of moisture to the root, it is an object to keep their radiculæ near the surface, for the sake of the light depositions of moisture incident to their season of growth; hence it will always be found of benefit to cover the earth over the rows with a little well rotted dung, and to point it in lightly.

If it be desirable to prevent the roots of any plant travelling in a certain direction, the soil on that side should be excavated and the cavity refilled with sand or some other unfertile earth, whilst the soil on those sides of the plant whither the roots are desired to tend should be made as fertile as is permissible with its habits.

To keep the roots of trees near the surface, gardeners make an impervious substratum beneath their borders, either by ramming a bed of chalk at the requisite distance from the surface, or by placing there an asphaltic mixture of hot coal tar and lime

$$
\text { E? }
$$


rubbish. Roots coming in contact with these do not tum aside, but immediately cease extending in length, and produce laterals.

It may be accepted as an universal maxim, that whatever causes an excessive developement of root prevents the production of seed; and rice versa, the production of seed, especially in tuberous-rooted plants, reduces the amount of root developed. Thus, - frequent transplanting the young plants of the lettuce, brocoli, and cauliflower causes the production of numerous fibrous roots, and is found effective in prerenting the mature plants advancing early to seed. The early varieties of the potato do not naturally produce seed; but if their tubers are removed as soon as they are formed, these early varieties blossom and bear seed as freely as the later kinds, a fact suggesting many experiments to the cultivators of shy-blooming tuberous-rooted flowers. Again, if the blossoms of these later varieties are plucked off is they appear, the weight of tubers produced will be very materially increased.

According to the usual acceptation of the term, the roots of plants do not emit excrements, yet it is quite certain that in common with all the other parts of a plant they perspire matters differing in their amount and composition in every species. The earth in contact with the tubers of a potato fully ripe contains mucilage, and has the peculiar odour of 
the root; that in contact with the roots of peas is also mucilaginous, and smells very strongly of that regetable; and the freshly up-turned soil where cabbages have been growing always smells offensively.

In addition to this, erery gardener knows that the vigour and luxuriance of a crop is influenced remarkably by that which immediately before pre-occupied the ground on which it is growing, and this does not arise entirely from the prerious crop having rolbed the soil of constituents required by its successor, but from that crop having left something offensire. Thus brassicas will not grow healthily upon soil where the immediately previous crop was of the same trike, but if the ground be pared and burnt they will grow luxuriantly; and the same occurs to ground exhausted by stramberries: $j$ if it be burnt and manured, strawberries will grow as rigorously as upon fresh ground, but they will not do so if manure only is applied. It has also been observed that the roots of plants placed in water give out their characteristic flarours to the liquid, but on this, as eridence that they emit excrements, no great reliance can be placed, for some of the roots during removal from the soil must be wounded.

The fact that the roots of plants do gire out peculiar and rarring matters to the soil which sustains them, aids to explain why one rotation of crops is superior to another, as well as why fallowing is beneficial.

Fallowing gets rid by decomposition of any offensive excrementitious matters, as well as accumulates 
that which is desirable to plants; and one crop succeeds better after some predecessors than others, because their exurix is more salutary. Upon similar principles is explained the association which, centuries since, was first observed to prevail between some plants. Thus, in 1570, Conrad Heresbach wrote thus: "Because there is a natural friendship and love between certain trees, you must set them the nearer together, as the rine and the olive, the pomegranate and the myrtle." Others, he adds, have a natural hatred, "as the rine with the filbert and the bay, \&c.;" and Cato says that the vine is at enmity with the cabbage.

That some plants are benefited by being grown in the vicinity of others, seems established by observation, and might be rationally expected. Thus the blue bottle (Centaurea cyanus) is rarely found flourishing, except in company with a com crop. The benefit arising from such associations is probably the consequence of the cereal grasses emitting the usual gases in proportions and at times grateful to the Centaurea, or from their excreting something in the soil that is acceptable to its roots. Then, again, the fragrance of the rose is said to be increased by having the onion or some other allium grown in its vicinity. Phillips, in his poem entitled "Cider," alludes to this result:

"The Pæstan rose unfolds

Her bud more lovely near the foetid leek, (Crest of stout Britons,) and enhances thence The price of her celestial scent." 
This increase of fragrance, if it be a truth, probably arises from the same cause that ammonia increases the pungent perfume of snuff. Flavours and scents, we all know, are often made more intense by combination.

Plants are very much benefited by having oxygen applied to their roots, being found to consume more than their own volume of that gas in twenty-four hours; and when applied by Mr. Hill to the roots of melons, hyacinths, \&c., the first were found to be improved in flavour, the second in beauty, and all in vigour. Everything, therefore, that promotes the presentation of oxygen to the roots of plants, must be beneficial; thus we find, that frequently stirring the ground about them promotes their growth; for, in proportion as the soil is loose can the atmosphere more easily penetrate it. Moist earth rapidly absorbs oxygen from the atmosphere, as Humboldt has demonstrated, but dry soil does not; this affords another reason for frequently stirring the earth about plants during the droughts of summer; for well pulverized soils admit the evening dews, more freely than others more consolidated, and consequently dews will be deposited more within their texture, and moisture is more firmly retained in such pulverized soils, in asmuch as that they are not so much heated by the sun's rays, being more pervaded by the air, which, like all gases, is one of the worst conductors of heat. 
M. Schluber has more recently published experiments upon this subject, and their results confirm those of M. Humboldt. No earth, in the following table, absorbed any oxygen from the air in which they were confined, so long as they were dry; but when moist, and confined in a similar bulk of atmospheric air for thirty dars, they had absorbed its oxygen in the following proportions:

Per cent.

Siliceous sand . . . . . 1.6

Calcareous sand . . . . . 5.6

Gypsum in powder . . . 2.

Sandy clay . . . . . . . 9.3

Loamy clay . . . . . . 11.0

Stiff clay or brick earth . . . 13.6

Grey pure clay . . . . . 15.3

Fine lime . . . . . . 10.8

Magnesia . . . . . 1\%.0

Humus . . . . . . 20.3

Garden mould . . . . . 18.0

Arable soil . . . . . . 16.2

Slaty marl . . . . . . . 11.0

The decomposing parts of animals and regetables contained in a soil are also highly absorbent of moisture: hence the more freely the air is exposed to them, the more effectually will they be enabled to exert this power. By being freely exposed to the influence of the air, such substances are more rapidly 
decomposed, which leads to a consideration of the practice of exposing soils as much as possible to the action of the atmosphere by ridging, \&c. When a soil is tenacious, or abounding in stubborn regetable matters, as in heath lands, it cannot be too completely exposed to the action of the air; but to light soils, which are in general deficient in organic decomposing matters, chemistry would say that ridging is accompanied by erils more injurious than can be compensated by the benefits obtained; for such light soils are easily pulrerized whenerer occasion requires, are so porous as at all times freely to admit the pervasion of the atmosphere; and therefore, by this extra exposure the regetable and animal remains are hastened in decomposing, and much of their fertile constituents evolved in the state of gas, or carried away by the rains, \&c., without there being any crop upon them to benefit by them. Thus theory argues, and practice certainly seems to support, in this instance, her doctrines. Switzer, one of our horticultural classics, says, "Rich, heary ground cannot well be ploughed too often to make it light, and the better manure by killing the weeds; as poor, light ground cannot be ploughed too seldom, for fear of imporerishing it."-(Ichnographia Rustica, vol. iii. p. 23r.)

The benefit derivable from the access of the atmospheric gases to the roots of plants, and the knowledge 
that fertile pulverized soil absorbs and retains from them moisture, explains why plants are benefited by haring their lateral roots kept near the surface, and by having that surface frequently loosened by the fork. This is no mere imagination of theory, for as long since as the days of Cato, half a century before the Christian era, the importance of pulverizing the soil was duly appreciated. "What is good husbandry?" inquires that writer. To plough. "What is the second point?" To plough. The third is "to manure." In later days, Mr. Barnes, one of the best practical gardeners of the present age, in a letter to me, dated August, 1844, says,"To secure good crops of carrots, parsnips, and oilions, I make it a standing rule to trench the ground well in winter, throwing it into rough ridges, forking and turning it over during frosty mornings, which not only sweetens and pulverizes the earth, but eradicates insects, for I prefer a good preparation to early sowing; and practice has proved to me that a good season for sowing is any time between the 15th March and the 10th April. My practice is, sow every thing in drills; hoe as soon as the plants can be seen breaking the surface, continuing the hoeing throughout the season at every opportunity when the weather will permit, but not during rain, or when the ground is full of water,-not for the sake so much to destroy weeds and insects, which 
are rarely to be seen by following up hoeing with spirit, but with a desire to keep one uniform pulverization and moisture throughout, which is the means of not only continuing the present crop in the greatest of health and luxuriance, but at the same time is making a beautiful preparation for the succeeding crop. No season, for some years, has proved this practice to be efficient more than that of 1844 , in proof of which, I have the great satisfaction of hearing, from many practical gardeners from various parts of the country, who have carried out the system of my practice, recommended in the "Gardener's Magazine," and elsewhere. For my own part, I never had more abundant or healthier crops of vegetables of all kinds than I have this season, although in this neighbourhood (Sidmouth) we were eighty-nine days without any rain, after the 5th April, and then only partial showers for a few days; and then drought set in again for some time, more rigorously than it had previously been. Onions with me are astonishingly large, weighty, and sound.

"I keep all ground, as soon as a crop is done with, well trenched, burying all the refuse I possibly can in a green state, casting the earth into rough ridges, tumbling those ridges over with a strong fork on frosty mornings in winter and spring, and 
during hot sunny days in summer; continually changing the crops; keeping the hoe at work at all seasons in suitable weather; forking up all odd corners and spare ground without loss of time. By this management, I find the ground is always in good condition, and never tired by cropping; some judgment only being exercised in applying such properties again to the soil that have been taken from it, or that are likely to be required by the succeeding crop. To rest or fallow ground for any length of time, is only loss of time and produce; more benefit will be obtained by trenching and forking, in frosty or hot sunny weather, in a few days, than a whole season of what is erroneously called rest or fallow. Trench, fork, and hoe; change every succeeding crop; return to the earth all refuse that is not otherwise useful in a green state, adding a change of other manures occasionally, especially charred refuse of any kind, at the time of putting the crop into the ground. Every succeeding crop will be found healthy and luxuriant, suffering but little either from drought, too much moisture, or vermin."

The benefit derived from keeping the roots near the surface is more apparent in fruit trees and other perennials than in our annual crops, inasmuch as that the roots of trees being thus kept within the 
influence of the solar rays, they always regetate early, and ripen well their young wood, yet the quantity of oxygen absorbed by the roots of annual plants is very large, being, in the instances of the radish, carrot, and others, not less than their own bulk in the course of twenty-four hours.

Digging, hoeing, and trenching are employed for: facilitating the access of the air to the roots of plants, by rendering the texture of the soil easily permeable, and they are practices requiring a separate consideration.

Very few people ever consider in detail the expenditure of labour required from the gardener when digging. It is a labour above all others calling into exercise the muscles of the human frame, and how great is the amount of this exercise may be estimated from the following facts:-

In digging a square perch of ground in spits of the usual dimensions, (seven inches by eight inches,) the spade has to be thrust in 700 times, and as each spadeful of earth, if the spade penetrates nine inches, as it ought to do, will weigh on the average full seventeen pounds, eleven thousand nine hun dred pounds of earth have to be lifted, and the customary pay for doing this is $2 \frac{1}{2} d$. !

As there are 160 perches or rods in an acre, in digging the latter measure of ground, the garden labourer has to cut out 112,000 spadefuls of earth, 
weighing in the agroregate 17,000 crt., or 850 tons. and during the work he moves over a distance of fourteen miles. As the spade weighs between eight and nine pounds, he has to lift, in fact, during the work, half as much more weight than that above specified, or 1,278 tons. An able-bodied labourer can dig ten square perches a-day.

A four-pronged fork, with the prongs twelve inches long, and the whole together forming a head eight inches wide, is a more efficient tool for digging than the common spade. It requires the exertion of less power; breaks up the soil more effectually; and does not clog even when the soil is most wet. It is less costly than the spade, and when worn can be relaid at a less expense.

The following table, being the results of the experiments of M. Schluber, exhibits the comparative labour required in digging various soils, and the same soil in various states. Thus if to penetrate with a spade, when dry, grey pure clay, required a force represented by 100 , then to penetrate an arable soil in the same state would require a force equal only to 33 , or about one-third; so in a wet state the clay would adhere to the blade of the spade with a force equal to $29.2 \mathrm{lbs}$. the square foot, while the arable soil would only adhere to the same surface with the force of $6.4 \mathrm{lbs}$. 
Firmness Adhesion to a square when dry. foot of iron when wet.

Siliceous sand .

Calcareous sand .

0

0

5.0

7.3

8.7

Humus

Magnesia

Sandy clay

11.5

57.3

$6 \mathrm{~S} .8$

83.3

100.0

7.6

33.0

23.0
$3.8 \mathrm{lbs}$.

4.1

14.3

10.7

8.8

5.8

7.9

10.6

17.2

27.0

6.4

5.8

4.9

The preceding observations and facts are applicable to hoeing, an operation beneficial in consequence of its loosening the soil, as much, or more, as by its destroying weeds. Moisture abounds in the atmosphere during the hottest months, and it is absorbed and retained most abundantly by a soil which is in the most friable state. Professor Schluber found, that 1000 grains of stiff clay absorbed in twenty-four hours only thirty-six grains of moisture from the air; whilst garden mould absorbed in the same time forty-five grains; and fine magnesia seventy-six grains. Then, again, pulverizing the soil enables it better to retain the 
moisture absorbed. This I demonstrated some years since, and the reason is, obriously, because a hard soil becomes heated'by the sun's rays much more rapidly than one with a loosened texture. The latter is better permeated by the air, which is one of the worst conductors of heat. I am glad to find my opinions confirmed by so practical and so intelligent a man as Mr. Barnes, gardener to Lady Rolle, at Bicton Gardens, Devonshire. He says, (Gard. Mag. Sept. 1843,) "I do not agree with those who tell us, one good weeding is worth two hoeings; I say, never weed any crop in which a hoe can be got between the plants; not so much for the sake of destroying weeds and vermin, which must necessarily be the case, if hoeing be done well, as for increasing the porosity of the soil, to allow the water and air to penetrate freely through it. I am well convinced, by long and close practice, that oftentimes there is more benefit derived by crops from keeping them well hoed, than there is from the manure applied. Weeds, or no weeds, still I keep stirring the soil; well knowing, from practice, the rery beneficial effect which it has.

"Raking the surface fine, I have almost wholly dispensed with in every department. By hoeing with judgment and foresight, the surface can be left eren wholesome, and porous; and three hoeings can be accomplished to one hoeing and raking. 
Much injury is done by raking the surface so very much. It is not only the means of binding and caking the surface, but it clears the stones off as well: The earth, in its natural state, has stones, \&c., to keep it open and porous, \&c. If the earth be sufficiently drained, either naturally or otherwise, and the surface kept open, there is no fear of suffering either from drought or moisture."

Exposing the soil in ridges during the winter is usually practised by gardeners for the purpose of destroying predatory vermin, but it is also beneficial by aiding the atmosphere to pervade its texture, which texture is also rendered much more friable by the frost. M. Schluber says that freezing reduces the consistency of soils most remarkably, and that in the case of clays and other adhesive soils. the diminution of this consistency amounts to at least 50 per cent. In hoeing clay he found it reduced from sixty-nine to forty-five of the scale already stated, and in the ordinary arable soil from thirtythree to twenty. He satisfactorily explains this phenomenon, by observing that the crystals of ice pervading the entire substance of the frozen soil necessarily separate the particles of earth, rendering their points of contact fewer.

We have seen that plants search after and acquire

- A finely pulrerized even surface cakes after rain much more than a surface rather rough. 
food by the agency of their roots; and the extremities of these appear to be the chief, if not the only parts employed, in the intro-susception of all food not in a gaseous state, for M. Duhamel observed that that portion of a soil was soonest exhausted in which the greatest number of the extremities of the roots were assembled.-(Pliysique des Arbres, vol. iii. p. 276.)

M.M. Sennebier and Carradori brought this to the test of direct experiment, and found that if roots of the carrot, scorzonera, and radish are placed in water, some with only their extremities immersed, and others with their entire surfaces plunged in, except the extremities, the former imbibe the water rapidly, and the plants continue regetating; but the others imbibe no perceptible quantity, and speedily wither. It suggests also the reason why the gardener, in applying water or manure to trees or shrubs, does so at a distance from their stems. A good rule for ascertaining the proper distance for such applications, seems to be to make them beneath the circumference of the head of the tree; for, as M. De Candolle observed, there is usually a relation between that and the length of the roots, so that the rain falling upon the foliage is poured off most abundantly at the distance most desirable for reaching the extremities of the roots.

'This explains why the fibrous points of roots are 
usually annually renewed, and the caudex (or main limb of the root) extended in length: by these means they each year shoot forth into a fresh soil, always changing their direction to where most food is to be obtained. If the extremity of a root is cut off, it ceases to increase in length, but enlarges its circle of extension by lateral shoots.

The distance to which the roots of a plant extend is much greater than is usually imagined; and one reason of the stunted growth of plants in a poor soil is, that the sap collected and elaborated by them has to be expended in the extension of the roots, which have to be larger in proportion as the pasturage near home is scanty. An acom accidentally deposited on a wall produced a young oak; but this made no progress until its root had descended the whole height of the wall, and had penetrated the soil at its base.

In deep, poor siliceous soils I hare traced the roots of trees from twelve to fourteen feet perpendicular without reaching their termination. Those of the Canada thistle, seven feet; common fern, eight feet; wheat, thirty inches; oats, twenty-four inches; potatoes, eighteen inches; onions, twenty inches; carrots, parsnips, and beet, two feet. The distance to which roots will travel, and their tenacity of life, render them, often, very obmoxious to the gardener. Thus the common couch grass (Triticum repens) is the most troublesome of weeds, for every fragment of

$$
\text { F } 2
$$


its far-spreading roots will regetate; and the Sweetscented coltsfoot and Lemon mint are not less to be aroided, for the same cause renders them extremely difficult of extirpation, and they never can be kept within moderate bounds. Iet these creeping rooted plants are not to be condemned without exception; for whoever has grounds under his care bordering upon the sea-shore, the sands of which are troublesomely light and shifting, may have them effectually bound down by inoculating them with slips of the root of these grasses, Elymus arenarius, Carex arenaria, and Arundo arenaria.

The roots of plants, unless frozen, are constantly imbibing nourishment, and even dereloping parts; for if the roots of trees planted during the winter be examined after an interval of a few weeks, they will be found to have emitted fresh radicles. The food they imbibe is slowly elaborated in the vessels of the stem and branches, and there deposited.

It is by their extremities, then, that roots imbibe food; but the orifices of these are so minute, that they can only admit such as is in a state of solution. Carbon, reduced to an impalpable powder, being insoluble in water, though offered to the roots of several plants, mingled with that fluid, has never been observed to be absorbed by them; yet it is one of their chief constituents, and is readily absorbed in any combination which renders it fluid. 
Roots then must obtain from a soil nourishment to plants in a gaseous or liquid state: we may next, therefore, consider what constituents of soils are capable of being presented in such forms. Water can be the only solvent employed; indeed, so essential is this liquid itself, that no plant can exist where it is entirely absent; and, on the other hand, many will exist with their roots in ressels containing nothing but distilled water. Plants with a broad surface of leaves as mint, beans, \&c., I have always found increase in carbonaceous matter, whilst thus vegetating; but onions, hyacinths, de. with small surfaces of foliage, I, as invariably, have found to decrease in solid matters. The first, at all times, obtain nourishment by decomposing the carbonic acid gas of the atmosphere: the latter do so in a much smaller proportion: hence the reason why the latter are so much more imporerishing crops than the former,' inasmuch as that they acquire nearly all their solid matter by means of their roots. These observations explain the conflicting statements of Saussure and Hassenfratz on this point: the former experimented with broad-leaved plants; the latter on such as have small foliage. The first maintained that plants increase in solid content when their roots are supplied with water only; the latter denied the fact.

It has been advanced that water is the sole food of plants; but all experiments are inconclusive which 
are presented as supporting the theory. In the first place, all waters contain earthy, saline, and organic matters: eren distilled water is not pure, as Sir H. Davy has proved; and rain water, Margraaf has demonstrated to be much less so. No plants, growing in water only, will ever perfect seed; and the facts, that different plants affect different soils, and that a soil will not bear through a series of years the same crop, whereas it will bear a rotation of different ones, demonstrate that they each take different kinds of food from the earth, and not that universal one, water, which is ever present and renewed.

So far, indeed, from water being the sole food of plants, they are injured and destroyed by its superabundance in the soils sustaining them. Such soils are always colder than well-drained soils, inasmuch as that the same quantity of caloric which will heat the earth four degrees, will only heat water one degree-or, to use the language of the chemist, the capacity for heat of water is four times greater than that of the earths. Secondly, the regetable decomposing matters in a soil, where water is superabundant, give out carburetted hydrogen, acetic, gallic, and other acids, instead of carbonic acid gas and ammonia-products essential to healthy regetation. Palliatives for such evils are the application of lime, or its carbonate (challi), to the soils in which these acids have been generated; and indeed after they 
have been formed, such an application is essential, though the radical cure and preventive of recurrence -thorough draining, be adopted. It is not an extravagant assertion, that there is scarcely a garden existing, that would not be benefited by under-draining. Every gardener knows the absolute necessity for a good drainage under his wall-trees and rines; but few gardeners ever think, for a moment, whether there is any escape, any outfall, for the water he has drained from immediate contact with the roots of the abore-named faroured trees. Every garden should have drains cut, rarying in depth from two to three feet, according to the depth of the soil, with an interval of twenty-four feet between the drains. At the bottom of the drains, should be placed one-inch pipes: these should be well puddled over, six inches deep, with clay, and then the earth returned a. They should have an outfall into a ditch, at the least elevated side of the garden. By having the pipes with a bore no larger than an inch, moles cannot creep in, and they are large enough to carry off all the water, after even the heaviest rains.

The expense is, comparatively, nothing, varying from $3 l$. to $5 l$. per acre; and I shall not stop to argue with any one, who doubts for an instant the advan-

${ }^{2}$ If the subsoil be clayey, the drains should be only twelve feet apart, and the draining tiles corered with stones. 
tage consequent upon removing all water from a soil not retainable by its own absorbent powers; and I will only state one relative fact, viz., that at Lord Hatherton's residence, Teddesley Hay, in Staffordshire. four hundred and sixty-seven acres, formerly letting for an average rental of $12 s$. per acre, were all drained for an outlay of $3 l .4 s .7 d$. per acre, and their rental now averages more than $31 s$. per acre!

To plants in pots good drainage is not less essential than to those in our borders.

To secure this not only should at least two inches of rubbly charcoal be placed beneath the soil put into the pots, but the soil itself should be allowed to retain its pebbles, instead of having them sifted out, as was the ancient practice. Hunt's pots, represented in the annexed figures, are well calculated to facilitate drainage, and, by permitting the passage of air beneath the pots, they also admit it more readily to the roots.

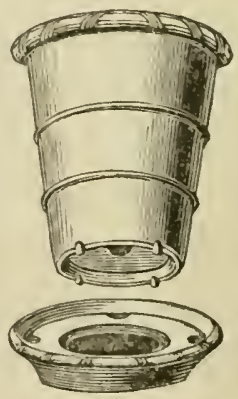

Drainage, however, is not the only desideratum to potted plants, for they have many other difficulties to contend against, from which those in the open soil are preserved. The soil, at a few inches below its 
surface, is always, during winter, some degrees warmer than the exterior air; but, owing to the evaporation from the sides of garden pots, this is rarely the case with the soil in them. To preserve this salutary warmth to the roots, a double pot has been suggested, as represented in the accompanying sketch.

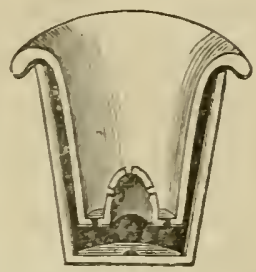

The importance of following the dictate of nature to keep the roots of plants, natives of the torrid and temperate zones, as warm or warmer than the branches, has been too much neglected by the gardener in his forcing department. In the vinery, for example, the stem and roots are too often absurdly exposed to the rigour of winter ; whilst the buds are expanding within the glass shelter in a temperature of $60^{\circ}$. A vine so treated, is like the felled elm, which, allowed to retain its bark, though rootless, puts forth its leares in the spring; expands its buds, and advances through the first stages of growth merely from the inspissated sap stored within its stem and branches. This is no mere suggestion of fancy; for repeated experiments have shown that hot-house vines, with their roots thus kept torpid by exposure to cold, had not their buds burst; whilst other vines, treated in all respects similarly, but with their roots kept genially warm, were actually in bloom. 
Although an excess of water applied to the roots of plants is injurious to them, yet all of them are benefited by a due supply of that liquid, and the supply has to be regulated by the amount of their daily transpiration. The gardener knows that this differs in every species, and during different seasons. For instance, in a dry hot day, a sunflower three feet and a half high transpired 1lb. 4ozs., being seventeen times more than the human body; during a hot dry night, 3ozs.; during a dewy night there was no transpiration; and during a rainy night the plant alsorbed 3ozs.

Therefore the gardener finds it best to apply water during dry weather, early in the morning, just before the chief demand occurs, which is from six A.M. till two in the afternoon; and during moist weather he refrains from the application entirely. Then, again, the gardener keeps his agaves and other fleshyleaved plants in a dry stove, for they transpire but sparingly in proportion to their mass, and require watering but seldom, and then abundantly; for they take up, as in their native siliceous habitats, a large supply, and retain it pertinaciously in defiance of the long-protracted droughts to which they are exposed.

In the same species I have always found varieties transpire abundantly, and require a larger supply of water in proportion to the extent of their transpiring surface. Thus the broad-leaved fuchsias and pelar- 
goniums transpire from two to three times as much as those varieties which have smaller and less abundant foliage.

The want of a few suggestions for the cultivation of plants in rooms has been so often brought to my notice that the subject may be here glanced over, especially as it will afford the opportunity for a few remarks upon potting generally.

Plants growing in pots, placed in our dwellinghouses, may be as successfully cultivated as other plants placed in green houses. It is quite true that they very rarely are so cultivated; but this does not prove that such success is impossible-it demonstrates no more than that either the cultivation is more difficult, or is less judiciously attended to, or that both these sources of failure attend upon our room plants; and that they do suffer from both, is the actual truth.

As the plants are placed in or near windows, there is no injurious deficiency of light, but as it comes to them most intensely on one side, they should be half turned round every day, that their heads may have a uniform appearance, and the leaves be not directed only in one direction. If the window faces the south, the intense heat and light should be mitigated during the middays of the summer months by lowering the blind.

Whenever the outdoor temperature is not below 
$34^{2}$, the plants will be benefited by having the window and door of the room open. They cannot have too much fresh air at any season of the year, if they are not grown under a Wardian case; for the exterior air always contains a due proportion of moisture, whilst the air of a room is as invariably drier than is beneficial to plants.

A due supply of moisture in the air, as well as in the soil, is absolutely necessary to our room plants. To obtain this in the best available degree, little porous troughs constantly filled with water should be kept on the stand among the pots; and the sancers of the pots themselves, if made according to Hunt's plan, may always have a little water remaining in them. The application of water to the soil requires far more attention than it usually receives. Room plants mostly are the protegés of the ladies, who administer the water with their own hands ; and so long as the novelty and leisure prompt to this attention, all goes well; but no room plant ever existed, perhaps, which was not at some period of its existence left to the tender mercies of a housemaid, with the frequent usual consequence of a deluge of water, cold from the pump, after the roots had become heated and parched by days of total abstinence. Plants so treated canmot flourish. The water should be allowed to stand in the kitchen for some hours before it is applied to the plants, so that it may be as warm or 
warmer than the soil to which it is to be added. It may be given in dry lot weather every second day, and in such abundance as to pass slightly through the earth into the saucers. These must be emptied as often as water appears in them, unless they be Hunt's saucers, in which case a little water may be allowed to remain, as before mentioned. These are general rules, to be modified only in the instances of plants requiring peculiar treatment. Among the exceptions are the different kinds of mimulus, hydrangea, and some others, which are benefited by the saucers being constantly filled with water.

If the thermometer does not fall below $60^{\circ}$ during the day, nor to less than $34^{\circ}$ at night, the usual room plants may be kept in lealthy growth during the winter. There is a much greater variety of temperature at command, even in a small room, than is generally imagined. Thus, in one twelve feet square, with a fire burning, and having the door open, I have observed the thermometer on the floor $59^{\circ}$; at six feet from the floor, 67\% ; and at nine feet, $74^{\circ}$. During serere frosts, the higher plants are placed from the floor the less liable will they be to suffer during the night, when the fire has become extinguished.

The soil varies according to the nature of the plant; but whaterer be its quality, instead of being 
sifted fine, as gardeners formerly directed, let all the small pebbles remain, and pieces of charcoal, none smaller than nuts, be mired so as to pervade the earth at distances of about two inches. Let the whole rest upon a drainage composed entirely of charcoal, the pieces not less than small walnuts. This treatment, suggested by nature, but first recommended, by Mr. Barnes, of Bicton Gardens, secures acceptable food to the roots, and prevents the occurrence to them of that fatal evil, stagnant water. Let the plants once a year be taken out of their pots, their heads reduced in size, and a portion of the exterior roots be removed. Let them be returned into the same pots, with similar attention to the soil and drainage, for it is an inconvenience mostly growing out of error, to give them larger pots amually. Mr. Knight grew even a nectarine tree for more than nine years in the same pot. This restriction to small-sized pots cannot be always effected; and when shifting is necessary, it is advisable to remove, as much as possible, the old soil, of course without injuring the roots. This is generally best effected by soaking the ball of earth in water; and thus it may be rashed almost entirely away, and the roots be left coated with a mud that is beneficial to them, and preserves them from drying, until the fresh soil is well settled about them. 
The number of roots within a given space of soil is much larger than when the plants grow in the open soil ; for, being restrained by the side of the pot, they fork into numerous fibres, spread over its surface and even turn inwards again in search of food, they being gifted with the power of forming an extra number of radicles whenever deficiency of food renders such compensatory power necessary. The gardener endeavours to render it needless by supplying the plants with liquid manure; but this richness of pasture can only be permitted to a certain extent, for if a plant is so well supplied with food as not to render a certain consumption of its proper juices in forming roots requisite, so much more of those juices is stored in the stem and branches, rendering the plant orer-luxuriant, and consequently unproductive of flowers and fruit.

Mr. Barnes, in a letter dated September 9th, 1844, obserres, that the common earth-worm is too generally regarded as an enemy, whereas by its perforations of the earth it facilitates the admission of air to the roots of plants ; and we have found that thrusting a knitting needle down through the soil of potted plants, as well as stirring its surface, is highly beneficial.

I am not an adrocate for putting room plants out of doors whilst rain is falling; it is a practice origi- 
nating in idleness, the cultivator allowing his plants to be overdosed with moisture, in order that the trouble of cleansing their leares with the syringe and sponge may be avoided. With these implements the cleansing is much more effectual than when the rain is allowed to be the agent; and it is a process promoting the plant's health, if repeated once a week, during a morning, when the weather is mild.

Returning to the consideration of the food obtained by a plant from the soil by the agency of its roots, we find that silica, or the pure substance of flint, is present in all soils; is soluble in water, requiring one thousand times its weight of this liquid to dissolve it (Kinwan's Mineralogy, vol. i. p. 10); is found in many plants, and in all the grasses that have been analysed. Alumina, or the basis of clay, present in all soils, is so soluble in water as to be inseparable by the filter, and is much more so when any of the acids are present (Sennebier's Physiolog. Veget. vol. iii. p. 18); it is found in plants in minute quantities, especially in the grain of barley, oats, wheat, \&c. (Schrecder, in Gehlen's Journ. vol. iii. p. 525.) Lime is found in almost all soils; it is easily soluble in water, and there is but one plant that is not known to contain some of it as a constituent, the Salsola Soda. (Ann. de Chimie, vol. xviii. p. 76.) Magnesia, generally present in soils, is soluble in water, and is 
found in many plants. Iron is present in all soils, in all natural waters, and in all plants. Manganese is found in some soils, is soluble in water containing acids, \&c., and is found in a few plants. But none of those substances in a state of purity, either simply or combined, have ever been found capable of perfecting a plant through all its stages of growth, when moistened only with distilled water; the contrary is the case, horrever, when the water contains in solution regetable or animal matters, as the dung of animals. Now these matters contain carbon, hydrogen, oxygen, nitrogen, and various salts : the three first are absolutely necessary for the existence of all plants, every part of which is chiefly composed of them; nitrogen is found in most plants; and the importance of salts to regetation is demonstrated by the facts, that clorer will not flourish where there is no sulphate of lime; that nettles follow the footsteps of man for the nitrate of potass, which always abounds near the walls of his habitation, and that marine plants linger for the common salt of their native haunts. Salts of some kind or other are found in every species of plant, but none of which the constituents have not also been detected in soils. During decay, regetable and animal matters exhale various gases. Carbonic acid, hydrogen, carburetted hydrogen, ammonia, \&c. are of the number. all of which have been applied to the roots of plants with great benefit by Sir H. Davy and others. 
Although plants will not grow upon soils composed of the earths only, yet these have a great influence over plants, not merely by their secondary powers of regulating the amount of moisture, heat, \&c.. but by entering directly into the constitution of the plant; for it is a result of experience, to which I know of no exception, that a plant contains more of any given earth if grown in a soil where it predominates, than if grown in a soil where it is in less profusion. This fact was first pointed out by Saussure. who found that the Rhododendron ferrugineum, when growing on the calcareous formation of Mount Jura. contained in its ashes 43.25 per cent. of carbonate of lime, but only 0.75 of silica. On the other hand, the ashes of the same plant, from the granitic district of Mount Brevere, contained 2.0 per cent. of silica, but only 16.75 of carbonate of lime.

However varying in the proportions, yet every soil is composed of silica, alumina, lime, magnesia, oxide of iron, salts, and animal and vegetable remains. The most important consideration is, what proportions those are which constitute a fertile soil.

The beau ideal of a fertile soil is one which contains such a proportion of decomposing matter and of moisture, as to keep the crop growing upon it always supplied with food in a state fit for introsusception, yet not so superabundantly as to render the plants too luxuriant, if the object in view is the production 
of seed: but, for the production of those plants whose foliage is the part in request, as spinach, or of edible bulbous roots, as onions, which have a small expanse of leaves, so as to be almost entirely dependent upon the soil for nourishment, there can scarcely be an excess of decomposed matter presenterl to their roots. Spinach, on rich soils, will yield successire cuttings; the same as asparagus: the latter. especially, demands abundant applications of nourishment to its roots; since, like the onion, it has little foliage and slightly fibrous roots, at the same time that, like the spinach, it has to afford repeated cuttings; and thus, requiring a repeated developement of parts, it needs abundant food in its im. mediate neighbourhood.

A soil with a just proportion of decomposing matter, will be capable of absorbing moisture during the droughts of summer from the atmosphere, for the most fertile soils are always the most absorbent, yet it must not be too retentive of moisture, which is the case in such soils as contain too much alumina; neither must it too easily part with moisture, a fault which is a characteristic of those soils which contain an excess of silica. A subsoil of gravel mixed with clay is the best, if not abounding in oxide of iron, for clay alone retains the moisture on the arable surface in too great an excess; and sand, or chalk, on the contrary carries it away too rapidly. It is, however, 
evident, that to insure these desiderata in any soil, at all seasons, is impossible; and it is as manifest that a soil that would do so in one climate would fail in another, if the mean annual temperature of them should differ, as well as the amount in inches of rain which fall during the same period. Since, in the westem parts of England, more than twice as much rain occurs as in the most eastern counties, or in the proportion of 42 to 19, a soil in the east of England, for any given crop, may be richer and more tenacious than the soil required for it on the western coast.

Alumina, or clay, imparts tenacity to a soil when applied; silica, or sand, diminishes that power; whilst chalk and lime have an intermediate effect. They render heary soils more friable, light soils more retentive. These simple facts are important: two neighbouring gardens, by an interchange of soils, being often rendered fertile, which, before, were in the extremes of tenacity and porosity.

From these statements it is evident, that no universal standard, or recipe, can be given for the formation of a fertile soil, but a soil, the constituents of which approach in their proportions to those of the following, camnot be unproductive in any climate. It is a rich alluvial soil, which Mr. Sinclair, in his invaluable "Hortus Gramineus Woburnensis," gives as being the most fertile for the grasses:

"Fine sand, 115; aluminous stones, 70 ; carbonate 
of lime, 23 ; decomposing animal and regetable matter, 34 ; silica, 100 ; alumina, 28 ; oxide of iron, 13 ; sulphate of lime, 2 ; soluble, regetable, and saline matter, 7 ; loss, 8 , total, $400 . "$

I have already stated what forms it a fertile soil; it may be added, that, to constitute it eminently such, its earthy particles must be in a minute state of division; the more so the more fertile it will be. In the above analysis, 185 parts only were separable by sifting through a fine searce, 215 parts were impalpable; whereas poorer soils will often have 300 parts coarse matter to every 100 of finely pulverized constituents.

In affording warmth to plants, we have seen that the earth is of considerable importance, and the power of accumulating and retaining heat varies as much in soils as the proportions of their constituents. Sir Humphrey Dary found that a rich black mould, containing one-fourth of regetable matter, had its temperature increased in an hour from $65^{\circ}$ to $88^{\circ}$ by exposure to the sunshine, whilst a chalk soil was heated only to $69^{\circ}$ under similar circumstances; but the first, when removed into the shade, cooled in half an hour $1 \check{\partial}^{\circ}$, whereas the latter lost only $4^{\circ}$. This explains why the crops on light coloured tenacious soils are, in general, so much more backward in spring, but are retained longer in verdure during 
autumn, than those on black light soils; the latter attain a genial warmth the more readily, but part from it with equal speed.

Different plants affect different soils. Every gardener must have obserred that there is scarcely a kitchen-garden but has some particular crop which it sustains in luxuriance far superior to any other garden in its neighbourhood, or to any other crop that can be grown on it. A garden I once cultivated, would not produce, without the preparation of an artificial soil, the common garclen cress. (Lepidium satium, whilst the raspberry was remarkably luxuriant; and we have seen that the composition of a soil has a main infunence in these peculiarities.

It is certain that a soil is often considered umproductive, and the umproductiveness attributed to some deficiency in its staple, when, in truth, the defect arises from erroneous management. I have before stated an instance of tap-rooted plants being produced of superior size and form, by means of applying the manure deep below the surface. In another instance, some parsneps being of necessity sown in a poor soil, having turned in some manure by trenching full twelve inches deep, I would not allow any to be applied to the surface; but, at the time of thinning. I set half the bed out at an average of twelve inches distance between each plant, the other half at nine 
inches: when taken up for storing, the whole were alike perfectly fusiform, but those grown at twelve inches apart were the finest, as four and a-half is to three. If manure had been applied to the surface, the fibrous roots, I calculated, would be multiplied at the expense of the caudex, to its much greater detriment, than by making the few, usually produced by this root, extend in length by enlarging the circuit of their pasturage.

Again, a more siliceous, darker-coloured soil should be employed for the growth of an early crop of any given plant, than is required by the main crop; because such soil will more readily get rid of the superfluous moisture, and earlier acquire a genial warmth, two great desiderata for vegetation in spring. On the contrary, in autumn, for a late crop of peas, for instance, the soil should be more ahminous; because in August and September, atmospheric moisture, in the form of night-dews, abounds, the foliage is therefore perpetually subject to alternate extremes of moisture and dryness, whilst the root is liable to a state of exceeding drought. The soil, therefore, should be rich; and kept in a minute state of division by frequent hoeing, that moisture may be absorbed; and it should be more aluminous, that such moisture may be retained.

I may now proceed to consider manures, a class of 
bodies of the first importance to the cultivator of the soil, yet of the economy of which he is generally most ignorant, inasmuch as that their judicious employment requires considerable chemical acquirements. Every substance increasing the fertility of a soil, when incorporated with it, is a manure; hence, the earths, when applied to regulate its retentive powers, are actually manures. Nanures are animal, vegetable, and mineral; they directly assist the growth of plants; first, by entering into their composition; secondly, by absorbing and retaining moisture from the atmosphere; thirdly, by absorbing the gases of the atmosphere; fourthly, by stimulating the vascular system of the plants. Manures approximately assist vegetation: first, by killing predatory vermin and weeds; secondly, by promoting the decomposition of stubborm organic remains in the soil ; thirdly, by protecting incumbent plants from violent changes of temperature.

All these properties seldom, if ever, occur in one species of manure, but each is usually particularized by possessing one or more in a superior degree. That is the most generally applicable manure which is composed of matters essential to the growth of plants ; the chief of these are carbon, hydrogen, and oxygen; therefore all animal and regetable substances are excellent manures. It would eridently 
be of great benefit, if every plant could be manured with the decaying parts of its orn species; the ancients made this a particular olject. We read that those rines were the most fruitful, which were manured with their own leaves and prunings, and the skins of expressed grapes ${ }^{a}$. This rule might be so far followed, as that the stems of potatoes, peas, \&c., could be dug respectively into the compartments where those crops are intended to be grown in the following year.

The following table shews the relative constitution of common stable manure and our usual crops :-

Stable manure.

$\left.\begin{array}{l}\text { Carbon . . } \\ \text { Hydrogen . . } \\ \text { Oxygen . . . }\end{array}\right\} \begin{aligned} & \text { These are the chief components } \\ & \text { oflants. }\end{aligned}$

Nitrogen . . . In some regetables.

Carbonate of lime In almost all plants.

Carbonate of soda.

Benzoate of soda.

Muriate of potash In cucumbers, garlic, \&c.

Muriate of soda . Perhaps in all.

Sulphate of soda.

Sulphate of potash In cucumbers, garlic, \&c.

a Crescentius Agric., sect. 2, c. 6. 
Magnesia . . In all con and many other plants.

Phosphate of lime Potatoes, onions, \&c. \&c.

Oxide of iron . In most plants.

$\begin{array}{ll}\text { Alumina . . . . . In most plants. } & \text {. . } \\ \text { Silica . . }\end{array}$

Stable manure, and for the same reason every other manure composed of animal or vegetable remains, is evidently valuable to plants, by affordingr them such matter's as they are composed of. But this is not the only reason that manures are beneficial : for in that case mere decayed parts of their own species should be the most fertilizing applications. There is no doubt that plants are essentially benefited by such applications; but why do potatoes, for example, grow inore luxuriantly on ground manured by sprats, than on ground manured with the dung of horses, and still more superior to the same crop grown on a plot manured with the decayed parts of its own species? Apparently. but only partly, because the manures mentioned decompose with a rapidity exactly proportioned to the order of benefit. Sprats decompose, and their parts become soluble and capable of introsusception, first and most ritpidly; then the dumg of animals; lastly, the vegretable remains. All the less solid animal matters decompose with greater rapidity than vegetable matters: hence the dung of such animals as are cal- 
nivorous is the most prompt in benefiting vegetation: witness night soil, pigs' dung, \&c.; but such inamures are not the most permanent. Hassenfratz. manured two portions of the same soil, No. 1 with it mixture of dung and straw highly putrefied: No. 2 , with a similar mixture, newly made. He olserved that during the first year the plants in No. 1 produced the best crop, but the second and third years (no more dung being added) No. 2 produced the best crop; after which, both seemed alike exhausteda. The same chemist found, that a soil manured with wood-shavings did not, during the two succeeding years, produce a superior vegetation to the same soil without any manure; the third year, however, it was better, but it was not until the fifth year that it reached the maximum of fertility. 'The site of a wood stack, and the newly cleared lands of America are eminently fertile, from the gradually decomposing vegetable remains they contain.

These facts and observations teach us that the most prompt manures are the reverse of economical. Vegetable remains, incorporated with a soil, will insure an average produce during several years; animal matters and dungs highly putrescent are powerfully but transiently beneficial. Putrefaction is evidently the means of rendering these substances available to plants: hence, thoroughly decayed stable

$$
\text { a Ann. de Chimie, xiv. } 57 .
$$


manure is usually employed by gardeners, as being of immediate benefit, admitting of clean husbandry, and as economy is not, in private establishments, the generally presiding genius of the gardens. If stable dung or other manure be allowed to putrefy in an uninclosed heap, the loss is immense; all the gases which pass off during decomposition, all the soluble matters which drain away, are highly nutritious to plants, as has been proved by Davy and others. If the decomposition be thus allowed to proceed until the heap becomes a saponaceous mass, the loss cannot be less than 50 per cent. Notwithstanding all the reasoning of chemists, however, putrefied dung will continue to be used; it admits of clean workmanship, with less labour, and insures a good immediate crop: to prevent as much loss as possible, therefore, the dung-heap should be in a brick cisterm, and covered orer with earth at' least nine inches deep, with a well at one comer to retain the drainage, which from time to time, should be returned over the heap.

The chief component of plants is carbon, and we shall not be far wrong if we estimate it as constituting 50 per cent. of every regetable: it is the decayed organic remains of the soil which supply a considerable portion of this to the growing plants. It is a sulject of debate amongst chemists, how the carbon of manures is imbibed by plants. Carbon, say they, is 
insoluble, and experiment has demonstrated that the roots cannot absorb it in a solid state. Sennebier. having observed that water impregnated with carbonic acid, when applied to the roots of plants, was beneficial, concluded that the carbon of manures is converted into carbonic acid, and is in that state imbibed by thema.

Thomson, in an early edition of his System of Chemistry. gave a still more elaborate theory; which, being in subsequent editions omitted, we have no occasion to demonstrate absurd. I consider that the facts of which we are in possession, if progressirely estimated, place the subject in a very clear light. Saussure found that a soil deprived of its soluble matters, by repeated decoctions with water. would not support regetation so well as that portion of the same soil not so deprived of its soluble constituents ${ }^{b}$. The extract thus obtained was evidently composed of saccharine matter, mucilage, extractive principle, \&c. These we know are nutritive to plants, and are elaborated and assimilated by them after introsusception. Now, regetable substances, as straw, \&c., gradually yield these soluble matters as they decay. Straw, wood, leaves, \&c., consist chiefly of woody fibre: to convert this into saccharine and mucilaginous matters is the work of putrefaction; to effect

a Phys. Vég. r. iii. p. 55.

- Recherh. sur la Vég. cr. sect. 11. p. 1 í0. 
this, oxygen must be absorbed, and the extra proportions of carbon be got rid of, as is evident from the following table of constituents:-

\begin{tabular}{|c|c|c|c|}
\hline Carbon & $\begin{array}{l}\text { Woody Fibre. } \\
52.53\end{array}$ & $\begin{array}{l}\text { Gum. } \\
42.23\end{array}$ & $\begin{array}{l}\text { Sugar. } \\
27.5\end{array}$ \\
\hline Oxygen & 41.78 & 50.84 & 64.7 \\
\hline Hydrogen & 5.69 & 6.93 & 7.8 \\
\hline & 100.00 & 100.00 & 100.0 \\
\hline
\end{tabular}

That such processes actually do occur, Saussure has demonstrated by experiment: he found that moist wood, exposed to the air, absorbed oxygen, evolved carbonic acid, and water was evidently decomposed. Thus, then, putrefaction seems to render organic matters fit for the nourishment of plants, by converting them into saccharine and mucilaginous compounds, capable of solntion in water. Hence the phenomenon of wood, which is slow of decomposition, being a permanent manure ; animal matters which rapidly putrify, being transient, though temporarily powerful : hence the economy of using partially decomposed composts is also rationalized ; when completely decomposed, their soluble matters, being more than can be consumed at the time by the crop, pass away with the drainage water, much is lost in the state of gas, and all that is left, are a few earthy, 
saline, and carbonaceous particles, of comparatively little value.

The quantity of soluble matter obtainable from a soil at any one time is rery small, seldom exceeding a one-thousandth part of its weight; and even pure vegetable mould, the debris of entirely putrefied plants, was found by Saussure to rield only oneelerenth of soluble matter. This mould was too rich for horticultural purposes, peas and beans grown in it being too luxuriant, and they were more productive in a soil containing only one-twentieth of organic constituents dissolvable by water. Small in amount, howerer, as is the soluble constituents of the most fertile soils, they are necessary for the rigorous vegetation of plants, for when a soil is deprived of those constituents by frequent washings with boiling water, it is much less fertile than before. Liebig and others have most illogically concluder from the smallness of the soluble extract contained in a soil, that, therefore, it is of trivial importance: but they forget that, as fast as this extract is remored from a soil by the roots of the crop, it is generated again by the decomposition of the animal and regetable remains within its bosom. This is one reason why fallowing is beneficial, the most easily decomposing matters have been exhausted by successive crops; and by a year's rest, and exposure to the putrefactive agency of the air, the more stubborn 
and more slowly decomposing exuriæ have time to resolve into and accumulate soluble compounds in the soil.

The mucilaginous and saccharine matters formed by manures, during their decomposition in the soil. are unquestionably absorbed by the roots along with its moisture; for if the whole of the branches of a vine or maple be cut away close to the surface of the ground, it will continue to bleed for many darss, and to the last its sap will continue to afford the same amount of those matters. But their saps, and that of all plants as jet suljected to analrsis, abound with carbonic acid gas, and there is no doubt that decomposing organic manures are very largely beneficial to plants by affording that gas to their roots, a subject which will be further considered when we are examining the phenomena attendant upon regetable decomposition.

Of the less general manures, which benefit plants by entering into their composition, a few words will suffice. Sulphate of lime (grpsum) is a component of clover, lucerne, turnips, \&c.; hence it has been applied with benefit to these crops, on such soils as did not already contain it. Bones, broken small, have lately become a very general manure; their benefit, which is very permanent, is easily accounted for. The bones of oxen contain about fifty per cent. of gelatine, which is soluble in water, and rapidly 
hecomes putrescent; the remainder is chiefly phosphate and carbonate of lime, salts which are components of wheat, rye, barley, oats, peas, beans, vines, cucumbers, potatoes, garlic, onions, truffles, \&c. Common salt, also, is employed as a manure, and is beneficial, partly in consequence of entering into the constitution of plants.

The dlay has long passed when it was disputed whether saline bodies are promotive of the growth of plants. It is now determined that some plants will not even live without the means of procuring certain salts. Borage, the nettle, and parietaria will not exist except where nitrate of potash is in the soil ; turnips, lucerne, and some other plants will not succeed where there is no sulphate of lime. These are facts that have silenced disputation. Still there are found persons who maintain that salts are not essential parts of a plant's structure: they assert that such borlies are beneficial to a plant by absorling moisture to the ricinity of its roots; or by improring the staple of the soil; or by some other secondary mode. This, however, is refuted by the fact that salts enter as intimately into the constitution of plants as do phosphate of lime into that of bones, and carbonate of lime into that of egg-shells. They are part of their very fabric, universally present, remaining after the longest washing, and to be found in the ashes of all and of 
any of their parts, when suljected to incineration. Thus Saussure observes that the phosphate of lime is universally present in plantsa. The sap of all trees contains acetate of potash; Beet-root contains malate and oxalate of potash, ammonia and lime; Rhubarb, oxalate of potash and lime; Horse-radish, sulphur; Asparagus, super-malates, chlorides, acetates, and phosphates of potash and lime; Potatoes, magnesia, citrates and phosphates of potash and lime; Jerusalem Artichoke, citrate, malate, sulphate, chloride, and phosphate of potash; Garlic, sulphate of potash, magnesia, and phosphate of lime; Geraniums, tartrate of lime, phosphates of lime, and magnesia; Peas, phosphate of lime; Kidney beans, phosphate of lime and potash; Oranges, carbonate, sulphate, and muriate of potash; Apples and Pears, malate of potash ; Grapes, tartrate of lime; Capsicums, citrate, muriate, and phosphate of potash; Oak, carbonate of potash; and the Lilac, nitrate of potash. Let no one fancy that the salts are a very trivial proportion of the fabric of plants. In the Capsicum, they constitute one-tenth of its fruit; of carrot juice, one-hundredth; of Rhubarb, one-eleventh; of Potatoes, one-twentieth; whilst of the seed of the Lithospermum officinale, they actually form more than one-half: their constituents being as follows.

a Sur la Veget. c. 8. s. 4. 
Carbonate of Lime . . . . . . . . 43.7

Silica . . . . . . . . . . . 16.5

Vegetable Matter, Phosphate of Lime, \&c. 39.8

These amounts of earthy saline matters are nearly as much as exist in human bones; but if we turn to the marrow, it only contains one-twentieth of saline matters; the blood only one-hundredth; muscle, only one-thirty-fourth; yet no one will argue that these saline constituents, though smaller than those in regetables, are trivial and unimportant.

The preceding facts shew why some saline manures are generally beneficial, and often essential. An important consideration, therefore, is contained in the answer to the query, so often put,-How should saline manures be applied? The answer is, that, when practicable, they ought to be in very small quantities and frequently, during the time of the plant's grouth. No plan can be worse than soaking seed in a saline solution, for the purpose of giving such salt to the plant of which it will be the parent. It is soddening the embryo with a superfluity totally useless to it, and, if it does not injure the germination, it will be washed away most probably before the roots begin to absorb such nutriment.

I may observe here, appropriately, that to arrive at a correct knowledge of manures by menns of expe- 
riments, far more forethought and care are requisite than are usually bestowed upon them. 1. A space should be left without any manure being applied, otherwise there will be no satisfactory basis of romparison.

2. The larger the space subjected to experiment for each manure, the more entitled to confidence will be the result. The reason for this is, obriously, that no two seeds will produce plants of precisely equal prolificacy. Imperfect ripening of the parent seed, rariance in the depth at which the seed is buried, and many other circumstances, will be more liable to have a controlling effect orer the weight of the produce from a small plot of crop than from a larger. A dozen super-prolific, or defective plants. on a square rod of ground, will have an influence on the result when calculated per acre, that would he scarcely appreciated, if the experiment were made on an eighth of an acre.

3. If manures in solution are employed for soaking the seed, a similar quantity of seed of the same sample should be soaked for a similar length of time in simple water. If liquid manures are giren experimentally to plants during their growth, other plants of like number and growth, and in every respect treated similarly, should at precisely the same time have simple water applied to them.

4. There should be a certainty that the manure 
employed be pure. No wonder that experiments are discrepant, when Mr. E. Solly has detected adulterations in fertilizers to the amount of 97 per cent.! Even when the dung of animals is employed, it raries most essentially, and according to the food on which they are kept. The richer their nourishment the more abounding are their excrements in the salts of ammonia and other fertilizing matters.

Some manures ameliorate a soil by absorbing moisture from the atmosphere. This property is at least as beneficial to ground that is aluminous, as to that which is siliceous; for it is equally useless to either during such periods of the year as are characterised by a plentiful deposition of rain; but in the drought of summer, when moisture is much wanting to plants, it is beneficial to both: in very dry seasons it is eren of greater importance to clayey than to light soils; for vegetation on the former suffers more from long continued drought than on the latter, inasmuch as that moisture being equally exhaled from each, the surface of the clayey soil becomes caked and impervious to the air, the only grand source of compensatory moisture that is available to the languishing plants, and which is more open to those which grow on light and, consequently, more pervious soils.

The following table of the comparative absorbent powers of many manures is extracted chiefly from 
An Essay on the Uses of Salt in Agriculture, by my brother, Mr. Cuthbert Johnson.

Parts.

Horse dung evaporated previously to dryness, at a temperature of $100^{\circ}$, absorbed during an exposure of three hours to air saturated with moisture at $62^{\circ}$. . . . . . . . 145

Putrefied tanners' bark, under similar circumstances, $\left(66^{\circ}\right)$

Unputrefied tanners' bark . . . . 115 Cow dung . . . . . . . . 130

Pig ditto . . . . . . . . . . 120

Sheep ditto . . . . . . . 81

Pigeon ditto . . . . . . . . . 50

Refuse marine salt $\left(60^{\circ}\right)$. . . . . $49 \frac{1}{2}$

Soot $\left(68^{\circ}\right)$. . . . . . . . 36

Burnt clay . . . . . . . . 29

The richest soil (in one hour) . . . $\quad 23^{\mathrm{a}}$

Coal ashes . . . . . . . . . 14

Lime (part carbonate) . . . . . . 11

Crushed rock salt . . . . . . . 10

Gypsum . . . . . . . . . . 9

Chalk . . . . . . . . 4

The absorbing power of a manure is much influ-

a Sir H. Davy. 
enced by the state in which it is presented to the atmosphere. In a finely divided state, mere capillary attraction assists it: hence, as before insisted, the importance of keeping the soil fre. quently stirred, by hoeing, \&c. But a mere mass of cotton, by means of capillary attraction, will absorb moisture from the air, yet it parts with it at a very slight elevation of temperature; it is of importance, therefore, to ascertain which are the manures that not only absorb but retain moisture powerfully The following results of my experiments throw some light on this point :-

Minutes.

Pig dung evaporated to dryness at a temperature of $106^{\circ}$, and then moistened with 6 parts of water, required for being reduced to dryness again, at . the above temperature . . . . . 135

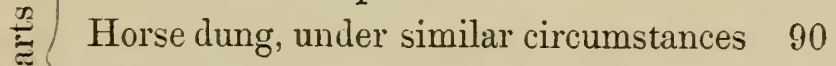

Common salt . . . . . . . . . . 75

8 Soot . . . . . . . . . . . . . 75

Rich Soil . . . . . . . 32

Chalk . . . . . . . . . . . 29

Poor soil (siliceous) . . . . . . . 23

Gypsum . . . . . . . . . 18

These experiments point out a criterion by which we easily ascertain the comparative richness of any 
two given soils or manures: the most fertile will be the most absorbent and retentive.

Some persons have argued that the moisture-retentive powers of manures must be injurious to plants. by withholding that moisture from their roots; but these theorists argue without an acquaintance with facts. Such manures have a greater attraction for moisture than is possessed by atmospheric air; but it is much less powerful than the power of suction possessed by roots. There is no saline body which they will not deprive of the moisture it has absorbed-nor will any be surprised at this, when they know that the root of a pear-tree, half an inch in diameter, absorbs water with such force and rapidity as to cause mercury to rise up an attached tube eight inches in six minutes a.

Some manures increase the growth and rigour of plants, by stimulating their absorbent and assimilating organs. This will only be admitted by those who, like myself, allow that plants are gifted with sensation-a topic more fully discussed in a future chapter; but a few illustrative facts may be here stated. The Venus's fly trap (Dioncea muscipula) has jointed leaves, which are furnished on their edges with a row of strong prickles. Flies, attracted by honey which is secreted in glands on their surface,

a Hale's Veg. Statics. Exp. xxi. 
venture to alight upon them: no sooner do their legs touch these parts than the sides of the leaves spring up, and locking their rows of prickles together, squeeze the insects to death. The well known sensitive plant (Mimosa sensitiva) shrinks from the slightest touch. Oxalis sensitiva and Smithia sensitiva are similarly irritable, as are the filaments of the stamens of the berberry. One of this initakle tribe, Hedysarum gyrans, has a spontaneous motion; its leares are frequently moring in rarious directions, without order or co-operation. When an insect inserts its proboseis between the converging anthers of a kind of dog s bane (Apocynum androsscemifolium) they close with a power usually sufficient to detain the intruder until death. The more I study the phenomena of regetation the more I feel convinced on this point. How often have I heard a farmer reply to an observation upon the tardy growth of turnips, "They will not grow apace, until their leaves are large enough for the wind to take hold of them;" and this is only because plants camot be healthy and vigorous without exercise. Mr. Kinight found that trees which were regularly shaken every day in his green-house, grew more rapidly and were stronger than others which were liept still.

The stimulating powers of excrementitious manures arise from the salts of ammonia they contain. Sir H. Dary found regetation assisted by solutions of 
muriate of ammonia (sal-ammoniac), carbonate of ammonia (volatile salt), and acetate of ammonia. Night soil, one of the most beneficial of manures, surpasses all others in the abundance of its ammoniacal constituents in the proportion of 3 to 1 . It may be observed, that the nearer any animal approaches to man in the nature of its food, the more fertilizing is the manure it affords. I have no doubt that a languishing plant one, for example, that has been kept very long with its roots out of the earth, as an orange tree recently imported from Italy, might be most rapidly recovered, if its stem and branches were steeped in a tepid, weak solution of carbonate of ammonia, and, when planted, an uncorked phial of the solution were suspended to one of the branches, to impregnate the atmosphere slightly with its stimulating fumes.

Manures are also of benefit to plants, by affording some of the gases of the atmosphere to their roots, in a concentrated form. A soil, when first turned up by the spade or plough, has generally a red tint, of various intensity, which, by a few hours' exposure to the air, subsides into a grey or black hue. The first colour appears to arise from the oxide of iron, which all soils contain, being in the state of the red or protoxide; by absorbing more oxygen during the exposure, it is converted into the black or peroxide. Hence one of the benefits of frequently stirring soils: 
the roots of incumbent plants abstract the extra dose of oxygen, and reconvert it to the protoxide. Coal ashes, in common with all carbonaceous matters, have the power of strongly attracting oxygen. Every gardener may hare observed how rapidly a bright spade of iron left foul with coal ashes becomes corered with rust, or red oxide. All animal and vegetable manures absorb oxygen from the air during putrefaction. If it be inquired, of what benefit this property is to plants, since the gases are frequently presented to them in the atmosphere, it admits the ready answer, that they enjoy the additional quantity which is thus collected to the ricinity of their roots, without the latter source being diminished; and, that plants are benefited by such additional application to their radiculæ, has been proved by the experiments of Mr. Hill, already quoted. The question may also be asked, whether the roots have the power to extract the oxygen from its combination. That they have this power admits of little doubt, since Saussure found that they were able to extract various saline bodies from their combinations; not only extracting, but selecting in those cases where several salts were in the same solution. Dr. Daubeny, the Oxford Professor of Agriculture, has also shown that Strontian is rejected by barley, pelargoniums, and the winged pea.

Carbonic acid is also of benefit to plants, when ap- 
plied to their roots in an advanced stage of their growth. Animal and vegetable matters evolve this gas whilst putrefying; and I am not aware of any manure that absorbs it from the atmosphere, so as to be for that reason beneficial to regetation. Lime attracts it rapidly; but combines with it so strongly, that it is useless to the plant, until the carbonate of lime so formed is imbibed and elaborated.

Manures assist plants, by destroying predatory vermin and weeds. This is not a property of animal and regetable manures-ther foster both those enemies of our crops. Salt and lime are very efficient destroyers of slugs, snails, grubs, \&e. It is astonishing how ignorantly neglectful are the cultivators of the soil, when their crops are devastated by the slug, not to dress them with caustic lime, so as to render the surface of the soil quite white, during the promise of a few days' dry weather: it is instant destruction to every slug it falls upon; and those that it misses, are destroyed by their coming in contact with it when moving in search of food.

It is a common practice to burn couch-grass, docks, gorse, and other vegetables, which are very retentive of life, or slow in decay: a more uneconomical, unscientific method of reducing them to a state beneficial to the land of which they were the refuse, cannot be devised. In breaking up heaths, such exuvix are very abundant; but, in all cases, if the weeds, 
leares, \&c., were conveyed to a hole or pit, and. with erery single horse load, and with barrow loads in proportion, a bushel of salt and half a bushel of lime were incorporated, it would, in a few months, form a mass of decared compost of the most fertilizing quality; the lime retaining many of the gases evolved during the putrefaction of the regetable matter, and the salt gombining with the lime to destror noxious animals, which might form a nidus in the mass. $\mathrm{Br}$ this plan, nearly all the carbonaceous matters of the refuse regetables are retained; by burning, nearly all of them are dissipated. The forming of a compost, such as that recommended, is justified and approved by the experience of many.

Stable manure, and all decomposing animal and vegetable substances, have a tendency to promote the decay of stubborn organic remains in the soil, on the principle that putrescent substances hasten the process of putrefaction in other organic bodies with which they come in contact. Salt, in a small proportion, has been demonstrated by Sir I. Pringle, to be gifted with a similar septic property; and that lime rapidly breaks down the texture of organized matters is well known.

There is no doubt that rich soils, or those abounding in animal and regetable remains, are less liable to change in temperature with that of the incumbent atmosphere, than those of a poorer constitution. 
This partly arises from causes alrealy explained when treating of the influence of the colour of soils upon vegetation. Some manures, as salt, protect plants from suffering by sudden reductions of temperature, by entering into their system, stimulating and rendering them more. rigorous, impregnating their sap, and consequently rendering it less liable to be congealed ${ }^{\mathrm{a}}$.

Every cultivator of the soil, by certain empirical signs, may be alle to determine that certain applications are required to render his land productive: for example, he knows when chalk may be applied to advantage; but no lengthened practice has yet enabled any one to judge of the quality of a chalk by its exterior appearance. Chemistry alone can do this. The farmers of a district in Yorkshire having experienced the benefit of lime, procured some from a neighbouring kiln, and were astonished to behold the injury it caused to their crops, and it remained an anomaly of their experience, until chemistry demonstrated that the lime near home contained a very large proportion of magnesia, which, absorbing carbonic acid very slowly, remained in a caustic state, to the injury of the roots of the plants, and the diminution of benefit from the carbonic acid evolved by the decomposing constituents of the soil.

The experiments of Saussure demonstrate the ${ }^{a}$ Cuthbert Johnson's valuable work on Fertilizers. 
benefit accruing to cultivated plants from animal and vegetable manures decomposing in the soil; but they do more, for they afford additional evidence to that already given, how erroneously those persons argue who recommend the seed to be soaked in powerfully stimulating manures, for no other reason than because they are grateful to the adult plant. Carbonic acid gas, though an efficient promoter of a plant's growth when mature, is a check to its progress whilst the root is forming. Saussure placed peas so that their just developed radicles were immersed, some in distilled water, and others in water impregnated with carbonic acid. The radicles when the experiment commenced were two lines and a half in length, and in ten days those in distilled water were five inches longer than those in the acidulated water, and the stalks and leaves were equally superior. But when a month had passed, the relative superiority was reversed, and in six weeks the plants fed with carbonic acid were in every respect most vigorous. Ruckert obtained nearly the same result when beans were grown in earth, some being watered with distilled water, and the others with water impregnated with carbonic acid.

Every farmer, in districts where marl is to be obtained, is aware that it is highly beneficial when applied to the land; few of them, however, know, that this various-coloured compound of earths contains 
always chalk, often to the amount of 50 per cent. They leam, from experience, that the marl of one district is most beneficial to their heary soils; that of a second district is productive of most benefit upon light land: yet they are ignorant, in the first instance. that the first marl contains silica or sand ; that the second has alumina, or clar. as a component, and if a new pit of marl is opened, ther have to wait the result of some years' practice before they ascertain its quality. The chemist can inform them in an hour, and this maturally leads to a consideration of the indications of a soil's sterility or productireness.

No soil is absolutely barren-not an instance is known of land, penetrable by the spacle or by the ploughshare, that will not support some species of plant serviceable to man. By the use of the term barren. therefore, in these pages, I intend no more than that the soil, in its present state, will not repay its cultirator for his expenditure of money and labour.

By the term fertility, I intend the exact converse. When a soil is spoken of as fertile, it must not be understood (unless so stated) that it is rich and largely remunerating; but merely that it is sufficiently productive to reward its cultivator for his expenditure, and to induce him to continue the application of his capital upon it.

Now the natural indications which may enable the 
inspector to pronounce, at once, upon the quality of the soil exhibiting them are obviously arrangeable under four heads. First, the regetation on the soil ; secondly, the soil itself; thirdly, the drainage water; fourthly, the meteorological phenomena; and on these heads I shall proceed to offer some observations in the order mentioned.

I. The Plants produced by the Soil.-If the common fern (Pteris aquilina,) furze (Ulex Europaus,) and heaths (Erica,) prevail, either separately or conjunctively upon a soil, they afford a certain indication that it is the most unproductive and unreclaimable of all light soils-a siliceous surface resting upon a sandy or gravelly subsoil. When I say unreclaimable, it is not intended that such a soil cannot be rendered productive, if clay, aluminous marl, or chalk be in the ricinity with which to improve its staple, but that it cannot be improved from its own bowels-that it has not the remedy for its sterility within itself.

In the east of England the Pteris aquilina, there knomn as the Brake, is estimated as the indicator of the most evil, and a common story is current amongst the Essex farmers expressive of this opinion. An old cultivator who was blind, when upon a farm that was to be let, being told that he might tie his horse to one of the brakes, replied "Nay, nay, then I'll go on further-the brakes shan't break me." 
It is certain, that where the brake flourishes, the siliceous nature of the soil invariably prevails to a very considerable depth. I have frequently seen the stem of this cryptogamons plant followed four or five feet into the soil without reaching its extremity. Some authorities say that the stem is often eight or nine feet long. When a frond of the brake is pulled up, the blackened portion of it must not be mistaken for root, it being merely the stem discoloured by exposure to the ferruginous soil, which strikes a black colour with the gallic acid and tamin in the bark of the plant, where the air can gam access.

Rooting to so great a depth, and each fragment of root being reproductive, it is extirpated with extreme difficulty. This renders it most obnoxious to the cultivator; but the depth of light unretentive soil it indicates, is also especially to be deprecated in the eastern comties of England, for such soils more rapidly become dry than any others; and the anmual depth of rain in inches in that district is never more than half as compared with the same atmospheric deposition in the western counties of England, and on an arerage of years much less.

I have not the tables by me; but I will quote two instances, from first-rate authorities, showing the difference of rain monthly in inches during one rear only, 184\%. The observitions were made at Thetford and Hereford, places nearly equidistant from the 
sea, and in the same parallel of latitude. I give them, because they demonstrate that a soil equally light mas be much less unproductive in the west than in the east of England, owing to its being better supplied with moisture.

Thetford. Hereford.

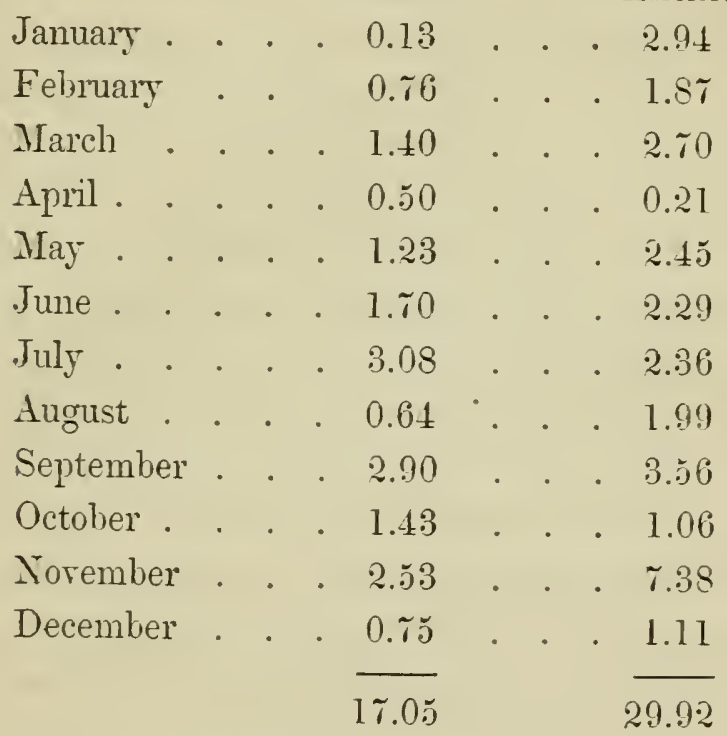

The brake will not live upon a rich soil; but the next plant to be mentioned, the furze, will live upon rich light land, although it speedily reduces it to sterility. I think it is a greater exhauster of a soil then any plant native of England. Nor is this difficult of explication; for being almost destitute of leaves, it has to derive its chief nutriment from the soil, which it does by its widely extending and enor- 
Inously disproportioned roots. So exhausting is its nature, that it absolutely seems to change the very staple of the soil on which it is planted. I remember this fact, most strikingly illustrated by a bank, on which a hedge of the furze was grown in the county of Essex. I had, unfortunately, no analysis of the soil previously to its being thus planted; but after the furze had grown upon it for some ten or more years, the colour and texture of the soil was completely changed; it appeared a mere effete sand, with but the smallest power of adhesion remaining.

Heath is another infallible demonstration that the surface soil is barren and siliceous; but it is not indicative of the subsoil being gravelly or porous. I have seen it abounding where a stiff brick earth was not many inches from the surface. The fineleaved heath (Erica cinerea) is the most inseparably associated with sterility. The cross-leared heath (Erica tetralix) will flourish in richer and better stapled soil than the preceding. The Erica tetralix is that which has waxen-looking flowers, varying in colour from almost pure white to the deepest pink.

Another infallible indication of a barren siliceous soil is the heath-grass (Triodia decumbens). Ground where it is found may be boggy, and disguised by the superfluity of its undrained water, but the staple will invariably be found to have a large excess of silica. 
The rest harrow or cammock (Ononis arvensis and Ononis spinosa) is also indicative of barrenness and lightuess of soil. I have gathered them on such land where clay pits were in the immediate vicinity. But where the broom (Spartium scoparium) abounds, we may be certain that no clay will be found within reach of its deeply penetrating roots. It thrives only in hungry deep gravels or sands.

The common nettle (Urtica urens) I have always considered indicative of fertility, and this will be found, I beliere, to be the fact, except in accidental cases. Thus was I once startled from such conclusion by seeing immense beds of this plant growing upon that most sterile of sandy soils, the rabbit warrens near Brandon, in Norfolk. But the explanation of this was easy upon remembering that the urine of the rabbit contains an excess of the salts of potash,salts absolutely necessary for the nettle's vigorous growth, - salts found, also, near old brick walls, and inducing the nettle to be so constant an attendant on the dwellings of man in temperate latitudesa.

Wherever the elm (Ulmus campestris) grows

a Vauquelin found in the urine of the rabbit,

Carbonate of lime.

Sulphate of lime.

magnesia.

—_— potash.

Sulphate of potash.

Chloride of potassium.

Urea.

Mucus and sulphur.

Its milkiness arises from carbonate of lime.-(Thomson's Animal Chemistry, 496.) 
rapidly and to a large size, it is well known that the soil is rich and open, and capable of producing abundant crops of almost any plant subject to the Farmer's care.

If the birch (Betula alba) be the most flourishing tree upon the land, it is most certainly light and poor.

Where the oak flourishes, wheat and beans, with good tillage, are sure to succeed, for the staple of the soil must be heary and deep. A very marked illustration of this is to be seen in a valley between East Grinsted and Lerres, near the residence of the Earl of Sheffield. In this valley the oak, the wheat, and the beans, flourish, whilst not one of the uplands around yield any thing approaching to an average growth. Again, near Littleton, the residence of Captain Dunn, not far from Hungerford, in Berkshire, I know an oak standing in a hollow, probably an old clay pit. The tree is of gigantic growth, and the field itself almost invariably grows better beans and wheat than any other inclosure on the estate.

Wherever the common way thistle, or saw-wort (Carduus arvensis of Smith, Serratula arrensis of Limnæus) grows luxuriantly, it is usually an intimation that the soil is fertile, and that the plant is rejoicing in its being rather aluminous. This weed will live and ammoy the cultivator on almost any soil, but if a rein of soil somewhat heavier than the rest 
of the land crosses a field, the way thistle will be found on that part to be remarkably the most luxuriant and robust.

If the colts-foot (Tussilago farfara) is prevalent and luxuriant, it may be considered certain that the soil is fertile; it may indicate that the land has been ill-farmed, and that under-draining, especially, is required; but the staple of the soil will generally be found to reward the judicious cultivator.

Where fennel Heum foniculum of Smith, Ancethum feniculum of Linnæus) is observed upon land, it indicates not only that the soil will reward the efforts of the cultivator, but that chalk (carbonate of lime) will in some form be found in the vicinity.

Corn mint (Mentha arensis) is never found upon unfertile soils, but it is a certain indication that underdraining is required. It will not live except where there is more moisture habitually in the soil than is required for the healthful vegetation of cultirated crops.

The scaly stalked spike-rush (Eleocharis caspitosa) is indicative of a soil not very easily reclaimable, viz. : the bog resting upon a retentive subsoil.

Common knot grass (Polygonum aviculare), black grass (Alopecurus agrestis), and the smaller leared creeping bent (Agrostis stolonifera angustifolia), are very far from being indicative of barremness. They are most noxious weeds, injurious to the legitimate 
crops, and most difficult of eradication, but I do not know that $I$ ever observed them upon any soil that would not amply reward the careful cultivator. It is also quite certain that they are never found prevailing upon well cultivated land.

I know some farmers who class unsparingly together "Poppies and Porerty," but this conclusion ought not to be without reservation. There is no doubt that this weed (Papaver rhceas) prevails and seeds most abundantly upon very poor sandy or gravelly soils, but I know it will be in profusion also even in the best land, with the exception of that which is very heary. On the latter I do not remember having ever seen the poppy very numerous.

Sprit (Juncus articulutus), Purple sandwort (Arenaria rubra), and Sweet Gale (Myrica gale), are unerringly indicative of a poor siliceous soil resting on a porous substratum.

II. The soil iiself.-The most fertile soils have the greatest difference of colour between the extreme surface, after it has been exposed for some days to the atmosphere, and that portion which is taken fresh from a few inches below that surface.

I am not aware of having ever met with a fertile soil that retained, after exposure to the dry air, the same colour, after the lapse of forty eight hours, that it had when freshly turned up. Such a soil invariably becomes much lighter coloured. 
Not so barren soils, for I know many that are nearly the same colour at all times, and some boggy soils that are even darker upon the dry surface than beneath.

Every one knows the fresh earthy smell peculiar to a fertile soil newly dug. This smell is never giren forth by boggy or sandy soils that are barren, neither is it emitted by chalk. It does not indeed appear to be perceptibly emitted by any soil not containing fire per cent. of alumina. It is totally absent from the soil on the most barren portions of Bagshot Heath, and is always most powerful upon the heaviest soils. The smell arises in fact from the alumina.

I hare never known a black sandy soil, containing a multitude of white pebbles, that ever repaid the expense of cultivation; especially if it was on the side of a declivity, and, I may add, that all the most fertile soils of England have a specific gravity not exceeding 2.4. I have never yet examined a productive soil with a specific gravity above 2.5 .

Although a black sandy soil, as last described, is invariably infertile, yet a dark coloured soil, if of correct staple, will always bear better crops than one lighter coloured. I know two soils, the specific gravities of which are the same; they have nearly the same amount of aluminous and decomposing matters, but one has much less silica and has much more chalk in its composition than the other. The chalky 
soil is lighter coloured, and although they both rest upon porous subsoils, yet regetation is always later, and harvest backwarder, on this than upon the other field. So much indeed has colour to do with forward vegetation, that, if the surface of one stetch in a field where wheat is sown be sprinkled thickly with coal ashes, it will be found to be earlier in every stage of growth than the corn growing around. This result of observation is readily explicable upon the fact demonstrated by Leslie and others, that dark surfaces absorb more heat from the sun than light coloured ones. The latter reflect its rays.

The sensation imparted to the hand when damp portions of various soils are grasped is very different. The greasy feel of the clayey; the grittiness of the sandy; and the cold softness of the chalky, are easily recognizable by those accustomed to such examinations.

There are two tests connected with handling damp soils that are far from bad criteria, whereby to judge of their fertility. Let a handful be grasped firmly of each soil under examination, and let each consolidated handful be placed upon a sheet of paper on a table in the same room, out of the sunshine. The handful which dries first and crumbles down the most easily will be the least fertile.

Take equal proportions of different equally damp soils, and expose them side by side, each on a 
separate sheet of paper, to the sun's rays for an hour, and then put them into a dark cold closet for another hour. Handle them in succession, and that which feels the warmest will be the most fertile. This is easily explicable from the fact that a fertile soil, that is, one haring a due proportion of alumina and decomposing matter, is always slower in cooling than one that is deficient in these constituents.

III. The drainage water.-Upon this I shall merely observe, that I have never been able to find that it affords any satisfactory criterion whereby to judge of the fertility of a soil. A red, ocherous deposit from such water shews that the subsoil through which it percolated is an irony gravel or sand. The dark film exhibiting the dove's-neck varying colours, often seen on the surface of drainage water, indicates its having passed through peat, bog, or wood, for that film arises from the vegetable extract it contains. Virgil tells us (Georg. ii. 245) to wash a soil, and that if the water employed becomes consequently nauseous and bitter, it indicates a salt soil unsuited to the growth of corn. I have never met with such a soil, except where soda was a product of the land, and this is not the case in England.

IV. Meteorological pihenomena.-Under this head I have only to remark that, wherever fogs or mists settle, or become apparent in the evening earlier than upon neighbouring soils, it is a certain indica- 
tion that that part is colder, and will be usually more unproductive and certainly later in its regetation. I once saw a remarkable proof of this. On one portion of a field the evening mist-cloud was always observed to settle sooner than on the other parts. This portion also always bore the lightest part of the crops grown. It was under-drained, and the early mists and unproductiveness simultaneously ceased. 


\section{CHAPTER III.}

THE STEII AND BRANCHES.

Althodgh every member of the vegetable form, from the minutest root to the most fragile flower, have their epidermis, cellular integument, bark, woody fibre, and medullary matter, yet as these are most apparent in the stem and branches, they can be commented upon most readily in this chapter, deroted to the consideration of those regetable members.

The first of these, the epidermis, is analogous to the human cuticle, or scarf skin, being the external envelope of the wholè surface. It is commonly transparent and smooth, sometimes hairy; in other instances hard and rugged, occasionally so abounding with silica or flint as to be employed as a polisher for wood, and even brass. In every instance it is a network of fibres, the meshes of which are filled with a fine membrane. The epidermis appears to be designed as a preservative from the injurious effects of the atmosphere, to regulate the quantity of gaseous matter and moisture respired, and as a shield from the attacks of animals, sc. It is certainly devoid of 
sensation. The texture of the membrane between the meshes varies much in different species of plants. In very succulent plants, it is so contrived, that it readily allows the absorption of moisture, but prevents perspiration. Such plants are, consequently, well qualified to inhabit hot climates and dry soils. Neither is it at all impossible, that it possesses the quality of allowing the passage of some gases, and rejecting others, as the bladder of animals permits water to pass through its texture, but is impervious to alcohol. In old trees it cracks, and in many cases becomes obliterated, the dead layers of bark performing its offices. Its growth is slower than that of other parts, and its powers of expansion, though great occasionally, camnot equal the rapid enlargement of the parts it incloses and defends. This is very frequently the case with the stem and branches of the cherry; the tree is then said by gardeners to be hide-bound, and is relieved by making longitudinal incisions. It is still more apparent in the fruit of the cherry and plum: when rain falls abundantly during their state of ripeness, their pulp swells so rapidly, that in an hour or two the epidermis of every ripe drupe upon a tree will be cracked. Gardeners are very prone to scrape with no gentle hand the bark of their fruittrees; whereas every care should be taken not to wound its surface umnecessarily; and never to reduce 
its thickness until all danger of serere frosts is passed.

The epidermis regulates the evaporation from a plant, and preserves it in some degree from the detrimental sudden changes of temperature to which our climate is liable. The birch (Betulus alba), has more films of epidermis than any other European tree; and it ascends to greater heights in the Alps, and approaches nearer to the frozen zone than other trees of the same climates.

Immediately below the epidermis occurs the cellular integument (otherwise known as the parenchyma and pulp.) It is a juicy substance; and, being the seat of colour, is analogous to the rete mucosum of man, which is red in the white, and black in the negro: the flesh of fruits is composed of it. Leares are chiefly formed of a plate of it, inclosed by epidernis. In herbs, succulent plants, leares and fruits, if it is destroyed, like the epidermis of the same, it remains unrestored; but in the case of trees and shrubs, it is regenerated after each remoral. In leares it is generally green ; in flowers and fruits, of every hue. It is always cellular, and evidently acts a part in the secretory system of plants.

Under the cellular integument occurs the bark, which, in annual plants, or branches of one year's growth, consists of a single layer, scarcely distinguishable from the wood; in older stems and branches, 
it is composed of as many layers as they are years of age. It is in the innermost of these, which is called the liber, that the rital returning circulation and secretions are carried on for the time being almost exclusively. These layers are concentric, or, as they are usually termed, cortical layers; they are thicker in feeble plants than in more vigorous plants of the same species; they are formed of waving longitudinal fibres, the meshes of the net-work they thus constitute being filled with pulp. If the outer bark is destroyed, but the wound does not penetrate below the liber, the wound is healed up, otherwise the remored part is unregenerated. In some roots, although only annuals, the bark is composed entirely of liber, and is very thick, as in the carrot and parsnep, in which it is remarkably separated by a lightcoloured ammular mark, from the central or woody part. The liber is composed of rarious longitudinal tubes, in which the true sap of the individual descends after elaboration in the leaves: consequently here are found in the most concentrated state the substances that are the peculiar products of each plant, as the resin of the fir, the bitter principle of the cinchona, or Perurian bark, \&c.

I will here pause, to remark upon some of the remedies which have been recommended for the removal of insects from the bark of trees. Oil has been directed to be smeared over them, for the de. 
struction of the aphis lanigera. moss, \&c. Whether this application will answer sucl purpose, I will not stop to argue, but will content myself with observing, that a more deleterious one is scarcely possible; for on the same principle that it destroys the parasites, namely, by closing their spiracles and pores, and thus suffocating them, it in a like manner clogs up the pores of the infected tree, and. in every instance, insures a weak and unhealthy regetation; for it is not a transient remed $j$, that will cease in its effects as soon as it has attained the desired end. The oil dries, and, as it were, forms a varnish over the epidermis for years, unremored by exposure to the atmosphere: and this effect is more decidedly insured by linseed oil being the kind recommended, it being one of the most unctuous and quick-drying of the oils. The most effectual, most salutary, and least disagreeable remedy is of trivial expense, and which a gardener need but try upon one individual to insure its adoption. It is with a hard scrubbing brush, dipped in a strong brine of common salt, as often as necessary, to insure each portion of the bark being moistened with it, to scrub the trunks and branches of his trees at least every second year. It most effectually destroys inserts of all kinds, and moss; and the stimulating influence of the application and the friction are productive of the most beneficial effects. The expense is not so much as that of dressing the trunks with a 
solution of lime, which, however efficient in the destruction of moss, is not so in the removal of insects -is highly injurious to the trees, by filling up the respiratory pores of the epidermis, and is decidedly a promoter of canker. Let my remedy be brought by every orchardist to the test of experiment under his own eye, that it may be effectually done, and he will not require me to theorise. Facts are stubborn opponents.

The injury inflicted by stopping the pores of the epidermis, on the stem and branches of a tree, is at once evident from the fact, that oxygen and water are absorbed, and carbonic acid erolved from them. the same as in the leaves, which operations are all parts of the process of elaborating the sap. It is no trivial inspiration of oxygen; for in twenty-four hours. the branch of an apple-tree has been found to inhale five times its own volume.

If the fibres emitted by the ivy, by which they cling to other trees for support, do not aid it in obtaining nourishment, yet by filling their respiratory pores, they are injurious, and should never be allowed to cling around serviceable trees.

Immediately beneath the bark is situated the rood, which forms the chief bulk of trees and shrubs. It is formed of concentric layers, one of which, at least, is added annually. These layers are formed of a tissue of longitudinal fibres, resembling net-work, the in- 
terstices of which are filled up with soluble matter, differing in each vegetable genus, but closely resembling its parenchyma The layer immediately in contact with the bark is the softest and palest in colour, and thence is called the alburnum. It is in this that the ressels which convey the sap from the roots to the leaves are chiefly situated. This layer is anmually renewed, that of the previous year becoming more complete rood. Although the chief part of the sap vessels, as just observed, is situated in the alburnum, yet others, though more scantily, are dispersed through the whole of the wood. Wherever situated, they extend from the extremity of the minutest root to the leaves. The idea that the annular layer of wood is rendered more dense and firm by severe winters, is denied by reason, and demonstrated to be false by actual observation. The layers are thickest on those sides of a tree where the largest branches occur, and are, throughout, of greater size, in such years as afford the most genial period to vegetation.

Wood is consolidated fastest in those plants which are most freely exposed to the influence of light and air, and those plants grow in height the slowest. This teaches a lesson to the gardener he often may remember with advantage; for it is often desirable to have specimens of the same shrub, varying in height; and he may often increase their stature, yet preserve them in health, by keeping them in a moist, 
shaded locality, during the early stages of growtls: and he may as certainly render them more dwarf, br exposing them to a drier, and the brightest atmosphere that they will healthily endure, and he can command. By the former treatment, I have seen heliotropes clustering round the pillars of a conservatory to the height of fifteen feet.

From the extension of the woody fibre being greater anl' longer continued on one side of a stem or branch thin on its opposite side, it frequently becomes contorted. Gardeners usually endearour to remedy this by making an incision on the inner side of the currature, and then employing force to restore it to a rectilinear form, causing a gaping wound, and mostly failing to attain the object. If the incision be made on the outer side of the curre, thus dividing the woody fibres that continue to elongate most rapidly, the l,ranch or stem, with but slight assistance, will recorer its due form, and there will be no open wound.

From the fact that there is invariably more woody matter deposited on the side of a stem or branch which is most exposed to the air and light, gardeners halve explained to them why those sides of their trained trees which are nearest the wall, ripen, as they term it, most slowly; and are benefited by being loosened from the wall so soon as they are relieved from their fruit. If they require any demonstration that this explanation is correct, they need only examine the 
trees in clumps and avenues; their extemal sides will be found to enlarge much more rapidly than their internal or most shaded sides.

In the centre of the wood is situated the medulla or pith. It is a soft, cellular, membranous substance, juicy when young, and extending from the ends of the roots to the extremities of the branches. In the first stages of vegetation, it occupies but a small space : it gradually dilates; and in shoots of a year old, and in young trees, it is of considerable diameter; as their age increases, it gradually diminishes and at length becomes totally extinct, its place being occupied by perfect wood. Its functions are little understood. It appears to be commected with the production of young shoots; for, as soon as it becomes extinct in a branch, that member loses, in a great degree, the power of producing them; that power apparently being transferred to those younger branches which still retain their pith in perfection.

The stem is by no means an essential part of the plant, since many are destitute of it; to such trees as naturally are gifted with one, it is somewhat injurious to prevent its formation. Standard fruit trees, under similar circumstances of soil, season, and culture, generally, produce finer flavoured fruit than either dwarf standards or espaliers. This fact appears to be accounted for by the discoveries of the indefatigable Knight, which evince that plants, during the latter 
part of the summer, are employed in preparing nourishment for the production of the foliage and blossom in the succeeding spring ; this nourishment is perfected and deposited in the albumum, and mixes with the sap during its ascent in that season. Of a consequence it is found to increase in density proportionate to the height at which it is extracted. 


\section{CHAPTER IV.}

THE LEAVES.

The leaies are highly vascular organs, in which are performed some of the most important functions of a plant. They are very general, but not absolutely necessary organs, since the branches sometimes perform their offices; such plants, however, as naturally possess them, are destroyed, or greatly injured by being deprived of them. The duration of a leaf is, in general, but for a year, though in some plants, they survive for twice or thrice that period. These organs are generally of a green colour. Light seems to have a powerful influence in causing this, since, if kept in the dark, they become of a pale yellow, or even white hue, unless uncombined hydrogen is present, in which case they retain their rerdure though light be absent. Hence their etiolation would seem to arise from their being unable to obtain this gas, under ordinary circumstances, except when light is present. Now, the only source from which they can obtain hydrogen, is by decomposing water; and how light assists in the decomposition may perhaps be 
explained by the disoxygenizing power with which it is gifted. The violet rays of the spectrum have this power in the greatest degree; and Semnebier has ascertained by experiment, that those rays have the greatest influence in producing the green colour of plants. When leares are of any other hue than green, they are said to be coloured. This variegation is often considered to be a symptom either of tenderness or debility; and it is certain, when the leaves of a plant become generally white, that that individual is seldom long lived. Mr. Knight, however, has demonstrated that variegation is not a certain indication of a deficiency of hardihood.

The functions of the leaves appear to be a combination of those of the lungs and stomach of animals : they not only modify the food brought to them from the roots, so as to fit it for increasing the size of the parent plant, but they also absorb nourishment from the atmosphere. The sap, after elaboration in these organs, differs in every plant, though as far as experiments have been tried, it appears to be nearly the same in all regetables when it first arrives to them. The power of a leaf to generate sap is in proportion to its area of surface, exposure to the light, and congenial situation.

Leaves throw off a very considerable quantity of water. Dr. Hales found that a cabbage emitted daily nearly half its weight of moisture, a sunflower, 
three feet high, perspired $1 \mathrm{lb} .14 \mathrm{oz}$., and spearmint exhales $1 \frac{1}{4}$ times its weight in the same period. But of all the plants the diurnal perspiration of which has been ascertained, the cornelian cherry (Cormus mascula) transpires the most ; the exhalation amounting to nearly twice the weight of the plant in twentyfour hours. This aqueous expiration takes place chiefly during the day; is much promoted by heat, and checked by rain, or a reduction of temperature.

On the free-performance of this function of plants, their health is dependent in a very high degree; and I believe that half the epidemics to which they are subject arise from its derangement. That consequence of the clubbing of the roots of the brassica tribe called fingers and toes arises, I consider, entirely from it. In the drought of summer, when the moisture supplied to a club-rooted cabbage by its root does not nearly equal the exhalation of its foliage, to supply this deficiency the plant endeavours, by forming a kind of spurious bulbous root, to adapt itself to the contingency; in the same manner that in dry situations, the fibrous roots of Phleum pratense, Alopecurus geniculatus, \&c., acquire a tuberous form, because bulbous or tuberous-rooted plants, it is well known, will exist in a soil so deficient in moisture as to destroy all fibrous-rooted regetables.

Evergreens transpire less moisture than deciduous plants; which would lead to the expectation that 
they are more capable of living in dry situations, which, in general, is really the case. The matter transpired by a healthy plant is nearly pure water, 5,000 grains of it never containing more than one grain of solid matter, and this is constituted of resinous and gummy matter, with carbonate and sulphate of lime. It appears to be nearly the same in all plants. The quantity, howerer, we have seen, varies in every species, probably in every individual-and is greatly influenced by the quantity of water applied to the roots. Under precisely similar circumstances, Sennebier obtained the following results:

Grs.

Grs.

A peach branch, imbibing 100 exhaled 35

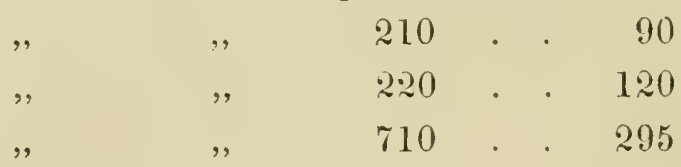

I have found the branch of a pelargonium, that, whilst growing on the parent stem, exhaled only twenty grains in twenty-four hours, more than trebled that quantity, in the same time, when cut from the stem, and placed with the divided end in water. This increased transpiration is attended by a proportionate reduction of temperature; for a collection of pelargoniums, in the midst of which Fahrenheit's thermometer stood at $55^{\circ}$, fell to $48^{\circ}$ within two hours after a plentiful watering to their roots only, 
though the water was of the same temperature as the greenhouse.

The transpiration of plants decreases with that of the temperature to which they are exposed, as well as with the period of their growth. This explains why the gardener finds that his plants do not require so much water in cold weather, nor during the time that elapses between the fall of their blossom and the ripening of their seed. During this period they do not transpire more than one-half so much as during the period preceding and attending upon their blooming. The transpiration takes place from the upper surfaces of the leaves; and, if these surfaces are coated with varnish, the leaves gradually decay and fall, and the growth of the plant ceases until fresh leaves are produced. Hence arises the benefit which plants derive in rooms, greenhouses, and other confined inclosures, from keeping those surfaces cleansed with the sponge and syringe. Some plants are particularly sensitive to injury from any check to their transpiration, among which are the tea-scented roses; and it thence arises, that they cannot now be cultivated in nursery-gardens near London, where they once flourished when that metropolis was less extensive. The advantage derived by plants from haring their leaves cleansed, was exemplified by the following experiment:-

Two orange trees, weighing respectively 18 and 
20 ozs., were allowed to regetate without their leaves being cleansed for a whole twelvemonth; and two others, weighing 19 and $20 \frac{1}{2}$ ozs. each, had their leaves sponged with tepid water once a week; the two first increased in weight less than half an ounce each; whilst of the two latter, one had increased two, and the other nearly three ounces. In all other respects they had been treated similarly.

It must be remembered, however, in using the sponge and the syringe, that the under side of leaves is an absorbing surface, benefited by being kept clean, and by the application of moisture. The kidney bean, sunflower, cabbage, and spinach, absork moisture equally by their under and upper surfaces; the cocliscomb, purple-leared amaranth, heliotrope. lilac, and balm, absorb most freely by their upper surfaces; and the vine, pear, cherry, apricot, walnut. imulberry, and rose, absorb most by their under surfaces.

The transpiration from the leaves of plants is effected through pores or stromates, varying in number and size in every species, but being, usually, either largest or most numerous in plants inhabiting moist or shady localities. This is a wise provision; for such plants, consequently, have an abundant supply of moist food to their roots, requiring a competent provision for its elaboration and reduction from superfluous water. Those plants which are natives of 
sandf, exposed soils, have, on the other hand, either fewer or smaller stromates. Crinum amabile, an inhabitant of swamps near Calcutta, has 40,000 of the largest known stromates on every square inch of its leaves; whilst an aloe from the exposed sands of the Cape of Good Hope, has 45,000 of the smallest, and not equal in transpiring porrer to half the same number of stromates in the leaves of the Crinum. I have not been able to test their relative transpiring powers; but of two similarly constructed plants, of nearly similar size, the rate of perspiring in July, both in a temperature of $65^{\circ}$, but not exposed to the sunshine, was as follows. In six hours, Mesembryanthemum Deltoides, native of an arid soil, exhaled eight grains, whilst Caltha palustris, found only in inarshy places, exhaled twenty-five grains. In the absence of certain information, therefore, the gardener may conclude, as a guide for his treatment of a new plant, that, if its stromates are large, it will require abundance of water.

Another circumstance most influential in controling the transpiration of plants, is the hygrometric state of the atmosphere in which they are growing. The drier the air, the greater is the amount of moisture transpired; and this becomes so excessive, if it be also promoted by a high temperature, that plants in hothouses, where it has occurred, often dry up as if burned. The justly-lamented Mr. Daniell 
has well illustrated this by showing, that if the temperature of a hot-house be raised only five degrees, viz. from $75^{\circ}$ to $80^{\circ}$, whilst the air within it retains the same degree of moisture, a plant that, in the lower temperature exhaled 57 grains of moisture, would, in the higher temperature, exhale 120 grains in the same space of time.

Plants, however, like animals, can bear a higher temperature in dry air, than they can in air charged with vapour; animals are scalded in the latter, if the temperature is very elevated; and plants die under similar circumstances as if boiled. MM. Edwards and Colins found kidney beans sustained no injury when the air was dry at a temperature of $167^{\circ}$ : but they died in a few minutes if the air was moist. Other plants, under similar circumstances, would perish, probably, at a much lower temperature; and the fact affords a warning to the gardener to have the atmosphere in his stoves very dry, whenever he wishes to elevate their temperature for the destruction of insects or other purposes.

Though growing plants can bear an elevated temperature without injury, a very different effect is produced upon them by even a lower heat, after they have been separated from their roots. This has to be borne in mind in the drying of potherbs, which, though it is a process very simple and very important for the winter's cuisine that it should be conducted 
correctly, is usually more neglected and more thoughtlessly practised than any other in the varied range of the gardener's duties. To demonstrate this. will only require to have pointed out how it ought to be managed. The flavour of almost every potherb arises from an essential oil which it secretes, and this being in the greatest abundance just previously to the opening of its flowers, that is the time which ought to be selected for gathering. Potherbs ought to be dried quickly, because, if left exposed to winds, much of the essential oil evaporates, and mouldiness occurring, and long continuing, destroys it altogether, for nearly every plant has its peculiar mucor, (mould,) the food of which is the characteristic oily secretion of the plant on which it regetates. A dry brisk heat is therefore desirable; and as the fruit store-room ought always to have a stove. and is untenanted when herbs require drying, no other place can be more efficiently employed for the purpose. The temperature should be $90^{\circ}$, for if it exceeds this. the essential oils are apt to burst the integuments of the containing vessels, and to escape. Forty-eight hours, if the heat be kept up steadily, are sufficient to complete the process of drying. The leaves, in which alone the essential oils of potherbs reside, should then be carefully clipped with scissors, not crushed, from the stalks, and stored in tightly corked wide-mouthed bottles. Each will thus preserve its 
peculiar aroma, not only through the winter, but for years, and be infinitely superior to any specimens producible in the forcing department, for these are unavoidably deficient in flavour.

Leaves have the power of absorbing moisture as well as of emitting it, which power of absorption they principally enjoy during the night.

During the day leaves also absorb carbonic acid gas, which they decompose, retaining its carbon, and emitting the greatest part of the oxygen that enters into its composition. In the night this operation is in a certain measure reversed, a small quantity of oxygen being absorbed from the atmosphere, and a yet smaller proportion of carbonic acid emitted.

Carbonic acid gas in small proportions is essential to the existence of leaves, yet it only benefits them when present in quantities not exceeding one-twelfth of the bulk of the atmosphere in which they are vegetating; though one twenty-fifth is a still more favourable proportion; and as hot-beds, heated by fermenting matters, rapidly have the air within their frames contaminated to a much greater extent than the proportions above-named, thence arises the injury to the plants they contain, from a too long neglected ventilation. The leaves turn yellow from the excess of acid, which ther are unable to digest, and which consequently effects that change of colour which also 
occur's in autumn, and which will be more fully considered when the decay of plants is detailed.

It is the accumulation of carbonic acid and other gaseous matters, such as sulphurous acid and anmonia, which renders ventilation so essential to the health of plants in forcing-pits and hot-houses. They cannot inhale air, orerloaded with these contaminations, without being speedily injured, and the proportions of those gases which rapidly cause disease, or even death, are much less than the gardener usually suspects, for if the sulphurous acid amounts to no more than one cubic foot in ten thousand of the air in a hot-house, it will destroy most of its inhabitants in two days. To avoid such destruction. for the comfort of visitors, and, above all, for the sake of the plant's vigour, air should be admitted as freely as the temperature will permit. The foul warm air can be easily allowed to escape through rentilators in the most elevated parts of the roof, and fresh warm air can be as readily supplied, through pipes made to enter near the flooring of the house after passing through hot water, another source of heat.

I am quite aware that Mr. Knight has stated that he paid little attention to ventilation, and that plants will be vigorous for a time in Wardian cases; but this does not prove that their Creator made a mistake when he placed regetables in the open air. Plants confined in houses or other close structures 
may be made to grow in spite of such confinement, but all experience proves that other farourable circumstances, such as heat, light, and moisture, being equal, those plants are most rigorous and healthy which have the most liberal supply of air.

Though an excess of carbonic acid gas is detrimental, yet its partial absence from the atmosphere is equally fatal to a plant's leaves, for without it they wither and fall. It is not a matter of indifference. therefore, whether a green-house or hot-house be whitened with a solution of lime, which absorbs that gas from the air, a fortnight or only a day or two before plants are introduced or foreing commenced; for it is the infliction of several trivial injuries to a plant that prevents its successful cultivation; no one who is entitled to practise in the higher departments of his art ever makes such great blunders as at once to destroy the plants under his care. That fresh-limed walls do injure plants is beyond dispute, for the plants in a row of small pots next the back wall in a propagating house which had been thus whitened only the day before, have been more than once observed to be the only plants that acquired a sickly hue, and shed nearly all their leares. Fleshy leaved plants would not be so liable to injury if obliged to be brought into a house fresh limed, for these require much less carbonic acid daily than thin leaved plants. Five plants of Cactus speciosissimus in the injured. 
row just noticed, were not apparently affected. Thin leaved plants consume daily from five to ten times their own bulk of carbonic acid gas, whilst fleshy leaved plants, such as the cacti, aloes, agares and mesembryanthemums, do not consume more than their own or double their own bulk of that gas.

Plants and their leaves if excluded from light become of a white or pale rellow colour, in which state they are said to be blanched or etiolated. This is occasioned by their being neither able to decompose the water they imbibe, nor to inhale carbonic acid. In the dark, plants can only inhale oxygen, and thus, deprived of free hydrogen and carbon, on the due assimilation of which by the leaves all vegetable colours depend, and saturated with oxygen, they of necessity become white. An excess of oxygen has uniformly a tendency to whiten vegetable matters; and, to impart it to them is the principle upon which all bleaching is conducted. An over-dose of oxygen causes in them a deficiency of alkaline, or an excess of acid matter, and light enables plants to decompose the acid matter and to restore that predominancy of alkalinity on which their green colour depends. Semnebier and Davy found most carbonic acid in etiolated leaves; and all green leaves contain more alkaline matter than the rest of the plant which bears them. Every cook knows that a little alkali, carbonate of soda, added 
to the water improves the green hue of her boiled vegetables. That this is the cause of the phenomenon is testified by direct experiment. Blanched celery and endive, and the white inner leaves of the cos-lettuce, contain about one-third more water than the same parts when green; and if submitted to destructive distillation do not yield more than half so much carbon. Then, again, if a plant of celery is made to regetate in the dark, under a receiver containing atmospheric air, with the addition of not more than one-twentyfifth part of its bulk of a mixture of carburetted hydrogen, and hydrogen such as is afforded by the distillation of coal, that plant, though it becomes paler than when grown in the daylight, still retains a verdant colour.

So effectual is the metamorphosis of plants effected by excluding them from the light, that Professor Robinson brought up from a coal-mine, near Glasgow, some whitish-looking plants of which no one could detect the name or character. After exposure to the light, the white leaves decayed, and were succeeded by green ones, which speedily revealed that the plants were tansy. They had found their way into the mine in some sods from a neighbouring garden; but though they had retained life in its dark galleries, they had entirely lost their natural colour, odour, and combustibility. This is only in accordance with the gardener's yearly expe- 
rience, for his blanched sea-kale, endive, and lettuce are totally dissimilar in flavour and appearance to the plant left in its natural state.

Sir H. Dary excluded a cos-lettuce from the light. In six days it was rendered very pale, and, at the end of another week, it was quite white: the growth of the plant was checked, and the analysis of its leares shewed that they contained more carbonic acid and water, but less hydrogen and residual carbon, than an equal weight of green leaves.

It deserves notice, that it has been proved by the experiments of Dr. Hope and others, that light from artificial sources may be concentrated so as to enable plants to absorb oxygen and perfect those elaborations on which their green colour depends; and the light of the moon has a similar influence. A similar concentrated light will make the pimpernel and other flowers which close until sun-rise open their petals, and rouse from their rest; a fact which gives another reason why plants in rooms frequented at night become weak and exhausted sooner than those that remain, as nature dictates, unexcited at night.

The yellow, red, and light brown tints which render the foliage of our plants so beautiful in autumn, arise from the absorption of an excess of oxygen gas. When the reduced temperature of the season deprives a leaf of the power to elaborate the 
sap, and, indeed, stops the circulation to it of that fluid, the absorbent powers of the organ are reversed, and instead of carbonic acid it inhales oxygen. The effect is speedily perceptible. Gallic acid forms, and this, modified by the differing saline constituents of different leaves, changes the hue of their green colouring matter, called chlorophyllite or chromulite, into various tints of yellow, red, and brown. This is the general effect of acids acting upon regetable greens, and that it is the cause of the autumnal change of colour in leares, is proved by the fact, that if a green leaf be dipped into an acid it assumes the same hue, and if a red or yellow leaf be dipped into an alkaline solution, it is rendered green-the alkali, evidently, neutralizing the acid that had wrought the umnatural change of colour.

The hints and warnings which these facts suggest to the mind of every reflecting practitioner are numerous. They explain and enforce the necessity of a regular, and by no means, as to quantity, indiscriminate, supply of water to plants; the importance of shading after their transplanting, and of a free circulation of air, \&c.; and the necessity of keeping the leaves as clean and as free from injury as possible. The leaves of plants must often be removed; and in some instances this is done with essential benefit; but the horticulturist should con- 
stantly keep in mind that, with every leaf that he removes, he deprives the plant of a primary organ of its existence.

Light, it has just been stated, is the cause of the green colour of plants; but it should be observed that its full power is only beneficial when directed upon their upper surface. This is evidenced by the position they always maintain. Trees nailed either to a north or south wall, or trained as espaliers, always turn the upper surfaces of their leares outwards, to where there is most light. Plants in a hot-house uninfluenced by the direction from whence proceeds the first supply of air or the greatest degree of heat, turn not only their leares but their rery branches towards the source of brightest light, and if not turned almost daily, entirely lose their symmetrical form.

If the branches of a tree trained against a wall, or other support, are so moved when their leaves are completely expanded, that the under side of the foliage is the most exposed to the light, they are always found to regain their natural position in a day or two. If the experiment is often repeated on the same individual, the leares to the last continue to revert, but become gradually weaker in the effort, partially decay, and their epidermis peels off. Succulent leaves are particularly sensible of light, but those of pinnated, leguminous plants, as the pea and French bean, are still more so. 


\section{CHAPTER V.}

THE SAP.

As there is a very close similarity in the blood of all animals, so does the same resemblance obtain in the sap of plants. Uniformly it is limpid as water, its chief constituent, and contains an acid, salts, and mucilage or saccharine matter. The proportions of course vary.

The basis of this sap is the moisture of the soil and atmosphere absorbed by the roots and other organs; and that that power of absorption is very great has been observed in a previous chapter. Neither is it an indiscriminate power; for if the roots of a plant are placed in water containing two or more salts in solution, they will alstract different portions of those salts, and will reject some of them entirely. Thus, when 100 grains of each of the following salts were dissolved in 10,000 grains of water, and plants of Polygonum persicaria, Mentha piperita, and Bidens camalina were made to grow in it, they took up six grains of sulphate of soda (glauber salt), and ten grains of chloride of sodium (common salt), but not a grain of acetate of lime. 
The moisture from the soil absorbed by organs having such powers of intro-susception and discrimination passes up ressels situated in the wood, but especially in the alburnum, impelled by their contractile power, a power so great that it drives the sap from the extremity of a cut rine branch with a force capable of sustaining a column of mercury thirty-two inches and a half high. If a proof of their contractile power, evidently resembling the peristaltic motion of the animal power, be required, Dr. Thomson justly refers for such proof to the evidence afforded by milky-juiced plants like the Euphorbia peplis. If the stem of this plant be divided in two places, the juice flows out at both ends so completely; that if it be again lisected between the two former cuts, no more juice will appear. Now it is impossible that these phenomena could take place without a contraction of the vessels; for the ressels in that part of the stem which has been detached could not be more than full; and their diameter is so small, that if that diameter continued unaltered, the capillary attraction would be more than sufficient to retain their contents, and, consequently, not a drop would flow out. Since, then, the whole liquid escapes, it must be driven out forcibly, and, consequently, the ressels must contract ${ }^{2}$.

Thus propelled, the sap is distributed along each a Thomson's Organic Chemistry, 988. 
branch, to every leaf, and to every fruit of the plants, gradually acquiring during its passage a greater specific gravity, not only by exhalation, but by dissolving the peculiar secretions of the plant formed during its previous year's growtl, and deposited in the alburnum from the sap, during its downward course in the inner bark from the leaves. It is in the leaves that the chief elaboration of the sap takes place, and those peculiar juices are formed characteristic of the plant, and which are found deposited there, or in the bark, or still further altered in the fruit and seed.

Although the sap increases in specific grarity, and consequently obtains an accession of solid matter during its progress up the stem, yet the matter thus obtained is not of paramount importance, nor absolutely controlling the subsequent changes to be effected, for in such case the greengage would be altered by its plum stock, and the nonpareil by its crab stem. So far from this being the case, the old gardener's maxim, "the graft overruleth the stock quite" is consonant with truth, though it is to be taken with some reservation. The graft prevails and retains its qualities, yet the stock has the power of influencing its productiveness as well as the quality of the fruit. Thus, a tree having an expansive foliage and robust growth, indicative of large sap vessels and vigorous circulation, should never be 
grafted upon a stock oppositely characterized, for the supply of sap will not be sufficient: illustrations are afforded by the codlin never succeeding so well on a crab, nor a bigoureux on a wild cherry, as they do on freer growing stocks. Indeed, I have no doubt that every tree and shrub succeeds best, is most productive, and freest from disease, if it be supplied with sap from roots and through a stem of its orm particular kind. This is evident to common sense, nor would any fruit-scion be grafted upon a stock of another species or variety, if it were not that such stocks are most easily obtainable. For example, our choicest cherries are, for the reason assigned, grafted or budded upon the wild cherry; and every one must have noticed the frequently occurring consequence, an enlargement, appearing like a wen, encircling the tree just above where the graft and the stock joined;- the growth of the former having far outstripped that of the latter. If a tree could be nourished from its own roots,- -from organs assigned by its Creator as those best suited to supply the most appropriate quantity and quality of sap, there can be no doubt that it would be productive of benefit; and this desideratum seems to be secured by the plan suggested by M. Aibret. In the instances of apples and pears, and I see no reason forbidding its adoption to any other grafted tree, he recommends the grafts always to be inserted 
close to the surface of the ground, or they might be even rather below the surface, by scooping out the earth around the stems of the stocks. When planted out, the lowest extremity of the graft should be about four inches below the surface. After two or three years, at the close of June, the soil should be removed, and just above the junction of the graft and stock, with a gouge, one-fourth of the bark removed, by four cuts on opposite sides of the stem. The cuts being deep enough to remove the inner bark, and the wounds covered immediately with rich soil, formed of one part putrescent cow-dung, and two parts maiden loam. If kept constantly moist with water, and occasionally with liquid manure, roots will usually be speedily emitted, especially if the place where a bud once was formed he thus kiept moist beneath the soil.

But the stock has some other influence over the sap, besides limiting the quantity of sap supplied to the scion, an influence not only arising from the size of its vessels, but upon its susceptibility to heat. It has a further influence over the scion by the sap becoming more rich, indicated by its acquiring a greater specific gravity in some stocks than in others, during its upward progress. The specific grarity of the sap of a black cluster vine stock on which a black Hamburgh had been grafted was, when obtained six inches from the ground, 1,003, and at five feet from 
the ground 1,006; but the same black Hamburgh, growing upon its own roots, had specific grarities at corresponding heights of 1,004 and 1,009. This increase is of great importance to a tree's growth, when the quantity of sap passing annually through its ressels is considered. The exact amount of this, it is perhaps impossible to discorer, but its extent may be appreciated by the quantity of moisture their roots are known to imbibe, and by the facts that a small rine branch has poured out sixteen ounces of sap in twenty-four hours; a birch tree a quantity equal to its orm weight during the bleeding season; and a moderate sized maple about two hundred pints during the same period.

The habit of the stock also is of much more importance than is usually considered. If it grows more rapidly, or has larger sap ressels than the scion or bud, an enlargement occurs below these; but if they grow more rapidly than the stock, an enlargement takes place just above the point of union. In either case the tree is usually rendered temporarily more prolific, but in the case where the stock grows most slowly, the productiveness is often of rery short duration, the supply of sap annually becoming less and less sufficient to sustain the enlarged production of blossom and leaves. This very frequently occurs in the freer growing cherries when inserted upon the wild species; and still more 
fiequently to the peach and apricot upon stocks of the slower growing plums. It is highly important, therefore, to employ stocks, the growth of which is as nearly similar as may be to that of the parent of the buds or scion.

'The earlier vegetation of the stock than of the bud or graft is also important; for if these are earliest in developement, they are apt to be exhausted and die before the flow of sap has enabled granulation and union between the faces of the wounds at the junction to occur. Mr. Kuight's observations upon this point are the results of experience, and are so consonant with the suggestions of science, that I will quote them in his own words without comment:

"The practice of grafting the pear tree on the quince stock, and the peach and apricot on the plum, where extensive growth and durability are wanted, is wrong; but it is eligible wherever it is wished to diminish the vigour and growth of the tree, and where its durability is not thought important. The last remark applies chiefly to the Moor-park apricot-the Abricot-peche, or Abricot de Nancy of the French.

"When great difficulty occur's in making a tree, whether fructiferous or ornamental, of any species or variety, produce blossoms, or in making its blossoms set when produced, success, probably, will be obtained, by budding or grafting upon a stock nearly enough allied to the graft to preserve it alive for a 
few years, but not permanently. The pear-tree affords a stock of this kind to the apple, and I have obtained a heary crop of apples from a graft inserted in a tall pear stock only twenty months previously, when every blossom of the same variety of fruit in the orchard was destroyed by frost. The fruit thus obtained was perfect extemally, and possessed all its ordinary qualities; but the cores were black and without a single seed; and every blossom, certainly, would have fallen abortively, if it had been growing upon its native stock. The graft perished the winter following.

"My own experience induces me to think very highly of the excellence of the apricot stock for the peach or nectarine; but whenever that or the plum stock is employed, I am confident the bud cannot be inserted too near the ground, if rigorous and durable trees are required.

"The form and habit which a peach-tree of any given variety is disposed to assume, is very much influenced by the kind of stock on which it is budded. If upon a plum or apricot stock, its stem will increase in size considerably as its base approaches the stock, and it will be much disposed to emit many lateral shoots, as always occurs in trees whose stems taper considerably upwards. Consequently, such a tree will be more disposed to spread itself horizontally, than to ascend to the top of the wall, eren when a 
single stem is suffered to stand perpendicularly. On the contrary, where a peach is budded upon a stock of some cultivated variety of its own species, the stock and the budded stem remain very nearly of the same size at the point of junction, as well as abore and below. No obstacle is presented to the ascent $01^{\circ}$ descent of the sap, which appears to arise more abundantly to the summit of the tree. It appears, also, to flow more freely into the slender branches, which have been the bearing wood of preceding years, and these extend consequently rery widely, compared with the bulk of the stock and large branches.

"When a stock of the same species, with the gruft or bud, but of a variety far less changed by cultivation is employed, its effects are very nearly allied to those produced by a stock of another species or genus. The graft, generally, overgrows its stock; but the form and durability of the tree generally are less affected than by a stock of a different species or genus. Many gardeners entertain an opinion, that the stock communicates a portion of its own power to bear cold without injury to the species, or rariety of fruit, which is grafted upon it: but I have ample reason to believe that this opinion is wholly erroneous; and this kind of hardiness in the root alone, never can be a quality of any value in a stock, for the branches of every species of tree are much more easily destroyed by frost than its roots. 
Many believe, also, that a peach-tree, when grafted upon its native stock, very soon perishes, but my experience does not further support this conclusion, than that it proves seedling peach-trees, when growing in a very rich soil, to be greatly injured, and often killed, by the excessive use of the pruning-knife upon their branches, when these are confined to too narrow limits. I think the stock, in this instance, can only act injuriously by supplying more nutriment than can be expended; for the root which nature gives to each seedling plant must be well, if not best, calculated for its support; and the chief general conclusions which my experience has enabled me to draw safely, are, that a stock of a species or genus, different from that of the fruit to be grafted upon it, can be used rarely with advantage, unless where the object of the planter is to restrain and debilitate; and that where stocks of the same species with the bud, or graft, are used, it will be found advantageous, generally, to select such as approximate in their habits and state of change, or improvement, from cultivation, those of the rariety of fruit which they are intended to support ${ }^{\mathrm{a}}$.

The only situation in which I can believe that the stock of another species can be advantageously employed, is where the soil happens to be unfriendly

a Trans. Hort. Soc. of London for 1816. 
to the species from which the bud or scion is taken. This is justified by my observing that in a garden so low-lying as to be very sulject to an overflow of water, the only pear-trees which were at all productive were those grafted upon quince stocks -and the quince is well known to endure water much better than either the apple or pear.

The ascent of the sap, like the circulation of the blood, is increased in rapidity by an addition to the temperature in which the plant is regetating, and when it is flowing from incisions made in a stem at various heights from the ground, a sudden reduction of temperature will cause a cessation of the flow from the upper wounds whilst it continues from those below.

These facts indicate most satisfactorily why the gardener finds his vines, peaches, and other plants in the forcing-houses injured by keeping them in a high temperature during the night. It is then, as in the animal economy, that the individual functions are renovated by a temporary repose, and if left to the dictates of healthy nature, the sap, like the blood, flows at night with a much diminished velocity.

That plants do become exhausted by too unremitting excitement is proved to every gardener who has a perch-house under his rule, for if the greatest care be not taken to ripen the wood by exposure to the air and light during the summer, no peach-tree 
will be fruitful if forced during a sccond successive winter, but will require a much more increased temperature than at first to excite it even to any advance in regetation.

Mr. Barnes, one of the best practical gardeners of the day, has rery justly observed that there is more judgment required in thoroughly ripening the wood of forced fruit trees, than in ripening their fruita. It is too generally an error to think that when the fruit is off no further trouble is required; that the wood has got to be hardened,-and that no other care is necessary until the times for pruning, forcing, dc., come round. This is a mistake fraught with failure. When the fruit is off, the whole vegetative power of the tree is employed, until the leares begin to fall, in imbibing and elaborating the sap which is to be the source from whence next year's growth and produce are to arise. The hurry some gardeners are in to expose the forced trees to the full influence of the air, and allowing them to remain without the shelter of glass at night, after the arrival of frosts, are all errors, sources of injury and loss. A far more judicious plan is to promote the lengthened rigorous regetation of the trees, by sheltering them during inclement weather; by not reducing the temperature of the house suddenly; by giving liquid manure occasionally, and never allowing the

a Gard. Mag. 6f4. 
trees to be subjected to a freezing temperature. It will be found, generally, that the forced tree that is kept longest regetating healthily after its fruit is gathered, will be the most vigorous next season.

The experiments of Harting and Munter upon rines growing in the open air, and those of $\mathrm{Dr}$. Lindley upon vines in a hothouse, coincide in testifying that this tree grows most during the less light and cooler hours of the twenty-four. But the hours of total darkness were the period when the vine grew slowest. This, observes Dr. Lindley, seems to show the danger of employing a high night temperature, which forces such plants into growing fast at a time when nature bids them repose a.

That the elevation of temperature at night does hurtfully excite plants, is proved by the fact, that the branch of a vine kept at that period of the day in a temperature not higher than $50^{\text {? }}$. inhales from one-sixteenth to one-tenth less oxygen than a similar branch of the same vine during the same night in a temperature of $75^{\circ}$. The exhalation of moisture and carbonic acid is proportionably increased by the higher temperature.

The eridence of the rine's growth being most rapid during the hours of diminished light, but not of entire darkness, is curiously coincident with the observation of Moses, that, though fruit is brought

a Hort. Trans. 109. 
forth by the sun, yet that the plant itself is put forth by the moon a.

The sap, after ascending the stem, and being distributed along the various branches, is poured by their vessels into their leaves and there undergoes that elaboration, the phenomena of which have been described in the last chapter. The sap ressels are ramified from the wood of the branches along the upper side of the leaf-stalks, are minutely subdirided so as to form a web resembling lace work, on their superior surfaces, and unite at the edge of the leaf with equally minute ressels, forming a similar web on their lower surfaces. These fall into larger vessels, which return the sap along the under side of the leaf-stalks into vessels traversing the inner bark of the branches, stem, and roots, and the sap is found to be converted, during its elaboration in the leares, into the peculiar juices of the plant. The limpid insipid sap has been converted into the austere Gallic acid and tamnin of the oak; the acrid perfumed oil of the lemon; the insipid gum of the cherry; the starchy matter of the potato, and the pungent resin of the pine tribe.

In its descent in trees and shrubs it deposits between the bark and the wood that juice, known as cambium, from which the year's increase or enlarged growth is obtained, and a superfluous store is depo-

${ }^{a}$ Deut. xxxiii. 14. 
sited rearly to be communicated to the sap in its upward course the following spring, as it may be required for the developement of the next year's foliage, flowers, and fruit. In the potato, dahlia, and other tuberous-rooted plants, it is deposited in the tuber; in the bulbs of the onion and tulip, and in the fibrous roots of the ranunculus and grasses.

A knowledge of these facts suggested to the gardener that if the return of the sap were checked by a ligature so tight as to compress the ressels of the bark, the fruit above the ligature would be rendered finer and more abundant. Practice has shewn that this is the desired result; and it may be taken as a rule, that whatever mechanical means check the downward flow of the sap, causes the enlargement of buds or the production of new. If it be practised upon the artichoke, a ligature being twisted round the stem, about three inches below the head, its size will be very much increased. If a similar ligature be passed round the branch of a fruit-tree just previously to the bursting of its buds in the - spring, the fruit will set more abundantly and be of finer growth. When the fruit is beginning to ripen, the ligature should be removed, that the reflux of the sap to the inferior parts may be less impeded, and the growth of those parts be, consequently, less checked. The power to do this renders a ligature much superior to another mode of producing the 
same effect, first introduced in Germany, viz., by removing an entire zone of bark, about an inch wide around the branch to be rendered more fruitful, and taking care that the bark be completely removed down to the rery wood. This was designated the ring of Pomona, but it certainly was not auspiciously received by that deity, for although it renders the part of the branch superior to the wound more fruitful for two or three seasons, yet it renders the branch unsightly, by the swelling which occurs around the upper lip of the round, and is always followed by disease and unfruitfulness.

If the branch of a tree be cut off; or if an incision be made so as to remore entirely not only a section of its bark, but also the alburnum of the mood beneath it, one bud or more, if the tree be vigorous, usually will be put forth below the incision. Lateral vessels are formed from the alburnum, communicating with the bud, and having a similar return communication with those of the bark, it speedily enlarges into a perfect branch, with its necessary leafy organs. If instead of learing the portion of the branch above the incision exposed to the air it be covered with moist earth, which is easily effected by the aid of a layering pot, roots will be protruded from the lips of the wound, and as these are furnished, like the bud produced from below, with ressels from the alburnum and bark, it is evident that the plant has the power of producing 
branches or roots accordingly as the medium, air or earth, renders the production appropriate. This may be proved in two ways; for if a gooseberry bush be trimmed, and then its head is buried in the earth with the roots exposed to the air, these will put forth leaves whilst the branches will emit roots. On the other hand, if a root be induced by the layering pot in the mode mentioned, and subsequently it is gradually introduced to the air, by removing the soil and filling the pot with moist moss, and then by remoring the moss and giving only moisture. it may erentually be left exposed, and will put forth leaves. The experiment will succeed with the codlin, and probably with the June-eating apple.

Buds contain the rudiments of a plant, and it very early suggested itself to the gardener that they might be employed adrantageously as a means of propagation; and budding has now become the most prevalent mode. In performing the operation, as the nourishment has to be afforded to the bud from the alburnum of the stock with which it is brought in contact, this should not be exposed to the air for one minute longer than is necessary to insert the previously prepared bud, for if the surface becomes dry in the slightest degree, regetation on that part is permanently destroyed. The alburnum of the stock only supplies sap, which is elaborated in the bud and its developed leaves; and through its bark is returned the peculiar juice from whence the woody 
matter is formed that unites it to the stock. A confused line marks the point of union, but all the deposit of mood is between that line and the bud, and is always the same in character as the tree from which the bud is taken.

A bud, with almost the solitary exception of that of the walnut, succeeds best when inserted on a shoot of the same year's growth, and apparently for the reason that the sap and juice it yields are most nearly of the same state of elaboration as they were in the parent of the bud; and because. as in the animal frame, repair of injury, the healing of wounds, is always advanced most favourably by the vital energy of youth.

The more mature any part of a plant the less easy is it excitable; a branch from which the leares have fallen in autumn requires a higher temperature to induce regetation, than does a similar branch in the spring. So is it with a bud; and, as was suggested by $\mathrm{Mr}$. Knight, it appears to be occasioned by those parts having passed into a state of repose; a decreased degree of vital energy occurring preparatory to their winter sleep. Let no man scoff at the idea of this vital energy continuing in a bud after a separation from the parent, for even the head of a polypus may be cut off and grafted, without injury, upon the decapitated body of another. The mature bud is consequently always inserted with more success 
in a stock, the buds of which are less mature, for it does not commence regetating until the supply of sap is abundant, nor until the union between the bark and alburnum have had time to be completed. When Mr. Knight reversed this comparative state of the stock and the bud, by inserting immature buds from a wall peach, upon peach trees in a forcing house, which had nearly completed their growth for the season, the buds broke soon after their insertion, and necessarily perished for want of sufficient nourishment.

Whatever promotes an over-luxuriant production of leaf buds, proportionately diminishes the production of flower buds, and the reason is obvious. A luxuriant foliage is ever attendant upoin an overabundant supply of moist nourishment to the roots, the consequent amount of sap generated is large, requiring a proportionately increased surface of leaf for its elaboration, and for the transpiration of the superfluous moisture, and as the bud becomes a branch or a root accordingly as circumstances require, so does it produce, as may be necessary for the plant's health, either leaves or flowers. This is ascertained by the universal fact that a tree or shrub, if headed down, throws out leaf-producing buds only, but never flower buds; the former are required for the plant's existence, but the latter are only needful for the propagation of its species. 
A clond of other testimonies might be produced, shewing the alteration of regetable form to accommodate the individual to altered circumstances. Place some aquatic plants in a running stream, the water cress, for instance, and its submerged leaves will be very small, thus giving the stream less power to force them from their rooted hold; but plant them in still water, and the leaves are uniform in size. Mountain plants have, for a similar reason, the smallest foliage near their summits, thus giving less hold to the boisterous winds which sweep over them. Nor is this contrary to reason, as some persons would have us believe; for the petals, and eren the minuter parts of every flower, are only different forms of the same alburnum, parenchyma, and bark, which takes another shape in the leaf. And it is only one other instance of that power of adaptation to circumstances so wisely given by God to all organized beings, which makes the wool of the sheep become scanty hair in tropical temperatures, and the brown fur of our hare become white amid the snows of the arctic regions. In the case of plants, it is familiar to every gardener; and he knows, that by differing modes of treatment, he can make, according to his pleasure, his plants produce an exuberance of leaves or of flowers, and a well-known instance is the Solandra grandiflora. This native of Jamaica had for many years been cultivated in our hot-houses, had been propagated 
by cuttings, and each plant put forth amnually shoots of surpassing luxuriance; but no flower had ever been produced: accidentally one plant was left for a season in the dry stove at Kew, and this plant had only a moderately luxuriant foliage, but a flower was produced at the extremity of every shoot. It now blooms every season in our stores, a drier and less fertilizing course of treatment being adopted.

Those who ridicule the idea of the leaf, the flower. and the fruit being only different developements of the same parts, which take different forms as the necessities of the plant render them desirable, surely forget that the leaf naturally takes such varying shapes, as in many instances to have more the appearance of fruit than of that usually assumed by foliage. Of this number are many of our fleshyleaved plants; and the tubular ressel at the extremity of the leaf of the Nepenthes distillatoria. In the calyx of the strawberry-spinach, (Blitum,) and in that of the mulberry, the transformation is still more complete; for here it actually changes colour when the flowering is orer, becoming the edible part of the fruit, and inclosing the seed like a genuine berry.

The difference of colour usually existing between leaves and petals is a very unsubstantial distinction. Many flowers are altogether green; many leaves are brilliantly coloured, as those of melampyrum, amaranthus, begonia, drc. Then again, green leaves become yellow, red, and brown, in autumn; and M. 
Macaire has shown, that the chromule, or colouring matter of leares and flowers is identical, being only more oxrgenised in the latter.

There are circumstances, there are certain degrees of nourishment, of heat, and of light, though our knowledge is too limited to assign them with arithmetical precision, which have a tendency to promote the derelopement of some regetable organs rather than others. Accordingly, as those circumstances prevail, we find the pistils increased in number at the expense of the stamens, as was observed by Mr. Brown, in the case of the wallflower, and in the Magnolia fuscata; and by M. Rœper, in the Campanula Rapunculoides; or the pistils changed into stamens, as was noticed by the same botanist in Euphorbia palustris and Gentiana campestris; so the petals have been observed converted to calyx in the Ranunculus abortirus, and the calyx into petals in Primula calycanthema; petals changed to stamens in the black currant, and in Capsella bursa pastoris; and stamens to petals in double flowers. But all the parts of a flower have been observed changed into leares: nor is this matter of surprise, for these are the organs most necessary for the well-being of a plant; and when the production of blossom fails, it is only because more foliage is required, for the elaboration of a superabundant sap. Illustrations of these changes of the floral organs into leares have been observed 
by $\mathrm{M}$. de Candolle and others, in a variety of the gilliflower (Hesperus Matronalis), in varieties of the anemone, ranunculus, and fraxinella (Dictamnus albus); in Ranunculus philonotis; Campanula rapunculoides, Anemone nemorosa, Erysimum officinale, and Scabiosa columbaria.

To promote the production of blossoms, and the maturity of the fruit they engender, is the usual object of pruning and training-confessedly two of the most difficult practices of the gardener's art; for if the branches are too much reduced in number, or are unfavourably trained, the developement of leaves is induced, and the production of blossom as proportionately prevented. The reason for this has already been explained; and in these pages, devoted to the science rather than the practice of gardening, I can add little more than a few hints upon the subject. The season for pruning must be regulated in some degree by the strength of the tree; for although, as a general rule, the operation should not take place until the fall of the leaf indicates that vegetation has ceased, yet if the tree be weak, it may be often performed with advantage a little earlier, but still so late in the autumn as to prevent the protrusion of fresh shoots. This reduction of the branches before the tree has finished regetating, directs a greater supply of sap to those remaining, and stores up in them the supply for increased growth 
next season. If the production of spurs is the object of pruning, a branch should be pruned so as to leave a stump; because, as the sap supplied to the branch will be concentrated upon those buds remaining at its extremity, these will be productive of shoots, though otherwise they would have remained dormant, it being the general habit of plants, first to develope and mature parts that are furthest from the roots. It is thus the filbert is induced to put forth an abundance of young bearing wood, for its fruit is bome on the annual shoots, and similar treatment to a less severe extent is practised upon wall fruit.

With regard to the practice of budding, the gardener finds it essential to insure success, that the bud should be sheltered from the direct rays of the sun, and the wound, where it joins the stock, from the air and from wet.

Moist bast is usually employed for closing the wound of the stock; but it is far preferable to use worsted, and over this a coating of the grafting wax, made according to the following recipe:

Ozs.

Burgundy pitch . . . . . . . . 1

Common pitch . . . . . . . . 4

Yellow wax . . . . . . . . . 4

Tallow . . . . . . . . . . 2

Nitre (carbonate of potash, powdererl) . 1 
These must be melted slowly in an earthen pipkin, and applied whilst warm. Common diachylon, sold in rolls by chemists, answers as well as the above. A laurel leaf, fastened at each end by a ligature round the stock, so as to arch over the bud, will complete the arraingement.

If the rays of the sun are not excluded from the scion for some time after its insertion, it is dried up by the transpiration from it being greater, owing to the uniting ressels being unformed, than can be supplied by its introsusception from the stock. If wet from the rains and dews be not excluded, the water from them settles in the wound, and, by mere capillary attraction, is absorbed between the bark of the bud and the alburnum of the stock, so diluting the sap as to prevent their organic union. If the air be not excluded sufficiently, a dryness of the parts, and consequent collapse of the vessels so as to prevent the requisite supply of sap is induced, equally fatal to the desired commexion.

Grafting is a more difficult mode of multiplying an individual, because it is requisite so to fit the scion to the stock that some portion of their albur11unns and inner barks must coincide, otherwise the requisite circulation of the sap is prevented. No graft will succeed if not immediately grafted upon a nearly kindred stock-I say immediately, because it is possible that by grafting on the most dissimilar 
species on which it will take, and then moving it, with some of the stock attached to another stock still more remotely allied, that a graft may be made to succeed, though supplied with sap from roots of a very dissimilar species. Thus some pear scions can hardly be made to unite with a quince stock; but if they be grafted upon a young shoot of a pear that can be so united to the quince, and this young shoot be afterwards inserted in a quince stock, they grow as freely as if inserted in a seedling pear stock.

The reason for this unusual difficulty in the way of uniting kindred species arises from one or more of these causes. First, the sap flowing at discordant periods; secondly, the proper juices being dissimilar; or thirdly, the sap vessels being of inappropriate calibre.

It is quite certain that the ancient Pomans were skilful grafters, for Cato, in his De Re Pusticâ, gives very full and accurate directions on the art. If it be true, as he asserts, in common with Varro, Palladius, Virgil, Columella, Pliny, and other writers, contemporary as well as more ancient, that they engrafted any kind of tree upon any stock, though of an entirely different genus, as the apple upon the plane, and the vine or the fig on the cherry, then, indeed, is there another added to the list of lost arts. But there is just reason for concluding that the ancients 
never possessed the linowledge thus claimed-not only because it is denied by modern experience and science; but because we know that by stratagem such unions may be made to appear as if effected, and none of the ancient writers on the soil's culture were practical men. Moreorer, in considering this question, it must not be forgotten that it was denied that such grafting was possible, even by some of their contemporaries. Columella, in his treatise on trees, has a chapter maintaining by argument the possibility of promiscuous grafting in opposition to some other authors who denied its practicability. Arguments would have been needless if there rere examples of success ready for reference.

Inarching differs from grafting only in having the scion still attached to its parent stem whilst the process of union with the stock is proceeding. It is the most certain mode of multiplying an individual that roots or grafts with difficulty, but is attended with the inconvenience that both the stock and the parent of the scion must be neighbours. The most ingenious application of inarching is one suggested by Mr. Knight. If a fruit-bearing branch becomes denuded of its leaves above the fruit it has produced, this either falls, or remains stunted and deficient in flavour, owing to being thus deprived of a supply of the elaborated sap or proper juice. In such case a branch having leaves of the 
same or of a neighbouring tree, may be inarched to the denuded portion of the branch, and the fruit will then proceed to maturity. Mr. Knight's experiment was tried upon a peach tree, the fruit of which he was anxious to taste, but which produced that season only two peaches, and from the branch bearing which all the leaves had fallen.

Cuttings for multiplying any individual may in general be taken either from the stem, branch, or root, and are, in fact, grafts, which by being placed in the earth, a medium favourable to the production of roots, expend their juices in the formation of radicles instead of aiding the stock to effect that developement of ressels necessary for their union to it had they been grafted. A due degree of moisture in the soil is all that is absolutely required from it by cuttings, for these will often produce roots if placed in water only. The time for taking off cuttings from the parent plant for propagation, is when the sap is in full activity, the vital energy in all its parts is then most potent for the developement of the new organs their altered circumstances require. Well-matured buds are found to emit roots most successfully, and apparently for the same reason that they are least liable to failure when employed for budding, viz., that being less easily excitable, they do not begin to develope until the cutting has the power to afford a due supply of sap. 
Therefore, in taking a cutting it is adrisable to remore al portion of the wood having on it a bud, or joint, as it is popularly called, of the previous year's production. Many plants can be multiplied by cuttings with the greatest facility, but others only with the greatest difficulty, and after every care has been taken to secure to the cutting erery circumstance farourable to the revelopement of roots.

Those plants which vegetate rapidly, and delight in either a moist or rich soil, are those which are propagated most readily by this mode, and such plants are the willow, gooseberry, and pelargoniuma budded section of these can hardly be thrust into the ground without its rooting.

Cuttings of those plants which grow tardily, or, in other words, form new parts slowly, are those which are most liable to fail. These are strikingly instanced in the heaths, the orange, and ceratonia.

A rooted cutting is not a new plant, it is only an extension of the parent, gifted with precisely the same habits, and delighting most in exactly the same degrees of heat, light, and moisture, and in the same food.

A cutting produces roots either from a bud or ere, or from a callus, resembling a protuberant lip, which forms from the alburnum between the wood and the bark round the face of the cut which dirided the slip from the parent stem. 
If the atmospheric temperature is so high that moisture is emitted from the leares faster than it is supplied, they droop or flag, and the growth of the plant is suspended. If a cutting be placed in water, it imbilues at first more rapidly than a rooted plant of the same size, though this power rapidly decreases: but if planted in the earth, it at no time imbibes so fast as the rooted plant, provided the soil is similarly moist; and this evidently because it has not such an extensive imbibing surface as is possessed by the rooted plant: consequently the soil in which a cutting is placed, should be much more moist than is beneficial to a rooted plant of the same species; and eraporation from the leaves should be checked by covering the cuttings with a bell glass, or a Wardian case would be still better. The temperature to which the leaves are exposed should be approaching the lowest the plant will endure.

The warmer the soil within the range of temperature most suitable to the plant, the more active are the roots, and the more energetically are carried on all the processes of the ressels buried beneath the surface of the soil: $\check{5} 0^{\circ}$ for the atmosphere, and between $65^{\circ}$ and $75^{\circ}$ for the bottom heat, are the most effectual temperatures for the generality of plants.

The cutting should be as short as possible consistently with the objects in riew. 
Three or four leaves, or even two, if the cutting be rery short, are abundant. They elaborate the sap quite as fast as required, and are not liable to exhaust the cutting by super-exhalation of moisture.

Cuttings taken from the upper branches of a plant flower and bear fruit the earliest, but those taken from near the soil are said to root most freely.

Cuttings which reluctantly emit roots, may be aided by ringing. The ring should be cut round the branch a few reeks before the cutting has to be remored; the bark should be completely remored down to the wood; and the section dividing the cutting from the parent be made between the ring and the parent stem, so soon as a callus appears round the upper edge of the ring.

The soil is an important consideration. The cuttings of orange-trees and others which strike with difficulty if inserted in the middle of the earth of a pot, do so readily if placed in contact with its side. The same effect is produced by the end of the cutting touching an under-drainage of gravel or broken pots. Why is this? and my observations justify me in concluding that it is because in these situations-the side and the open-drainage of the pot-the atmospheric air gains a salutary access. A light porous soil, or even sand, which admits air the most readily, is the best for cuttings; and so 
is a shallow pan rather than a flower-pot, and apparently for the same reason. I have no doubt that numerous perforations in the bottom of the cutting pan would be found advantageous for cuttings which root shyly.

Some plants may be successfully propagated by means of the leares; and among those whose numbers are thus most commonly increased are the Cacti, Gesneræ, Gloxiniæ, and other fleshy-leared plants. Lately, the suggestion has been revived, that the majority of plants may be thus propagated, a suggestion first made by Agricola, at the commencement of the last century. He states that M. Mandirola had raised a lemon tree in this mode; and thence concludes, rather too rashly, "that all exotic leares may, at any time, be converted into trees." Since that was written, in 1721 , it is certain, that plants have been raised from leares that previously had been considered totally incapable of such extension. Thus Mr. Neumann has succeeded with the Theophrasta latifolia; and, going a step further, he has even bisected a leaf, and raised a leaf from each half. Mr. Knight has also recorded, in the Horticultural T'ransactions of 182:, that leaves of the peppermint, (Mentha piperita,) without any portion of the stem upon which they had grown, lived for more than twelve months, increased in size, nearly assumed 
the character of evergreen trees, and emitted a mass of roots.

That leares may be made almost universally to emit roots, there appears little reason to doubt; for the same great physiologist had long before proved, that the roots of trees are generated from ressels passing from the leaves through the bark; and that they never, in any instance, spring from the alburnum. But the question arises, will they produce buds? and, at present, the answer derived from practice is in the negative. Orange leaves, Rose leaves, leaves of Statice arborea, have been made to root abundantly; but, like blind cabbage-plants, they obstinately refused to produce buds. Dr. Lindley thinks that a more abumdant supply of richer food, and exposure to a greater intensity of light, would have removed this deficiencya; and I see every reason for concurring with so excellent an authority; for buds seem to spring from the central ressels of plants, and these vessels are never absent from a leaf. If an abundant supply of food were given to a wellrooted leaf, and it were cut down close to the callus from whence the roots are emitted, I think buds would be produced, for the very roots themselves have the same power.

a Gardeners' Chronicle, January, 1845. 


\section{CHAPTER VI.}

THE FLOWER.

THE organs of fructification are absolutely necessary, and are always producible by garden plants properly cultivated. They may be deficient in leares, or stems, or roots, because other organs may supply their places; but plants are never incapable of bearing flowers and seeds, for without these they can never fully attain the object of their creationthe increase of their species.

Every flower is composed of one or more of the following parts, viz., the calyx, which is usually green and enveloping the flower whilst in the bud; the corolla or petals, leaves so beautifully coloured, and so delicate in most flowers; the stamens, or male portion of the flower secreting the pollen, or impregnating powder; the pistils, or female portion, impregnatable by the pollen, and rendering fertile the seeds; and lastly, the pericarp, or seed-vessel.

It is not within the scope of this work to trace these parts through their various forms, - a research belonging to the botanist,- - but we may profitably consider their structure. 
Their organization closely resembles that of the branch by which they are borne, and they are only its parts taking other forms. Tracing, says the late Mr. Knight, the progress of the organization in the full grown fruits of the apple and pear, I found, as Linnæus has described, that the medulla, or pith, appeared to end in the pistils. The central ressels diverged round the core, and approaching each other again in the eye of the fruit, seemed to end in ten points at the base of the stamens, to which I believe they give existence. The spiral tubes, which are, in all other parts, appendages to these ressels, I could not trace beyond the commencement of the core; but as the ressels themselves extend through the whole fruit, it is probable that the spiral tubes may have escaped my observation.

Although the medulla is traced to the base of the pistils, the central ressels to the part enveloping the seed, and to the stamens, and the spiral ressels throughout the fruit, jet over every part is extended the parenchyma and epidermis, and the sap circulates through the entire of the flower and fruit-ascending, being elaborated, and descendingas regularly as through other parts of the plant. Coloured infusions may be traced through the ressels in the stem to the fruit, and if a ligature be passed round a peach or an apple, the enlargement is greatest above, that is between the ligature and 
the footstalk; and Mr. Kinight succeeded, by intergrafting, in proring that the leaf-stalk, the tendril of the rine, the fruit stalk, and the succulent point of the annual shoot, may be substituted for each othera bunch of grapes grew and ripened when grafted upon the leaf-stalk; and a succulent young shoot of the rine, under the same circumstances, acquired a growth of many feet.

The stamens are the only portion of a flower which can be remored without preventing the formation of fertile seed, and their loss must be supplied by the introduction to the pistils of pollen from some kindred flower.

The calyx is not useless so soon as it ceases to envelope and protect the flower, for the flower-stalk continues increasing in size until the seed is perfected, but ceases to do so in those plants whose calyces remain long green if these be removed. On the other hand, in the poppy, and other flowers from which the calyx falls early, the flower-stalk does not subsequently enlarge.

The corolla or petals, with all their varied tints and perfumes, have more important offices to perform than thus to delight the senses of mankind. Those bright colour's and their perfumed honey serve to attract insects, which are the chief, and often essential, assistants of impregnation; and those petals, as observed by Linnæus, serve as 
wings, giving a motion, assisting to effect the same important process. But they have a still more essential office, for although they are absent from some plants, yet, if remored from those possessing them before impregnation is completed. the fertilization never takes place. They, therefore, perform in such cases, an essential part in the regetable economy; and that they do so is testified by all the phenomena they exhibit. They tum to the sun open only when he has a certain degree of power. and close at the setting of that luminary: their secretions are usually more odorous, more saccharine, and totally differing from those of the other organs of plants; and in the absence of light those secretions are not formed.

The corolla is not always short-lived, for, although in some, as the cistus, the petals which open with the rising sum, strew the border as it departs; so some, far from being ephemeral, contintie until the fruit is perfected. The duration of the petals, however, is intimately comnected with the impregnation of the seed, for in most flower's they fade soon after this is completed; and double flowers, in which it occurs not at all, are always longer enduring than single flowers of the same species. Then, again, in some flowers they become green, and perform the functions of leaves after impregnation has been effected. A familiar example occurs in the Christ- 
mas rose (Helleborus niger), the petals of which are white, but which become green so soon as the seeds have somewhat increased in size, and the stamens, and other organs comnected with fertility, have fallen off.

It is quite true that some fruit will not ripen if the part of the branch beyond is denuded of leaves; but this only shews that those fruits cannot advance when deprived of leaves as well as of calyx and corolla- the only organs for elaborating the sap; and there are some flowers, as the Daphne mezereon, autumn crocus, and sloe, that have their flowers perfected and passed away before the leaves hare even appeared.

That the petals perform an important part in elaborating the sap supplied to the fruit, is further proved by the flower being unable to bloom or to be fertile in an atmosphere deprived of its oxygen; and by their absorbing more of that gas, and evolving more carbonic acid than even a larger surface of leaves of the same plant.

So essential is oxygen to the fertility of a flower, that we shall find, in a future chapter, that the stamens of one plant absorb 200 times their bulk of the gas at the time of impregnation; and Saussure found that double, or unfertile flowers, do not absorb so much oxygen as those which are productive. The following table shows the number of rolumes of this 
gas inspired by one volume of the flowers and leares:

By the By the flowers. leaves.

Cheiranthus incanus, 6 р.м. . . 11.0 . 4.0 Ditto double-flowered

Polyanthes tuberosa, 9 A.x. $\quad$ - $\quad 9.0 \quad 3.0$ Ditto double-flowered $\quad \mathbf{7} 4$

Tropæolum majus, 9 A.м. . . . $\quad 8.5$. 8.3

Ditto double-flowered $\quad$..25

Datura arborea, 10 A.x. . . $\quad 9.0$. 5.0

Passiflora serratifolia, 8 A.1r. . . 18.5 . 5.25

Daucus carota, 6 р.хг. . . . 8.8 . 7.3

Hibiscus speciosus, $\tau$ A.r. • • $\quad 8.7$. 5.1

Hypericum calicinum, 8 А.м. . .

Cucurbitamelo-pepo, male flowers,

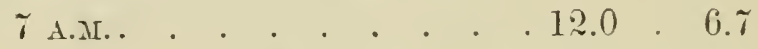

Ditto female ditto, 7 A.u. 3.5

Lilium candidum, 11 A.м. . . . $5.0 \quad 2.5$

Typha latifolia, 9 А.м. • · · $\quad 9.8$. 4.25

Fagus castanea, 4 P.M. . . . . 9.1 . 8.1

As the flowers inhale more oxygen than the leaves, so do they exhale more carbonic acid than these organs; and, unlike leares, they pour it forth not only during the night, but in the sum-light-at least, Dr. Priestley, Dr. Ingenhouz, and M. Saussure found this was done by the rose, marigold, and honeysuckle.

It is upon the oxygen combined with their paren- 
chyma, that the colour of a petal depends; for sulphurous acid, (the fume aising from a burming match,) which has a most powerful affinity for oxygen, destroys the hue of all coloured flowers, though it leares that of white flowers unchanged. Mr. Smithson's experiments, and those of M. Schluber, seem to indicate that the colouring matter of flowers and fruits is fundamentally blue-rendered red by acids or the addition of oxygen, or yellow by the presence of an alkali or the subtraction of oxygen. Mr. Smithson says, that the colouring matter of the riolet is the same in the ruddy tips of the daisy, geranium, blue hyacinth, hollyhock, lavender, and various plums, in the leares of the red cabbage, and in the rind of the salmon radish. The acid which causes the red tint seems to be usually the carbonic.

No seed ever attains the power of germinating, unless the pollen from the stamens in the same, or some nearly-allied flower has reached and impregnated its pistils. This was known to the most ancient of the Greeks; for Herodotus relates that the cultivators of the date (Phonix dactilifera) brought the flowers of the barren plants, which they called the males, and attached them to the fruitful trees, that their produce might not fall without attaining maturity, a phenomenon explained both by Anaxagoras and Empedocles, who flourished in the fifth century before the Christian era, by claiming for 
vegetables the same sexuality as animals. Subsequent researches bave established the fact beyond the reach of reasonable doubt.

In favourable seasons, when genial warmth and gentle winds prevail. impregnation is readily affected by the plant's own provision. The pollen is never shed from the anther of the stamen, until the stigma of the pistil is fully developed; and this soon withers after the contact. The gaping of the stigma when the pollen is about to fall, and at that time only, may be observed in the heart's-ease (Viola tricolur); and every morning, on the summit of the stigma of the Jacobean lily (Amaryllis formosissima), a drop of viscous liquid protrudes, to be re-absorbed as regularly at noon, with the pollen shed upon it, until impregnation is completed-the drop then exudes no more. But, as was first observed by Sir J. E. Smith, the process, as it is effected in the berberry (Berberis vulgaris), is the most curious. In the flowers of this shrub the six stamens, spreading moderately, are sheltered under the concave tips of the petals, until some extraneous body, as the feet or trunk of an insect searching for honey, touches the inner.part of a filament near the bottom. The irritability of that part is such, that contracting and thrown forward spasmodically, it dashes the anther, full of pollen, against the stigma.

The above are only a few of the modes by which 
plants are, by their own powers, enabled to effect the impregnation of their seed; but where there is any more than ordinary difficulty, their all-provident Creator has invariably provided efficient assistance. The agents usually called in are insects: these, in their search after honey and wax, visit the inmost recesses of flowers, and bear from the anthers to the stigma, and from flower to flower, the fecundating dust. Here, too, I may remark upon another instance of that Proridence, which makes all things fitting and appropriate; for those who have made the bee their study relate, that though this insect does not confine itself to one species of flower, yet it restricts its visits during each ramble to that kind which it first visits. How this facilitates impregnation is obrious, when it is remembered, that no flower can be fecundated but with pollen from a kindred species.

The most remarkable instance of the agency of insects, and of the artifice, if the term be permissible, employed to render them efficiently serviceable, occurs in the Aristolochia Clematitis; and is thus described by Willdenow. The corolla is tubular, terminating in a globular extension at the base. The tubular part is lined with stiff hairs, pointing downwards, like the wire entrances to some mouse-traps. The globular part contains the pistils, surrounded by the stamens; but the latter being very much the 
shorter, and as the flower always holds itself erect, the pollen cannot reach the stigmas, but would fall to the bottom of the corolla, if it were not for the agency of a particular insect. This diminutive visitant is the Tipula pennicomis, which entering the tube in search of honey, in vain tries to repass the phalanx of hairs which easily yielded to it an entrance; in its search for a way of escape, it carries the pollen to the stigma, and impregnation being effected, the hairs lose their rigidity, sink to the side of the tube, and the prisoner easily escapes.

The efficient agency of insects suggested that in hot-houses from whence they are almost totally excluded, other artificial means might be adopted with success to render fertile flowers that had hitherto failed in producing seed. One of the earliest instances on record of the experiment being tried with a prosperous result was on the Abroma angusta, which had bloomed unfertilely for several years in a hot-house at Berlin. The gardener by the aid of a hair pencil applied a little pollen to the stigma, and for the first time perfect seed was produced, from which plants were raised. This practice is now very generally adopted to all plants cultivated under glass from which a produce of either fruit or seed is desired ; for fruit rarely attains its full size if the seeds within it are unfertilized. Thus the gardener always finds the advantage of using the camel 
hair pencil to apply pollen to the stigmas of his forced melons, cucumbers, cherries, and peaches.

That seed can be rendered fertile by the agency of other flowers than their own parent has long been known, for it had come within the observation of the Israelites, some three thousand four hundred years now past, as may be gathered from Deuteronomy, xxii. 9 ; Jeremiah, ii. 21 ; and Leviticus, xix. 19; but it was not rendered useful knowledge, until the late President of the Horticultural Society, Mr. Knight, commenced his experiments in 178\%. Mr. Bradley, seventy years before, had demonstrated that hybrid plants may be grown, partaking of the qualities of both their parents; but to Mr. Knight first occurred the happy thought that the good characteristics of one parent might thus be employed to correct deficiencies which would otherwise occur in the offspring of another parent of the same species. Since his time, this system of crossbreeding has been practised by gardeners upou almost every genus of plant that comes under their care, and by its agency the size, colour, and form of flowers have been improved and raried; the magnitude and flavour of fruits have been increased; and tender plants have been made to bring forth a hardy progeny.

Bradley had only carried out the suggestions of others, for both Lawson and Evelyn, half a century 
previously, had related that new apples ad infinitum might be raised from kernels; and Bacon, whose penetrating eye pierced the most dark recesses of nature, had observed that "The compounding and mixture of plants is not found out, which, nevertheless, if it be possible, is more at command than that of living creatures; wherefore, it were one of the most noble experiments touching plants to find this out; for so you may have a great variety of new plants and flowers yet unknown. Grafting doth it not: that mendeth the fruit, or doubleth the flower, but it hath not the power to make a new kind." My own observations, and those of others, justify the following statements, as affording some guide to the raiser of varieties.

1. The seed-vessel is not altered in appearance by impregnation from another plant; therefore, no hasty conclusion of failure is justified by that want of change.

2. The colour of the future seed, not of that first hybridized, seems to be most influenced by the male plant, if its seeds and flowers are darker than those of the female. Mr. Knight found, that when the pollen of a coloured blossomed pea was introduced into a white one, the whole of the future seeds were coloured. But when the pollen of a white blossom was introduced to the stigma of a coloured blossom, the whole of the future seeds were not white. Capt. 
Thurtell, from his experiments on the pelargonium, also informs me, that he has always found the colour and spot of the petals to be more influenced by the male than by the female parent. Indeed, all experience prores that the progeny usually, though not invariably, most resembles in colour the male parent.

3. Large stature and robustness is transmitted to the offspring by either parent. It does not absolutely matter, for obtaining this characteristic, whether it be the male or female which is large; but Mr. Knight generally found the most robust female parent produced the finest offspring.

4. Capt. Thurtell, from lengthened observation and experiment, has ascertained that the form of the petals follows most closely that of the female parent.

5. Mr. Knight says that the largest seed from the finest fruit that has ripened earliest and most perfectly should always be selected. In stone fruit, if two kernels are in one stone these give birth to inferior plants.

6. The time which elapses before seedlings attain a bearing age is very various. The pear requires from twelve to eighteen years; the apple, five to thirteen; plum and cherry, four to fire; vine, three to four; raspberry, two; and the strawberry one.

7. The most successful mode of obtaining good and rery distinct varieties is to employ the pollen from a male in a flower grown on another plant than 
that bearing the female parent. To avoid previous and unclesired impregnation, the anthers in the female parent, if they are produced in the same flower with the pistils must be remored by a sharppointed pair of scissors, and the flower enclosed in a gauze bag to exclude insects, until the desired pollen is ripe. Another effectual mode of aroiding undesired impregnation is bringing the female parent into flower a little earlier than its congeners, and remoring the anthers as above described; the stigma will remain a long time rigorous if unimpregnated.

8. Although the fertility of all the seed in one seed-ressel may be secured by applying pollen only to one style, even where. there are several, yet the quantity of pollen is by no means a matter of indifference. Koëlreuter found that from fifty to sisty globules of pollen were required to complete the impregnation of one flower of Hybiscus Syriacus: but in Mirabilis Jalapa and M. longiflora, two or three globules were enough a, and in the case of pelargoniums, Capt. Thurtell says, two or three globules are certainly sufficient.

9. M. Haquin, a distinguished horticulturist at Liège, has impreguated flowers of the Azalea with pollen kept six weeks; and Camellias with pollen kept sixty-five days. He gathers the stamens just previously to the anthers opening, wraps them in writing

3 Willdenow, 323. 
paper, places them in a warm room for a day, collects the pollen they emit, and preserves it in sheet lead in a cool dry place. M. Godefroy suggests that two concave glasses, like those employed for vaccine virus, would be better. The globules of the pollen must not be crushed. MI. Haquin thinks the pollen of one year will be effective if preserved until the year following. Mr. Jackson of Cross Lanes Nursery, near Bedale, says, he has found the pollen of the Phododendron Smithii tigrinum retain its fertilizing power eren for twelve months.

10. It is easy to discern whether impregnation has been effected, as in such case the stigmas soon wither. The stigmas which have not received the pollen remain for a long time green and vigorous.

"By the aid of the Stanhope lens," observes Capt. Thurtell, in a letter now before me, "I fancy I can discover the seed of the pelargonium being closed over in the space of four hours after impregnation."

11. When double flowers are desired, if a double flower should chance to have a fertile anther or two, these should be employed for fertilization, as their offspring are almost sure to be very double.

12. Many analyses of the pollen of various plants have been made by chemists, without throwing any light upon hybridizing. M. Grotthus found the components of twenty-six grains of the pollen of the tulip were :- 
Vegetable albumen

Malates of lime and magnesia .

Malic acid . , , . . . .

Malate of ammonia

Colouring matter

Nitrate of potash .

13. Superfœtation has been doubted, but as it occurs in the dog, we see no reason for disbelieving its possibility in plants. Capt. Thurtell thinks it may be done by the bee introducing mingled pollens at the same instant. Then why not, if a similar mixture is inserted by the camel's hair pencil of the cultivator? I think it quite possible, that different seeds in the same pericarp, may be fertilized by pollen from more than one different male species; but nothing but the strongest evidence will convince me that the same seed can be effectually fertilized by more than one pollen. M. Foulard gravely asks us to believe that his Rosa perpetuosissima had four male parents, the Bengal, the tea, the hundredleaved, and the noisette!

14. Plants nearly related, that is, closely similar in the structure of their various parts, are those only which will immediately impregnate each other; but it is impossible, at present, to say what families of

a Schweigger's Journ. xi. $2 \$ 1$. 
plants may or may not be brought into fertile union through intermediate crosses. A rery short time ago the azalea and rhododendron were thought incapable of such union, but this opinion is now exploded, for rhododendron ponticum has been fertilized with the pollen of azalea sinensis, and the progeny, between that evergreen and this deciduous shrub, is the previously unknown phenomenon a yellow rhododendron. Though such unions may be effected, I entirely agree with Mr. Knight in anticipating that the progeny will be mules, incapable of producing offspring. It is quite true that many plants, said by botanists to be distinct species, have between them produced fertile seeds, but I incline decidedly to the opinion, that this fact demonstrates that they are not distinct species, but only deviations from a common origin. For example, the peach and almond are considered distinct species by botanists, yet the fruit of both and of the nectarine have been borne spontaneously by the same tree. "I cannot," says Mr. Knight, "by any means admit that plants ought to be considered of originally distinct species, merely because they happen to be found to have assumed somewhat different forms or colours in an uncultivated state. The genus Prunus contains the P. armeniaca, P. cerasus, P. domestica, P. insititia, P. spinosa, P. sibirica, and many others. Of these I feel perfectly conficlent that no art will ever obtain offspring (not being mules) between the Prunus 
armeniaca, P. cerasus, and P. domestica; but I do not entertain much doubt of being able to obtain an endless variety of perfect offspring between the P. domestica, P. insititia, and P. spinosa; and still less doubt of obtaining an abundant variety of offspring from the P. armeniaca and P. sibirica. The former, the common apricota, is found, according to MI. Regnier, in a wild state in the oases of Africa. It is there a rich and sweet fruit of a yellow colour. The fruit of the P. sibirica, seeds of which came to me last year from Dr. Fischer of Gorenki, is, on the contrary, I understand, black, very acid, and of small size : but nevertheless if these apparently distinct species will breed together, and I confidently expect they will, without giving existence to mule plants, I shall not hesitate to pronounce these plants of one and the same species, as I have done relatively to the scarlet, the pine, and the chili strawberries. Botanists may nevertheless, if they please, continue to call these transmutable plants, species; but if they do so,

a The early period at which the apricot unfolds its flowers leads me to belicve it to be a native of a cold climate: and I suspect the French word abricot, the English apricock, and the African berrikokka, to have been alike derived from the Latin word pracocia, which the Romans (there is every reason to believe) pronounced praikokia, and which was the term applied to early varieties of peaches, which probably included the apricot. The Greeks also wrote the Latin word as I suppose the Romans to have pronounced it.-Hardouin's ed. of Pliny, lil. 15. sec. xi. 
I think they should find some other term for such species as are not transmutable, and which will either not breed together at all, or which breeding together give existence to mule plants.

"If hybrid plants had been formed as abundantly as Linnæus and some of his followers have imagined, and such had proved capable of affording offspring, all traces of genus and species must surely long ago have been lost and obliterated; for a seed ressel eren of a monogynous blossom often affords plants which are obviously the offspring of different male parents; and I believe I could adduce many facts which would satisfactorily prove that a single plant is often the offspring of more than one, and, in some instances, of many male parents. Under such circumstances, every species of plant which, either in a natural state or cultivated by man, has been once made to sport in varieties, must almost of necessity continue to assume variations of form. Some of these hare often been found to resemble other species of the same genus, or other varieties of the same species, and of permanent habits, which were assumed to be species; but I have nerer yet seen a hybrid plant capable of affording offspring, which had been proved, by any thing like satisfactory evidence, to have sprung from two originally distinct species; and I must therefore continue to believe that no species capable of propagating offspring, either of plant or 
animal, now exists, which did not come as such immediately from the hand of the Creator."

Hybridizing, aided by cultivation, gives birth to those splendid objects of the gardener's care, generally designated double flowers, which are such beauteous ornaments of our borders and parterres. To the uninitiated it seems incredible that the double moss-rose should be a legitimate descendant from the briar; neither do the flowers of the Fair maid of France appear less impossible derivatives from those of the Ranunculus platanifolius; nor Bachelor's buttons from the common buttercup, yet so they are. Double flowers, as they are popularly called, are more correctly discriminated as the full flower, the multiplicate flower, and the proliferous flower.

The full-flower is a flower with its petals augmented in number by the total transformation into them of its stamens and its pistils. One-petalled flowers rarely undergo this metamorphosis; but it is very common in those having many petals, as in the carnation, ranunculus, rose, and poppy. But this is not the only mode in which a flower becomes full: for, in the columbine (Aquilegia) it is effected in three different ways, viz., by the multiplication of the petals to the exclusion of the nectaries; by the multiplication of the nectaries to the exclusion of the petals; and by the multiplication of the nectaries whilst the usual petals remain. Fadiated 
flowers, such as the sunflower, dahlia, anthemis, and others, become full by the multiplication of the florets of their rays to the exclusion of the florets of their disks. On the contrary, various species of the daiss, matricaria, \&c., become full by the multiplication of the florets of the disks.

The multiplicate flower has its petals increased by the conversion of a portion of its stamens, or of its calyx, into those forms. It occurs most frequently in polypetallous flowers. Linnæus gives the only instances I know of the conversion of the calyx into petals, and these are to be observed in the pink (Dianthus caryophyllus) and a few of the Alpine grasses.

A proliferous flower has another flower, or a shoot produced from it. This is most strikingly exemplified by that variety of the daisy popularly known as The-hen-and-chickens. It occurs also more rarely in the ranunculus, pink, marigold, and hawk-weed. A leafy shoot often appears in the bosom of the double-blossomed cherry, anemone, and rose.

The influences regulating the production and developement of leaves and flowers are these:-If an excess of water to the roots, or too little light to the superior parts of plants be applied, they produce an increased surface of leaf, and few or no flowers; for it is a wise power given to them by their Creator, that those parts shall increase in size, 
which circumstances render most necessary. An excess of moisture requires an increased transpiratory surface, as in the case of Solandra grandiflora before mentioned.

This knowledge that flower-buds and leaf-buds are mutually convertible is no novel discovery, much less a visionary theory, for, as long ago as the begimning of 1817 , the late Mr. Knight thus expressed the results of his experience, when writing to the London Horticultural Society relative to the pruning of peach-trees:- "The buds of fruit-trees, which produce blossoms, and those which afford leaves only, in the spring, do not at all differ from each other, in their first organization, as buds. Each contains the rudiments of leaves only, which are subsequently transformed into the component parts of the blossom, and, in-some species, as the fruit also." And he then proceeds to state his experience that leafbuds of the apple and pear have been thus transformed, and of his having succeeded in obtaining every gradation of monstrous transformation, adding, that " every bunch of grapes commences its formation as a tendril, it being always within the power of every cultivator to occasion it to remain a tendril," either by removing a considerable portion of the leaves, or reducing the temperature and light to which the vine is exposed.

A deficiency of light decreases the decomposing 
power of the leares. For this reason the best glass should always be employed in the sashes of the hothouse, conservatory, and other structures of the forcing department. But the benefit sought for is frustrated if that glass be not constantly well cleansed. The best glass, if dirty, allows fewer rays of light to pass through than inferior glass if kept bright.

A thorough cleansing should be given both to the outside and inside trice annually, during the first weeks of March and of October, and a third cleansing, on the outside only, at the end of June. In proportion to the deficiency of light, does the plant under glass become, in the gardener's phraseology, draun. That is, its surface of leaves becomes unnaturally extended, in the rain effort to have a sufficient elaboration of the sap effected by means of a large surface exposed to a diminished light, for which a less surface would hare been sufficient if the light were more intense. The plant with this enlarged surface of leaves becomes unfruitful, the sap being expended in their production, which should have been appropriated to the formation of fruit.

Mr. Williams made some experiments intended to illustrate this point, and he found that varieties of the vine, when grown under white, or crown glass, under green glass and in the open air, had 
the diameters of their leaves, in inches, altered as in the following table :-

\begin{tabular}{|c|c|c|c|}
\hline Name. & White. & Green. & Open Air. \\
\hline White Muscat . & 8 & 12 & $\tau$ \\
\hline Malmsey Muscadine & $6 \frac{1}{2}$ & 12 & 6 \\
\hline Syrian . . . . & 8 & $14 \frac{1}{2}$ & .. \\
\hline White Sweet Water & 6 & 9 & 6 \\
\hline Black Hamburgh . & 8 & $13 \frac{1}{2}$ & .. \\
\hline White Frontignac & 6 & 11 & 6 \\
\hline White Muscadine & 6 & 11 & 6 \\
\hline
\end{tabular}

A due supply of moisture, but rather less than the plant most delights in when the production of seed is the desired object, a superabundant supply of decomposing organic matter to its roots, and an exposure to the greatest possible degree of sunlight, are the means successfully employed to promote that excessive developement of the petals which characterize double-flowers.

By these means a greater amount of sap is sup. plied to the flower than the natural extent of petal can elaborate, and, following the laws of nature already specified, those parts required for the extra elaboration are developed at the expense of those not demanded for the purpose. The chief office of the petals is this preparation of nourishment for the stamens, and, for the most part, they fade together, usually enduring until impregnation has been effected, 
or has altogether failed. In double flowers, too, as was observed by the late Sir J. E. Smith, the corolla is much more durable than in single ones of the same species, as anemones and poppies, because, as he conceived, in such double flowers the natural functions not being performed, the vital principle of their corolla is not so soon exhausted. Advantage may be taken of this to prolong the duration of flowers by cutting away the pistils, or stamens, whichever are least conspicuous, with a sharp pair of pointed scissors.

The transmutation of the stamens into petals is most readily traceable in the water-lily (Nymphac alba) and the common China rose. Sometimes, as is justly observed by a writer in the Gardener's Chronicle, sometimes a stamen is half changed, and then half an anther is found on one side, while the other is expanded into the thin texture of the petal. Sometimes the anther seems to struggle with the petal for mastery, and resolutely maintains its ground at the point while the filament as resolutely expands, till at last it rises above the anther on each side, as if to smother that which it cannot otherwise destroy.

Although an abundant supply of nourishment is absolutely necessary for the production of double flowers, it is quite as certain that such supply will not, of a certainty, cause their appearance-there 
must be some tendency in the parent thus to sport, otherwise the superfluity of food will not have the desired influence. That abundance of nourishment is necessary appears from the fact, that if the doubledaisy, or the double-narcissus be grown in a poor soil they speedily produce none but single flowers, yet, if they again be restored to a rich soil, they may, with care, be made to produce an unnatural profusion of petals. Mr. D. Beaton's estimate of at double flower is original. He says that cultivation having enlarged all the parts of a plant, the constitutional vigour thus obtained is transferred to the next generation, and to some of the seedlings, in a measure, even greater than that possessed by the parent. Extraordinary supplies of nourishment. under favourable circumstances, invigorate still further the improved race, and so on through many generations. During this time cultivation produces the very opposite of double-flowers, and Mr. Beaton thinks it would continue to do so if it were possible to keep up every member of each generation to the same degree of health and vigour; but accidents and diseases overtake some of the plants, and doubleHowers are the produce from these decrepits. Cultivation, according to this idea, is only indirectly the cause of double-flowers, and these a retrograde step from a high state of developement. 
Whether my own opinion or Mr. Beaton's be correct, it is quite certain that in practice the plants from which double-flowered varieties are sought must be kept in the highest state of developement by supplying them abundantly with all the assistants to vigorous growth, and when the seedvessels are formed these should be reduced in number, in order to make the seed in these remaining as large and perfect as possible. In the course of a few generations seedlings appear having flowers, with an excess of petals and seeds being obtained from these, or from other flowers impregnated by their stamens, and the same high cultivation continued, the excess of petals increases, and becomes a permanent habit. 


\section{CHAPTER VII.}

THE FRUIT AND SEED.

WHEN the blossom begins to fade, "the joy of the plant" is departing, but other beauties and parts more important to the animal world are advancing to succeed the decaying inflorescence. The fruit and the seed are then entering on the season of maturity; will soon offer to the palate some of our most delicious luxuries, nor will beanty of colour be altogether wanting. "The ripened tints of autumn are equally pleasing with the bloom of spring, and the colours of the peach and apricot, the plum and cherry, are in nothing inferior to the blossom which preceded them."

The petals, stamens, pistils, and frequently the calyx having performed their destined functions, fall and leave the ovary or embryo seed-vessel, remaining attacher to the parent plant. This increases in growth and becomes the fruit, which title is not restricted merely to such as are edible, but includes every matured ovary with its contents, and which matured ovary, in botanical language, is known as the pericarp. This takes various distiuct forms, 
and as ail are subjects of interest to the gardener, each may have advantageously a separate notice.

1. The capsule is dry, woody, or membranous, containing one or more cells, as in the poppy, clematis, ash, and pæony.

2. The siliqua or pod, is long, dry, and has two valves separated by a linear receptacle, along the edges of which are ranged the seeds alternately. Instances are in the stock, wall-flower, and cabbage.

3. The legume has two dry long valres united by a seam at their edges, having no dividing receptacle as in the pod, but with the seed attached to one edge, as in the pea, bean, laburnum, and other leguminous plants.

4. The drupe or stone fruit is usually soft and fleshy, not separating into ralves; but enclosing a woody nut to which it is attached, as in the peach, plum, olive, and cherry; but sometimes more dry, as in the almond and cocoa nut.

5. The pome, or apple, is usually fleshy like the drupe, but enclosing a capsule with several seeds, instead of a nut, as in the common apple and pear.

6. The berry is pulpy and has its seed embedded in its substance as in the asparagus, currant, gooseberry, strawberry, raspberry, potatoe, orange, melon. cucumber, and medlar.

7. The strobile or cone is scaly, tough, and woody, formed of the catkin or calyx which has become 
indurated. It is the seed-vessel of the pine tribe. the plane tree, and comptonia.

Though thus varying in form, they have all one common office, the protection and maturing of the seed they contain. To effect this they require a due supply of sap as well as of the peculiar juice of the parent plant; for they make no further adrance, if the entire wood, be cut through below them, so that they are only attached to the parent by a strip of bark; neither will they advance though fully supplied with sap, if the peculiar juices are cut off from them by removing the leaves that are above them on the branch. The loss of such leares, as stated in a preceding page, may be supplied by inarching to the denuded branch one still retaining its foliage. I have also shem that the application of a ligature to a peach or apple, shews by the enlargement on one side of the ligature, that the sap really circulates through them.

Tet each fruit has a peculiar elaboration of its own to perform, for though the fluids afforded by the branches and leaves be nearly similar, yet each fruit differs from another in fragrance and flavour: six different varieties of the peach and of the apple budded upon the same branch, still retain unaltered their times of ripening, and their distinctive colours and flavours. Now the processes going on at different periods of a fruit's growth are very opposite 
in their character. During their green and growing state they are usually converting gummy matter into an acid; but during ripening they, as commonly, are converting an acid into sugar.

To convert gum or mucilage into tartaric acid, as in the early growth of the grape, oxygen in excess should be absorbed, for their relative components stand thus :

Gum.

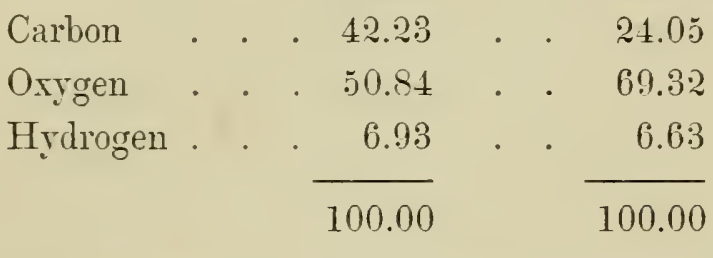

They might therefore be expected to absorb more oxygen than the leares, and this is actually the case, for though a rine branch will continue to regetate in a glass globe hermetically sealed, yet the grapes upon it will not increase in size unless oxygen gas be from time to time admitted. The same phenomenon occurs during the ripening of the grapes; oxygen has to be absorbed during the conversion of the tartaric acid into sugar, but a larger rolume of carbonic acid has to be erolved, and this is coincident with the result of well established experiments, uniformly testifying that carbonic acid is given out abundantly by ripening fruit. "Six equivalents of tartaric acid," says Liebig, " by absorbing six equiva- 
lents of oxygen from the air, form grape sugar, separating at the time twelve equivalents of carbonic acid."

This, however, is not the only decomposition taking place whereby sugar is formed in ripe fruit, but there is sufficient reason to believe that its mucilage and starchy constituents are converted into saccharine matter by the combined agency of warmth and the acids. It is thus that apples are renderéd so much sweeter by baking, and M. De Candolle states that the pulp of apple dissolved in water with a vegetable acid is converted into sugar; that gummy matter obtained from starch and mixed with tartaric acid aided by warmth effects a similar transmutation; and M. Tirchoff proved long since that starch, digested at a gentle heat with diluted sulphuric acid, became sweet.

During the ripening process, both of fruit and seed, all plants give out more carbonic acid and less oxygen than during the earlier stages of their growth, and thus is given a reason why room plants should be removed when once past their meridiun vigour.

Now to effect these changes, to ripen perfectly, that is to generate its best proportions of sugatr and aroma, every plant requires a certain amount of sap, light, heat, air, and moisture; and how these are best secured to them, so far as training and the atmosphere around them is concerned, may be here appropriately 
considered. These circumstances, so far as the roots and leaves were also concerned, have been examined in previous chapters.

Sap.-The more rapidly and consequently the greater the amount of this poured into the branches, the greater surface of leaf is required for its elaboration; and, as the plant lias power given it of increasing most freely, and eren at the expense of others. those organs which are most necessary, the leares of such abundantly supplied branches are increased both in number and size, whilst the blossom is proportionately diminished in number, or is obliterated eutirely. A plant propels its sap with greatest force perpendicularly, so much so that the sap rising in a vine branch growing in a right line from the root with a force capable of sustaining a column of mercury twenty-eight inches high, will, if the branch be bent

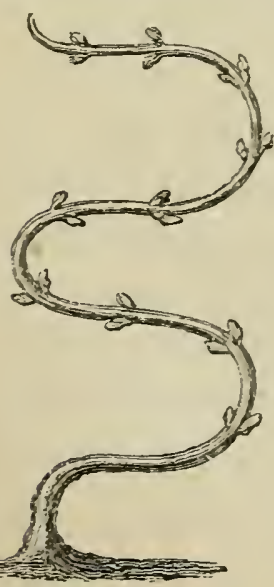
down to a right angle, support barely twenty-three inches, and if bent a few degrees below the horizontal, the column sustained will not be more than twenty one inches. This is the reason why, at such angles, gardeners find the trained branches of their wall trees rendered more productive of blossoms, and furnished with a smaller surface of leaves. A similar effect 
is produced by training a branch in a waving form. for two thirds of its length are placed horizontally as in the accompanying outline. Other modes of interrupting the rapid flow of the sap by checking its return has been noticed in a previous chapter. Among which modes are ligatures and mounds round the bark.

Light and heat are so combined, and so equally essential for the ripening of fruit, that they may be considered conjointly. They are both diminished in ungenial summers, and in such, fruit ripens indifferently, or not at all, being, if it does ripen, deficient in colour, as well as flavour. In our latitudes, however. warmth is more deficient than light for the maturing of exotic plants-therefore, by securing to them a higher temperature, we have the peach, the melon, the mango, and the pine-apple as richly flavoured. and even superior to the excellence they attain in their native climes.

It must be remembered, in considering this branch of our subject, that all cooling is occasioned either by the heat being conducted from a body by a colder, which is in contact with it, or by radiating from the body. cooled, though circumstances accelerate or retard the radiation, and whatever checks the radiation of heat from a body keeps it warmer. For example,-a thermometer placed upon a grass-plat, exposed to a clear sky, fell to $35^{\circ}$, but another thermometer within a 
few yards of the preceding, but with the radiation of the rays of heat from the grass checked by no other covering than a cambric pocket-handkerchief, declined no lower than $42^{\circ}$. No difference of result occurs, whether the radiating surface be parallel or perpendicular to the horizon; for when the mercury in a thermometer, hung against an openly exposed wall, fell to $38^{\circ}$, another thermometer against the same wall, but beneath a web of gauze stretched tightly at a few inches distance, indicated a temperature of $43^{\circ}$.

These results explain the beneficial operation of apparently such slight shelter to our wall-fruit when in blossom. A sheet of canvas, or of netting, prevents the direct radiation of heat from the wall-the cooling goes on more slowly, and is not reduced to that of the exterior air at night before the return of day begins to re-elevate the external temperature.

The colder the body surrounding another body, the more rapid the radiation from the latter; for it is a law of heat that it has a constant tendency to be diffused equally, and the greater the diversity of temperature between two bodies in contact with each other, the greater is the rapidity with which the progress towards equilibrium goes on. This is one reason why a temperature of $32^{\circ}$ with a brisk wind attending it will injure plants to a far greater extent than a temperature many degrees lower with a still atmosphere, but it is aided by the operation of 
another law of heat, viz. that aëriform bodies convey it from a cooling body, as a wall or a tree, by an actual change in the situation of their own particles. 'That portion of the air which is nearest to the cooling body is expanded, and becoming specifically lighter, ascends, and is replaced by a colder portion. This, in its turn, becomes heated and dilated, and gives place to another colder portion, and thus the process goes on until the cooling body is reduced to the same temperature as the air. In a still atmosphere this goes on slowly, the air in contact with the wall and tree rises very gradually as it imbibes warmth from them, but if there be a brisk wind, a constant current of air at the lowest temperature then occuring is brought in constant contact with them, and the cooling is rapid in accordance with the law of equilibrium just noticed. A shelter of netting, or even the sprays of evergreens are of the greatest service in preventing the sweeping contact of cold air at such times.

It is not altogether immaterial of what substance netting is formed. Worsted is to be preferred, not only because it is the most durable, but because it is the best preventive of a wall's cooling. I have found the thermometer under a hemp net sink during the night from two to four degrees lower than that under a net of worsted, the meshes being small and of equal size in both nets. 'This can only be because worsted 
is a known worse conductor of heat than hemp, and not absorbing moisture so easily, is not so liable to the cold always produced by its drying.

Snow is a protection to plants from the three foregoing reasons-it prevents heat radiating from themprotects them from the chilling blasts-and is one of the worst conductors of heat. I have never known the surface of the earth below a covering of snow colder than $32^{\circ}$, even when the temperature of the air above has been $28^{\circ}$. A similar protection, though less effectual, is afforded by straw.

Strange as it may appear, ret it is nevertheless true, that a shelter is more beneficial in preserving the temperature of trees, when from three to six. inches from them, than when in immediate contact with their surfaces. When a woollen net was suspended four inches from the wall, on which a peach-tree was trained, the thermometer fell very slowly, and the lowest degree it reached was $38^{\circ}$; when the same screen was twelve inches off, it fell to $34^{\circ}$; and when drawn tightly over the tree. it barely kept above $32^{\circ}$, the temperature of the exterior air. When at twelve inches from the wall, it permitted the too free circulation of the air; and when in immediate contact with the polished bark of the peach, perhaps another law of cooling came into operation. That law is, that polished surfaces radiate heat slowest. Thus if two glass 
bottles, equal in size and thicknes of glass, and of the same shape, be filled with warm water, and one of the bottles be covered with an envelope of fine muslin, this bottle will give out heat to the surrounding air with much greater rapidity than the other bottle: so that in a given time the bottle with the envelope will be found colder than the one which has no covering.

Shelters such as the preceding, or the slighter agents, sprays of evergreens, placed before the branches of wall-trees, or other plants, as already noticed, operate beneficially in another way-checking the rapid passage of the air over them-such passage is detrimental in proportion to its rapidity, for the more rapid it is, the greater is the amount of eraporation, and consequently of cold produced. Mr. Daniell says, "That a surface which exhales 100 parts of moisture when the air is calm, exhales 125 parts when exposed to a moderate breeze, and 150 parts when the wind is high. During all high winds, but especially when blowing from points varying between the east and the south-for they are the driest in this country-the gardener will always find shelters beneficial to his plants whether in blossom or with fruit in its first stages of growth, for these winds cause an eraporation much exceeding in amount the supply of moisture afforded by the roots." In March, such shelters are inuch required, 
for the winds are then violent and dry even to a proverb; but it is during the days of its successor, April, that sets in the only periodical wind, known in this island. It comes intermittingly, and with variable force, from points ranging from E. to x.E., and is one of the most blighting winds we have. It continues until about the end of the second week in May, though often until its close; and it is a good plan to have the trees during the whole period, by day as well as by night, protected. This periodical wind is occasioned, probably, by Sweden and Norway remaining corered with snow, whilst England is some $20^{\circ}$ or more warmer; an upper current of warm air is consequently flowing hence to those countries, whilst a cold under current is rushing hither to supply its place. This wind, and its consequent cold weather, is so regular in its appearance, that in Hampshire and some other parts of England the peasantry speak of it as " the blackthorn minter," that bush being in blossom during a part of its continuance.

Colour has very considerable influence over a body's power of absorbing heat. If a thermometer on a hot summer's day be exposed to the sun, it will indicate a temperature of about $100^{\circ}$, but if the bulb be blackened with Indian ink, or the smoke of a candle, it will rise from ten to twenty degrees higher. The reason for this is, that the polished surface of the glass reflects some of the sun's rays, but the blackened 
surface absorbs them all. Blue absorbs all but the blue rays-red all but the red-green and yellow, all but those of their own name, and white reflects all the rays. The lightest coloured rays are the most heating, therefore light coloured walls, but especially white, are the worst for fruit trees. The thermometer against a wall rendered black by coal tar rises $5^{\circ}$ higher in the sunshine than the same instrument suspended against a red brick structure of the same thickness; nor will it cool lower at night, though its radiating power is increased by the increased darkness of its colour, if a proper screen be then employed. The elevation of the temperature of a dark coloured fruit compared with that of a lighter coloured of the same kind is often remarkable, as in the instance of the muscle plum and greengage, growing on standard trees. But there are other causes than colour for fruit often remaining of a cool temperature in the hottest weather, and among these causes is their covering. Every one must have noticed the delicious coolness of the peach's flesh compared with that of the nectarine grown on the same wall and in the same bright sunshine; and the reason of this is, that the dense woolly cuticle of the first, like all other downy coverings, is one of the worst conductors of heat. Similar coverings are found on Mexican and Cretan plants which have to endure exposure to a torrid temperature. 
Despite all the contrivances for rendering more effectual the natural sources of temperature offered by our climate, these can never obtain during the twelre months, by night as well as by day, a heat sufficient for the successful cultivation of most tropical plants. Hence arises the necessity for employing hothouses and other shelters of that description. In these, fuel has to be employed to elevate the temperature, and some transparent medium as a covering, to prevent the radiation of the heat thus obtained, as well as to shut out the colder atmosphere, without excluding the light. But few words will suffice relative to the fuel employed, this being so generally coal; yet there are some facts ascertained by the chemist, which afford guides to the gardener in the selection of his fuel, as well as tests to enakie him to judge whether he employs it economically.

The heating quality of the different coals known in Great Britain are in the following proportions:

Scotch Cannel . . . . . . . 199

Lancashire Wigan . . . . . . 196

Yorkshire Cannel . . . . . . 188

Newcastle (best Wallsend) . . . 169

Gloucestershire (Forest of Dean) . 108

Welsh (common) . . . . . 25

Hence, if the Scotch Cannel coal cost 19s., when the 
Gloucestershire could be had for 10 s. per chaldron, the latter would be no cheaper; for the heating powers of the first is as 199 to 108 of the latter. In other words, 108 chaldrons of Scotch would afford as much heat as 199 chaldrons of Staffordshire.

The following are the quantities of the fuels named, required to heat eight gallons of water, from $52^{\circ}$ to $212^{\circ}$ :

lbs.

Caking coals . . . . . . . . 1.2

Splint, or hard coal $\}$. . . . 3.13

Cannel coal . . .

Cherry, or soft coal . . . . . 1.5

Wood of lime . . . . . . 3.10

" beech . . . . . . 3.16

. elm. . . . . . . 3.52

" oak (chips) . . . . 4.20

" ash . . . . . . . 3.50

" maple . . . . . . 3.00

" service . . . . . . . 3.00

" cherry . . . . . . . 3.20

" fir . . . . . . 3.52

" poplar . . . . . . . 3.10

" hornbeam. . . . . 3.3

Peat (average, not compressed) . . 7.6

Charcoal of wood . . . . . . 1.5\%

" peat . . . . 3.28 
The specific heat of water being 1 , and that of atmospheric air 0.00035 , or $\frac{1}{285} ;$ th, if the quantity of fuel which will heat a cubic foot of water one degree be multiplied by 0.00035 , the product will be the quantity of fuel required to heat a cubic foot of air one degree, and twenty times that quantity will heat it twenty degrees, thirty times will heat it thirty degrees, and so on. Now 0.0075 lbs. of best coals will heat a cubic foot of water one degree, therefore, $0.000002625 \mathrm{lbs}$. of coal will heat a cubic foot of air one degree.

It is essential to good and profitable fuel that it should be free from moisture; for unless it be dry, much of the heat which it generates is consumed in converting that moisture into rapour; hence the superior value of old, dense, dry wood, to that which is porous and damp. A pound of dry will heat thirtyfive pounds of water from $32^{\circ}$ to 212 , but a pound of the same wood in a moist or fresh state, will not similarly heat more than twenty-five pounds. The value, therefore, of different woods for fuel is nearly inversely as their moisture; and this may be readily ascertained, by finding how much a pound weight of the shavings of each loses by drying, during two hours, at a temperature of $212^{\circ}{ }^{3}$

${ }^{a}$ C. Johnson's Farmer's Encyce. p. 512. 
The above are the average of results obtainable in a common well-constructed furnace. By a complicated form of boiler, perhaps, a small saving of fuel in obtaining the same results may be effected; but it will be found, generally, that the original cost of apparatus, and the current additional expenses for repairs will more than exceed the economy of fuel.

Flues for imparting heat to hot-houses are, for the most part, superseded by either tanks or hot-water pipes; but where retained, the top should be formed of iron plates, these admitting the heat most readily into the house, and consequently requiring a less consumption of fuel. If it be desirable to have a covering for the flues that will retain the heat longer, as when the fires are made up at night, this may be readily accomplished, by putting a row of the thick square paring tiles on the top of the whole length of the flue, an hour or two before the houses are finally closed.

The power of retaining heat, or, in other words, of cooling slowly and gradually, which renders the corering of paring tiles desirable, renders the tank system of heating by hot-water still more efficient. It is a scientific operation throughout, and will be best appreciated by a reference to the annexed diagram, borrowed from Mr. Rendle's pamphlet, 
CH. VII.]

entitled the "Tank System of communicating Heat :"

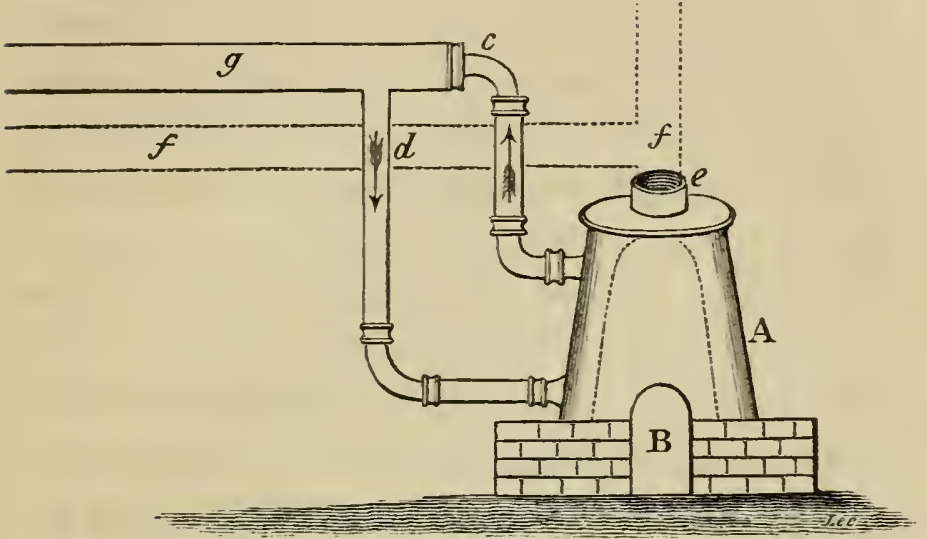

It is a law of fluids, that their hottest portions rise to the surface of the containing ressel, and the coldest portions as invariably subside to the lowest surface; because heat makes them expand, and consequently diminishes their specific gravity; and the abstraction of heat makes them contract, and, as consequently, increases that gravity. When the boiler $A$ and the tank $g$ are filled with water, as well as their connecting pipes, and a fire is lighted in B, the hottest portions rise to the top, pass up $c$, flow along the surface of $g$, and getting cool, sink to its bottom, and passing down $d$, enter A again at the lower part, to be once more heated and pass through the same 
circulatory system. A very small boiler will speedily raise the heat of the water. in a very large tank, to 180 degrees; and if this heat be imparted late in the evening, it will retain its heat but little diminished until the morning. The smoke, br means of a flue, $f$, may be made to impart heat to the house, by passing through it, or may at once enter the chimney or pipe attached to the summit of the boiler.

Hot water in a tank is superior to the same source of heat in pipes, because it is not liable to freeze; and it is preferable to steam, because its heating power continues, until the whole mass of water is cooled down to the temperature of the house, whereas steam ceases to be generated as a source of heat the moment the temperature falls below $212^{\circ}$.

If steam be employed, Mr. Tredgold has given the following rules for calculating the surface of pipe, the size of the boiler, the quantity of fuel, and the quantity of ventilation required for a house thirty feet long, twelve feet wide, with the glass four feet high in front; rertical height of the glass roof eight feet; length of the rafters fourteen feet; height of the back wall fifteen feet. The surface of glass in this house will be 720 feet superficial, viz.' 540 feet in the front and roof, and 180 feet in the ends. Now, half the vertical height, $r \mathrm{ft} .6$ in., multiplied by the length in feet, and added to $1 \frac{1}{2}$ time the 
area of glass in feet, is equal to the cubic feet of air to be warmed in each minute, when there are no double doors. That is $\overline{\tau .5 \times 30}+\overline{1 \frac{1}{2} \times 720}=1305$ cubic feet. But in a house with wooden bars and rafters, about $\frac{1}{10}$ th of this space will be occupied with wood-work, which is so slow a conductor of heat, that it will not suffer a sensible quantity to escape, therefore 130 feet may be deducted, leaving the quantity to be warmed per minute $=1175$ cubic feet.

To ascertain the surface of pipe required to warm any given quantity of air, multiply the cubic feet of air to be heated per minute by the difference between the temperature the house is to be kept at, and that of the external air in degrees of Fahrenheit's thermometer, and divide the product by 2.1, the difference between 200 , which is the temperature of the steam pipes, and the temperature of the house; the quotient will be the surface of cast iron pipe required.

Now in the house, the dimensions of which are above given, if the lowest temperature in the night be fixed at $50^{\circ}$, and $10^{\circ}$ are allowed for winds, and the external air is supposed to be at zero, or 0 of Fahrenheit, then $11 \% 5$ multiplied by 60 , and the product divided by 2.1 , the difference between 200 and 60 , will give us the quotient 236 $=$ to the surface of pipe required. Now the house 
being thirty feet long, five pipes of that length, and five inches in diameter, will be about the proper quantity.

If hot water be employed instead of steam, the following proportions and information, ohtained from Mr. Rendle, may be adopted confidently as guides. In a span roof propagating house forty feet long, thirteen feet broad, seven feet high in the centre, and four feet high at the two fronts, having a superficial surface of glass amounting to 538 square feet, Mr. Rendle has a tank eighty-three feet long, running round three sides of the house, four feet wide and about eight inches deep, and consequently capable of containing nearly 300 cubic feet of hot water, though only half that quantity is used. This is closely approaching to the size pointed out according to Mr. Tredgold's formula. The mean temperature of a hot water tank will never be much above $160^{7}$, so that for the sized house mentioned by that skilful engineer, the divisor must be 2.1 times the difference between 160 ' and $60^{\circ}$, which gives as the quotient 335 cubic feet.

The tank in Mr. Rendle's propagating louse is built of bricks lined with Roman cement, and if the temperature at the time of lighting the fire be $90^{\circ}$, the temperature of the atmosphere of the house $67^{\circ}$, and the temperature out of doors $50^{\circ}$, the quantity of small coal, or breeze, required to raise the tem- 
perature of the water to $125^{\circ}$ is $281 \mathrm{lbs}$. In twelve hours the water cools, after the fire has been extinguished, from $125^{\circ}$ to $93^{\circ}$.

When steam is employed, the space for steam in the boiler is easily found by multiplying the length of the pipe in feet, by the quantity of steam in a foot in length of the pipe.

\begin{tabular}{|c|c|c|c|c|c|c|}
\hline $\begin{array}{l}\text { Interior dia- } \\
\text { meter of pipe } \\
\text { in inches. }\end{array}$ & & & & & & $\begin{array}{l}\text { Decimal parts } \\
\text { a cubic foot } \\
\text { steam in ea } \\
\text { foot of pipe }\end{array}$ \\
\hline 1 & . & . & & & . & . .00545 \\
\hline $1 \frac{1}{2}$ & . & & & . & . & .01225 \\
\hline $2^{-}$ & . & . & . & . & . & .02185 \\
\hline $2 \frac{1}{2}$ & & . & . & . & . & .034 \\
\hline 3 & . . & . & . & . & . & .049 \\
\hline 4 & . & & $\cdot$ & . & & .0873 \\
\hline 5 & . & . & . & . & . & .1363 \\
\hline 6 & . & . & . & . & . & .1964 \\
\hline 7 & & . & . & . & . & .267 \\
\hline 8 & & . & & . & . & .349 \\
\hline 9 & . & & . & . & & .442 \\
\hline 10 & & & & & & .545 \\
\hline
\end{tabular}

In the above noticed house the length of pipe, 5 inches in diameter, is 150 feet, and these multiplied by $1.363=20.5$ cubic feet of steam; and as the pipe will condense the steam of about one cubic foot and one third of water per hour, therefore the boiler should be capable of evaporating $1 \frac{1}{2}$ cubic feet 
of water per hour, to allow for unavoidable loss. In the extreme case of the thermometer being at zero, the consumption of coals to keep up this evaporation will be $12 \frac{5}{4} 1$ lbs. per hour a.

These calculations are all founded upon the supposition that the condensed water is returned to the hoiler whilst hot; but if this cannot be effecter, then one-twelfth more fuel will be required. The boiler for the supply either of steam or hot-rater should be covered with the best available non-conductor of heat, and this is either charcoal or sand. A case of brick-work, with pulverized charcoal between this and the boiler, is to be preferred to any other. A boiler having a surface of serenty feet exposed to the air in a temperature of 32 ' requires an extra bushel of coals to be consumed per day. to compensate for the heat radiated and conducted from that surface; and the smaller the boiler the greater is the proportionate waste.

The surface of the pipes should be painted black, because surfaces of this colour give out more heat in a given time than any other.

Solar light is essential to the ripening of all fruit; it will not ripen in the dark, and the greater the light's intensity and the longer its daily endurance, the

a For these rules I an chiefly indebted to Mr. Tredgold's raluable work on "Warming and Ventilation," which will well repay the gardener for the perusal: 
sweeter and the higher is the fruit's flavour. No fruits are so luscious as those grown within the tropies, and the fruits of the temperate zone are excellent in proportion to the brightness of its seasons.

That light is essential in causing the colour of the leaves and other parts of plants has been noticed already; and it aids the ripening process of fruit in a similar manner, to convert their acid and mucilaginous constituents into sugar; much carbon and hydrogen have to be got rid of, and this is effected, if light be admitted, by the evolution of carbonic acid and watery rapour. How light operates in promoting this and other decompositions which are effected by the vegetable organs is at present a mystery, but so it is; and the gardener promotes its access as much as lies within his power by removing overshadowing leaves, by employing the best glass in his hot-houses, and by haring their interior whitened, for white surfaces reflect all the rays of light back upon the objects those surfaces enclose.

The angle formed by the glass roof of the hot-house is of very considerable importance, because rays of light are reflected in proportion to the obliquity with which they fall upon any given surface; those which fall upon it perpendicularly from the source of light pass through with very slight diminution, but those falling upon it in a slanting or oblique direction are reduced in number in proportion to the obliquity of 
that direction. To ascertain how a glass roof may be constructed so as to receive the greatest number of rays of light from the sun perpendicularly or near to perpendicularity at any given time of the year, it is necessary to know the latitude of the place where the hot-house is erected, and the sun's declination at the period when most light is required. The latter information may be obtained from most almanacks, and if it be subtracted from the latitude, the remainder will be the angle desired.

If London be the place, and May the 6th the time about when the most light is desired, the latitude being $51^{\circ} 31^{\prime}$ and the sun's declension then $16^{\circ} 36^{\prime}$ north, therefore the roof ought to slope at an angle of $34^{\circ} 55^{\prime}$.

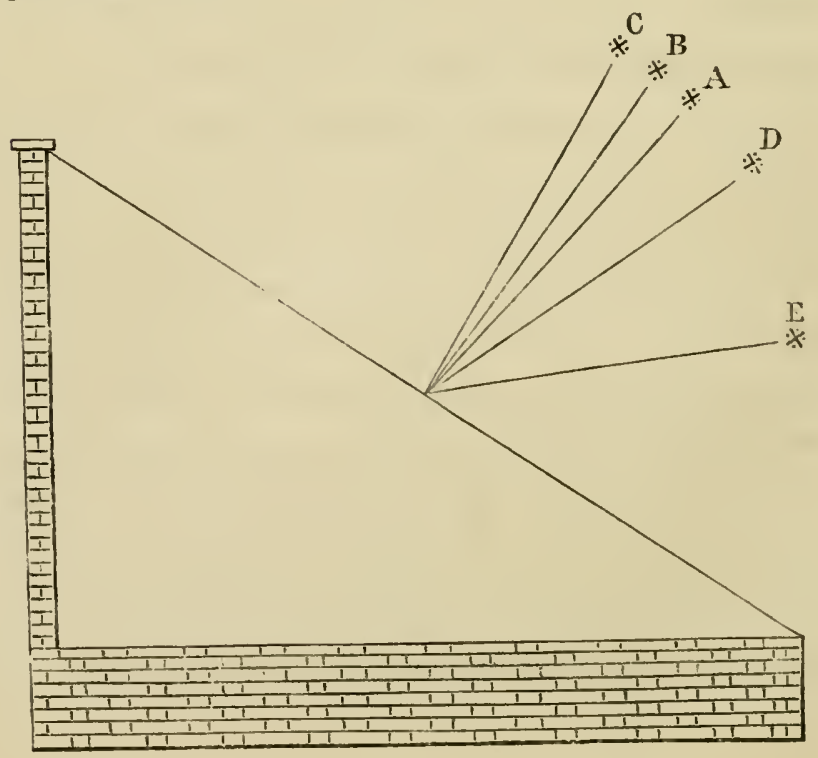


In latitude $52^{\circ}, \mathrm{Mr}$. Knight found, from lengthened experiment, that the best angle is about $34^{\circ}$, considering the services of a hot-house through the year; and to illustrate this, he gave the preceding diagram.

About the middle of May, the elevation of the sun at noon, corresponds nearly with the asterisk A; in the beginning of June, and early in July it will be vertical at 'b, and at midsummer at $c$, only six degrees from being vertical. The asterisk $D$ points out its position at the equinoxes, and $\mathrm{E}$ its position at midwinter?

If the best glass be employed it is an excellent plan to have it put double in each sash, an interval of half an inch being left between the two panes, and a small hole at the corner of the inner one to prevent the glass being broken by the expansion or contraction of the air between. This confined air is one of the worst possible conductors of heat, keeping the house from being rapidly cooled during the coldest weather; and thus is effected a very great economy of fuel, whilst little or no extra interruption is caused to the entrance of light.

Moisture.-Every fruit-bearing tree requires a larger supply of moisture during the growth of its fruit, and in proportion to its abundance, than at any other season, and for the obvious reason that, as the fruit is a reservoir of accumulated and elaborated

${ }^{a}$ Hort. Society's Trans. 
sap, that sap requires for its formation an extra supply of moisture, inasmuch as that its chief ingredient is water.

Though abundance is required it must not be excessive, for if this does occur, the sap poured into the fruit is so abundant that it camnot elaborate it sufficiently fast; and instead of exhaling the superfluous moisture, its cells enlarge, and the fruit greatly increases in size, but at the expense of its flavour. In very wet seasons the supply of moisture is so great that the cells of the parenchymous or fleshy part of the fruit swells faster than its epidermis can expand, and this consequently bursts. This is continually occurring to the plum and cherry. When this happens to the greengage, and its extremely saccharine juice is exposed to the air, vinous fermentation speedily takes place, and an appreciable quantity of spirit of wine (alcohol) is formed, a discovery to which I was led by observing, what every gardener must have observed, that wasps, after feeding plentifully upon the juice that has been thus exposed, usually fall to the ground stupified and inebriated.

Fruit has also the power of imbibing water through the pores of its epidermis, a power taken adrantage of by those gooseberry growers, who ain at size rather than flavour. They keep the calyx end of the berry dipped in a saucer of water.

Fruit for storing should be gathered before it is 
quite mature, for the ripening process, the formation of sugar, with its attendant exhalation of carbonic acid and water, goes on as well in the fruit-room as in the open air, at the season when the functions of the leaves have ceased, and the fruit no longer enlarges. In gathering fruit every care should be adopted to avoid bruising, and to this end, in the case of apples, pears, quinces, and medlars, let the gathering basket be lined throughout with sacking, and let the contents of each basket be carried at once to a floor corered with sand, and taken out one by one, not poured out, as is too usual, into a larger basket, and then again from this into a heap; for this systematic mode of inflicting small bruises, is sure to usher in decay, inasmuch as that it bursts the divisional membranes of the cells containing the juice, and this being extravasated speedily passes from the stage of spirituous fermentation to that of putrefaction. To avoid this is the principal object of fruit storing, whilst, at the same time, it is necessary that the fruit shall be kept firm and juicy.

Now it so happens that the means required to secure the one also effects the other. To preserve the juiciness of the fruit, nothing more is required than a low temperature and the exclusion of the atmospheric air. The best practical mode of doing this, is to pack the fruit in boxes of perfectly dried pit-sand, employing boxes or bins, and taking care 
that no two apples or pears touch. The sand should be thoroughly dried by fire-heat, and over the uppermost layer of fruit the sand should form a covering nine inches deep.

Putrefaction requires indispensably three contingencies,-moisture, warmth, and the presence of atmospheric air, or at least of its oxygen. Now burying in sand excludes all these as much as can be practically effected. The more minutely divided into small portions animal or vegetable juices may be, so much longer are they preserved from putridity,hence one of the reasons why bruised fruit decays more quickly than sound-the membranes of the pulp dividing it into little cells are ruptured, and a larger quantity of the juices are together; but this is only one reason, for bruising allows the air to penetrate, and it deranges that inexplicable vital power which, whilst uninjured, acts so antiseptically in all fruits, seeds, and eggs. Bruises the most slight, therefore, are to be avoided; and instead of putting fruit in heaps to siceat, as it is ignorantly termed, but in fact to heat, and promote decay, fruit should be placed one by one upon a floor covered with dry sand, and the day following, if the air be dry, wiped and stored away as before directed. Fruit for storing should not only be gathered during the midday hours of a dry day, but after the occurrence of several such. 
Although the fruit is stored in sand, it is not best for it to be kept there up to the very time of using, for the presence of light and air are necessary for the elaboration of saccharine matter. A fortnight's consumption of each sort should be kept upon beach, birch, or elm shelves, with a ledge all round to keep on them about half an inch in depth of dry sand. On this the fruit rests softly, and the racancy caused by every day's consumption should be replaced from the boxes as it occurs. If deal is employed for the shelving, it is apt to impart a flarour of turpentine to the fruit.

The store-room should have a northern aspect, be on a second floor, and have at least two windows to promote rentilation in dry days. A stove in the room, or hot water pipe with a regulating cock, is almost essential, for heat will be required occasionally in very cold and in damp weather: the windows should have stout inside shutters. Sand operates as a preservative, not only by excluding air and moisture, but by keeping the fruit cool, for it is one of the worst conductors of heat, and moreover, it keeps carbonic acid in contact with the fruit. All fruit in ripening emits carbonic acid, and this gas is one of the most powerful preventires of decay known.

The temperature of the fruit-room should never rise above $40^{\circ}$, nor sink below $34^{\circ}$ of Fahrenheit's thermometer, the more regular the better. Powdered 
charcoal is even a better preservative for packing fruit than sand, and one box not to be opened until April, ought to be packed with this most powerful antiseptic. If it were not from its soiling nature, and the trouble consequent upon its employment, I should adrocate its exclusive use. I have kept apples perfectly sound in it until June.

It is not unworthy of observation, that the eye or extremity furthest from the stalk is invariably the first to ripen. This is most perceptible in pears, especially in the Chaumontelle. That end, therefore, should be slightly embedded in the sand, as thus excluding it from the light, checks its progress in ripening.

The perfecting of seed is a process very similar to the maturation of fruit-indeed, for the most part, whatever advances the one promotes the other. The chief difference is that, if seed be the exclusive object, less moisture and rich food should be supplied to the plants, inasmuch as that an abundant supply of these increases excessively the developement of the succulent part of the fruit, and yet the ressels from this to the seed wither and render it abortive. A similar defective fertility occurs if the female parent in animals is over-stimulated and fat. In the gardener's departinent it is most apparent in the pine apple. 


\section{CHAPTER VIII.}

THE DISEASES OF PLANTS.

Dr. Goop, the distinguished medical writer, has remarked, that the morbid affections to which the vegetable part of the creation is liable, are almost as numerous as those which render lecrepid and destroy the animal tribes. It would be difficult, perhaps, whatever system of nosology is followed, to place a finger upon a class of animal physical diseases, of which a parallel example could not be pointed out among plants. The smut, which ravages our corn crops; the mildew, which destroys our peas; the curl that is annually infecting more destructively our potatoes; the ambury, or clubroot, to which our turnips, and other species of brassica, are liable; the shanking, or ulceration, which attacks the stalks of our grapes, are only a few of the most commonly observed diseases to which the plants we cultivate are liable.

Numerous as are the regetable diseases, and destructive as they are to the interests of the cultivator, yet no subject connected with his art has obtained so little attention, and never was even trivial attention followed by benefit less important. 
The reason of this deficiency of benefit is not difficult of detection.

Common experience teaches us that diligence and perseverance, directed by judgment, are the essential preliminaries of success: and these are more particularly requisite in examining, in searching for the causes of the diseases and decay of regetables, because we have fewer guides, less assistance from the regetable affected, than we have from a diseased animal; fewer symptoms marking the commencement, or seat of the evil. Yet where is the cultivator who erer took a fraction of the care, or a decimal of the attention to discover the cause, progress, or remedy of one disease, sometimes bringing destruction upon his harrests, as he does to detect the disorder or discover the panacea for some miserable pig?

The subject is one beset with difficulties, but it is commensurately important. Difficulty, however, is very distinct from impossibility; and the importance of the research is a stimulus to exertion. Human knowledge being acquired by observation and experience, by conversing with the things about us, -that is by noticing them attentively, and recording and reflecting upon the facts they reveal,every gardener should do this, especially whenever he finds his crops diseased. He should record from what soil he obtained his seed; how and in what 
weather it was committed to the ground: the subsequent culture of the crop; the crops which preceded it; the thermometrical and hygrometrical registries of the seasons through which it has grown; the treatment of the soil; its drainage; with the ma zures employed; the waterings; the pruning; and any other miscellaneous observations his own com. mon sense may dictate. If this were done, vegetable medicine would soon adrance more in one year towards that state of reasoned knowledge, which alone deserves the name of science, than it has done during the last century.

As observations multiply, the adjutant sciences, chemistry and physiology, will contribute and apply their improved stores of information, and if but few specifics for the diseases of plants resulted, yet I am quite satisfied that the causes of diseases would be more accurately ascertained: and every one is aware that to know the cause of an evil is the most important step torards the prevention of its occurrence.

It is a very important preliminary to the study of the diseases of plants, that the nature of these be understood-for our ignorance of, or inattention to, the nature of these organized creatures, is one of the causes from whence arises the little progress made in this branch of natural philosophy.

Its students ought fully to understand that this 
part of the creation, even the commonest weed they uproot, is so highly organized, so exhibiting intimations of the functions, circulations, and secretions more highly developed in the superior animals, that it is not possible to point out where animal life terminates, and where vegetable life begins: the zoophytes connect the two lingdoms. It is absolutely necessary, I think, for this to be understood and felt by those who enter upon the investigation of vegetable diseases, because I have a strong opinion that these, in very many instances, are caused by the plants which they infect being treated as if they were totally insentiate matter, scarcely more susceptible of injury at some periods of their growth than the soil from whence they partly derive their sustenance.

To determine the question, whether plants possess a degree of sensation, is not so easy as the cursory inquirer may believe; and Mr. Tupper is much nearer to truth when observing that it is as difficult to ascertain the nature of regetable existence as to determine what constitutes the living principle in animals.

Dr. Darwin, by the aid of imaginary beings similar to the Dryads and other minor deities of the heathen mythology, has raised plants to a position, in the order of nature, superior even to that to which animals are entitled. Other philosophers 
adopting a totally antagonist opinion, estimate regetables as bodies, only somewhat more organized than crystals, but like these entirely and uncontroledly subject to chemical and mechanical changes.

Each of the foregoing extreme opinions is similarly erroneous, as will hare been gleaned from the facts mentioned in preceding pages, and as will more clearly appear from those which now follow. The gradation from reason to instinct, from instinct to inanimation, might easily be shewn to be as gradual as are the transitions of light in our climate from the noontide to the midnight of a summer's day. But we must, in this rolume, confine our attention to that section of creation commencing from the close of the animal classes in the zoophyte, and terminating where inorganic matter commences in the crystal, and the details here given must be directed specially to demonstrate how closely it approaches, how indistinctly it is divided from, the former.

Let us first consider the comparative composition of animals and plants as revealed by the researches of the chemist, and it must be somerhat startling even to the most sceptical to find that their constituents are identical. Carbon, hydrogen, oxygen, nitrogen, sulphur, phosphorus, acids, alkalies, earths and metals are the components of both.

Nitrogen was considered as a constituent, marking, by its presence, animal from vegetable matters; 
but this distinction is now admitted to fail; for although in the former it is usually most abundant, yet later researches shew it to be present in all seeds, it is abundant in regetable gluten, and per. vades the whole frame of the tobacco plant, yet is absent from some animal substances.

If we follow the above-named chemical bodies through their combinations, we shall find that the similarity between animals and plants still obtains, and are equally numerous and intricate in each.

Of the acids there are contained in

Animals.

1. Sulphuric,

2. Phosphoric,

3. Muriatic,

4. Carbonic,

5. Benzoic,

6. Oxalic,

\%. Acetic,

S. Malic,
Vegetables.

1. Sulphuric,

2. Phosphoric,

3. Muriatic,

4. Carbonic,

5. Benzoic,

6. Oxalic,

7. Acetic;

8. Malic,

besides others still more numerous, peculiar to each.

Of the earths and alkalies, lime, magnesia, silica, soda, and potass are found in both classes; and of the metals, iron and manganese are their conjoint constituents. If we follow the two orders of organized creatures through their more compound constituents, 
we shall find the close analogy still continues, for they contain in common, sugar, mucus, jelly, colouring matters, gluten a, fibrin, oils, resins, and extractives.

The functions of animals and plants are in a like degree analogous. Animals take in their food by the agency of the mouth, and prepare it for digestion either by rarious degrees of mastication, or by attrition, as in the gizzards of birds. In this they differ from plants; but these have a sufficient compensation, inasmuch as that they imbibe their food in a fluid form, liquid or aëriform, and consequently in a state already of the finest possible division. Animal and regetable remains are their common food, and salts of various kinds are their condiments and stimulants; plants having this advantage over animals, that as they absorb only the soluble and finer parts of their nutriments, and their absorbing organs have the power of rejecting that which is offensire, they have no offensive matters to separate such as appear in the excrements of animals.

In the animal stomach the food undergoes an $e x$ tensive change, being reduced to a pulp of greater specific grarity, and being altered entirely both in taste and odour. In the sap vessels of plants, which may be truly considered as their primary organ of digestion, their food or sap undergoes a change pre

2 The gluten of plants is the albumen of animals. 
cisely similar; its colour and flavour are altered, and its specific gravity increased.

From its stomach the animal's food passes into the intestines, is there subjected to the action of the bile, and the chyle or nutritive portion separated from that which is excrementitious. In its passage through the intestines, the chyle is absorbed by the lacteal vessels, and conveyed into the blood; and these mingled liquids are propelled by the heart into the lungs, to be there exposed to the action of the air. The vital liquid now changes its purple hue to a florid red, loses a portion of its carbon and watery particles, the former combining with the oxygen of the atmospheric air in the lungs, and being breathed forth in the form of carbonic acid gas. As plants take in as food no gross, mneeded ingredients, it is obvious that no process like the biliary operation is required in their course of digestion. But in them the food or sap, proceeding at once along the branches, is poured into the leaves, which are the very lungs of the regetable world. Here, as is the blood, its colour is changed, and oxygen emitted from it during the light hours of the twenty-four; but carbonic acid is breathed forth during the night, and, at all periods, a considerable amount of watery vapour is emitterl.

From the lungs, by the agency of the heart, the blood is propelled through the arteries over the whole 
animal frame, supplying nourishment and warmth to all the parts, and where, by those being abstracted, it is again converted into purple or renous blood, and is returned by the reins to undergo a repetition of those changes already noted as being effected in the lungs. In plants the sap, after exposure to the action of the air in their leares, is returned by another set of ressels, situated in the bark, ministering to the growth and support of the whole plant. It is true, that only under certain circumstances, detailed in another chapter, is heat evolved during the processes of regetation; but the circulation of the sap in plants, beyond all doubt, enables them to resist the intense colds and heats of their native climates. In frosts, the most intense and prolonged, we find the interior of trees remain unfrozen; and, under the meridian sun of the tropics, the sap of the palm and all other trees retain temperate coolness. This power to resist extremely elevated and depressed temperatures is characteristic of all animated nature.

Such is the close similarity in the digestive and circulatory processes characterising the members of the two great kingdoms of organized nature, a resemblance which obtains in all the other functions enjoyed by them in common. During respiration, the air inhaled by animals through the mouth and nostrils proceeds immediately to the lungs, and acts upon the blood; in plants, the air inhaled by their 
leaves operates instantaneously upon the sap. The changes which occur have been detailed in previous pages, and there it has been shown, that as oxygen is the vital air of animals, so that gas and carbonic acid gas are equally essential to plants. If animals be placed in a situation where they inhale pure oxygen, their functions are highly excited and increased in rapidity; but it is an exhilaration speedily terminating in exhaustion and death, if the inhalation be continued for a protracted time. So plants will flourish with increased vigour in an atmosphere containing $\frac{1}{12}$ th of carbonic acid, but even this brings on premature decay; and if it exceeds that proportion, destruction is still more rapidly induced. During sleep, animals exhale less carbonic acid than during their waking hours, so plants emit a much diminished amount of oxygen during the night.

We might now proceed to enumerate the observations and facts demonstrative that plants are gifted with sensation, if these had not already been recorded at p. 104. In addition to those I will only observe, that plants are obviously stimulated by light. Everybody must have observed, that they bend towards the point whence its brightest influence proceeds. M. Bonnet, the French botanist, demonstrated this by some very satisfactory experiments, in which plants, growing in a dark cellar, all extended 
themselves towards the same small orifice admitting a few illuminating rars.

Almost every flower has a particular degree of light requisite for its full expansion. The blossoms of the pea and other papilionaceous plants, spread out their wings in fine weather, to admit the solar rars, and again close them at the approach of night. Plants requiring powerful stimulants do not expand their flowers until noon, whilst some would be destroyed if compelled to open in the meridian sun-of such is the night-blooming Cereus, the flowers of which speedily droop, even if exposed to the blaze of light attendant on Indian festivities.

From these and other facts incidentally mentioned in the preceding chapters, without believing that they demonstrate sensation to exist in plants as acute as that possessed by the superior or more perfect classes of animals, yet they certainly are satisfactory evidence that plants possess it to a degree nearly as high as that with which the zoophytes, or even the polypus and leech, are gifted. Some of these animals may be cut into pieces, and each section will become a perfect individual; of others, their heads being taken off, may be grafted upon other bodies; and a third class of them may be turned with their insides outwards, without any apparent inconvenience. If plants be endowed with no more or even less sensation than must be that of such animals as these, it 
explains the causes, and throws light upon the prevention of many diseases affecting those which we cultivate, and warns the cultivator from the late performance of many of his operations, as well as from being needlessly violent in his treatment. If a grapevine be pruned too late in the spring, the bleeding or effusion of sap has been known to be so excessive, that the tree has died from absolute exhaustion. Stone-fruit trees, if severely bruised, are frequently destroyed by the inroads of a disease, resembling, in all its characteristics, the cancerous affections of animals; and I have known a whole crop of wheat affected with a swelling of the stem or culm, evidently caused by an extravasation of the sap from its ruptured vessels, owing to a heavy roller being passed over the crop, when of a forward growth.

I shall now proceed to the consideration of a few of the most usual diseases affecting cultivated plants, but without any attempt at classification, for our knowledge is too imperfect as yet to justify an attempt to form a system of regetable nosology. It is readily perceivable that plants have their epidemics, for at certain seasons a disease, such as the mildew, will devastate a whole neighbourhood. They have their endemics for some diseases, as the Ambury is often confined to a single compartment in a garden; but these and other detached portions of similar knowledge are too slight and unconnected 
to enable me to attempt a classification of their diseases. Neither shall I attempt in this volume to enter upon the consideration of the injuries to which plants are subjected either from predatory insects, or from parasitical plants: my space will not permit this, and I regret it the less because they are now the subjects dwelt upon by master minds in the pages of the Gardener's Chronicle.

The Curl.-No disease appears to me to arise from impaired vital energy in the plant more clearly than the curl, that of late years has made such extensive ravages upon our potato crops a. Any one can insure the occurrence of this disease, at least I have found it so in the county of Essex, by keeping the sets in a situation farourable to their regetation, as in a warm damp out-house, and then rubbing off repeatedly the long shoots they have thrown out. Sets that have been so treated, I have invariably found produce curled plants. Is not the reason very apparent. The vital energy had been weakened by the repeated efforts to regetate; so that, when planted in the soil, their energy was unequal to the perfect developement of the parts; for the curl is nothing more nor less than a distorted

a The opinions of Mr. Monro, of Brechin Nursery, coincides with mine. He considers "weakness is the cause" of the disease.-Gardener's Magazine, xi. 417. 
or incomplete formation of the foliage, preceded by an imperfect production of the fibrous roots.

The following experiment I consider as very decisive : it was made in the year 1830 , in my garden at Great Totham, in the county of Essex. The soil in this case, and in all others that will be stated hereafter, unless otherwise specified, is light, deep, moderately fertile, resting on a substratum of silicious gravel, and is constituted as follows:

\begin{tabular}{|c|c|c|}
\hline Water & & 30.5 \\
\hline Stones and coarse sand & & 15.5 \\
\hline Vegetable fibres . & . & 5 \\
\hline Saline matters . & . & \\
\hline Oxide of iron . & . & \\
\hline Carbonate of lime. & . & 7.5 \\
\hline Decomposing matter . & . & \\
\hline Alumina $\quad \cdot$ & . & 15 \\
\hline Silica . & . & 102.5 \\
\hline
\end{tabular}

The variety employed was the early Shaw. An equal number of whole moderately-sized potatoes that had been treated in three different modes, were planted the last week of March. No. 1: Twenty sets that had been carefully kept cold and dry throughout the winter, firm, unshrivelled, and with scarcely any srmptoms of regetation. No. 2. Twenty sets 
that had been kept warm and moist, and from which the shoots, after attaining a length of six inches, had been thrice removed. No. 3. Twenty sets that had been kept warm and moist for about half the time that No. 2 had, and from which the shoots, three. inches in length, had been removed only twice.

All the sets were planted the same morning, each exactly six inches below the surface, and each with an unsprouted eye upwards. The spring was genial.

Of No. 1, nineteen plants came up. The twentieth seemed to have been removed by an accident. Of the nineteen not one was curled. The produce a full arerage crop.

Of No. 2, all came up, but from ten to fourteen days later than those of No. 1, and three of the plants sixteen days later. Fourteen of the plants were curled.

Of No. 3, all came up, but from ten to fourteen days later than those of No. 1. Four plants were as sererely curled as those in No. 2 , eight were less so, and the remainder not at all; but of these the produce was below an arerage, and a full fortnight later in ripening.

Dickson, Crichton, Knighta, and others have found, that tubers, taken up before they are fully ripened, produce plants not so liable to the curl as those

${ }^{a}$ Caledonian Hort. Mem., Horticultural Trans., Loudon's Gardener's Mag., \&c. 
that have remained in the ground until completely perfected; and I believe, under ordinary treatment, this to be the fact, for it is rational. The process of ripening proceeds in the potato, as in the apple, after it has been gathered, and until that is perfected, it is accumulating vigour, shews no appetency to vegetate, consequently is not exhausting its vitality, which is a great point, considering the careless mode usually adopted to store them through the winter; for this energy commences its decline from the moment it begins to derelope the parts of the future plant. Tubers taken from the soil before perfectly ripe, never are so early in shewing symptoms of regetation. Crichton, Hunter, and Young, in some of the works before referred to, have also agreed, that exposing the sets to light and air, allowing them to become dry and shrivelled, also induces the curl in the plants arising from them. This result of experience also confirms my conclusion, that the disease arises from deficient vital energy; for no process more than this drying one of exposure to the light and air, tends to take away from a tuber the power of vegetating altogether. A farmer, Mr. G. Allaker, residing in the same village that I did, employed in the year 1836 rather small sets: cutting a moderate-sized potato into at least two pieces. Unfavourable weather, other business, and a somewhat dilatory habit, caused him to leare those 
sets upon a barn floor, drying for more than a week. He planted with them a two-acre field, and not more than three-fifths regetated; of which three-fifths, a fourth was in various degrees curled.

Similar results were obtained in the experiments of Mr. Wright, a market gardener of Westfield. When the sets were allowed to ferment in a heap, allowed to sprout, \&c., he had a crop, one-fifth of which was curled ${ }^{a}$.

Every one acquainted with the cultivation of the potato, is aware of the great difference existing in the varieties as to their early and rapid regetation; those that excel in this quality are, of course, the most easily excitable. A consequence of this is, that they are always planted earliest in the spring before their vital power has become very active: and of all crops, practice demonstrates that these early ones are least liable to the curl. But what is the consequence on the contrary, if an early variety is planted for a main crop later in the spring, when extraordinary pains in keeping them cold and dry have not been employed to check their regetation, and consequent decrease of vital energy? Such crop then is, more than any other, liable to the disease; and a good preventive has been suggested by Dr. Lindley, namely, that of planting the tuber's in autumn immediately after they have ripened.

a Gardener's Mag. x. 436. 
The statements of a practical man in the Gardener's Magazine, vol. x. 433., entirely support my views of the disease. He remarks that in 1836 , through the prevalence of rain, the late crops of potatoes never sufficiently ripened so as to be marketable. They were reserved for planting the next season, and the consequence was, that the curl affected the crops that year to a great extent; but those who planted well ripened tubers had crops free from the disease, and as productive as usual. Now we all know that the rital energy is always the most powerful in a bulb or seed that is perfectly ripened.

The results of my view of the disease, sustained by numerous experiments, are, that it will never occur if the following points are attended to:-First, that the sets are from tubers that exhibit scarcely any symptoms of incipient regetation. To effect which, they ought, throughout the winter, to be preserved as cool, and as much excluded from the air as possible. Secondly, that the tubers should be perfectly ripened. Thirdly, that they should be planted immediately after they are cut. Fourthly, that the manure applied should be spread regularly, and mixed with the soil, and not along a trench in immediate contact with the sets. Fifthly, that the crop is not raised for sereral successive years on the same area. 
The Ambury a, Anbury, Hanbury, or club root. The deficiency of knowledge relative to the diseases of plants, is well illustrated by the imperfect and inaccurate observations that have been adventured upon this disease. Where there is much difference of opinion there is little real knowledge, and both these are certainly the case in the instance before lis. Some cultivators assert that the disease arises from a variableness and unfarourable state of the seasons; a second party of theorists advance, that it is caused by insects; and a third, that it is owing to a too frequent growth of the same crop upon the same site.

Every man having formed an opinion, usually clings to it pertinaciously, and sets its estimate far above its real value, or correctness,

"'Tis with our judgments as our watches; none Go just alike, vet each believes his own."

The chief error appears to be in considering any of the abore enumerated causes as the exclusive one, for, beyond doubt, they each contribute, either im-

2 This, the correct name, is evidently derived from the Saxon word ambre, a wart suffused with blood, to which horses are subject. In Holderness, a district of Yorkshire, this disease is known as "Fingers and Toes," from its causing the tap-root of the turnip to be divided into swollen fibres, resembling those members of the human body. On this Mr. Spence, the entomologist, wrote a very sensible pamphlet, entitled "Obserrations on the Diseases in Turnips termed in Holderness, ' Finger and Toes.' Hull, 1812." 
mediately or remotely, to induce or exasperate the attacks of the ambury.

I am about in the first place to consider the disease exclusively as affecting the cabbage, and secondly, as it operates upon the turnip, though other species of brassica, the hollyhock, \&c., are subject to its attacks. Its progress has invariably appeared to me as follows:

Cabbage-plants are frequently infected with ambury in the seed-bed, and this incipient infection appears in the form of a gall or wart upon the stem, immediately in the vicinity of the roots. If this wart is opened, it will be found to contain a small white maggot, the larva of a little insect called the weevil. If the gall and its tenant being removed, the plant is placed again in the earth, where it is to remain, unless it is again attacked, the wound usually heals, and the growth is but little retarded. On the other hand, if the gall is left undisturbed, the maggot continues to feed upon the alburnum or young woody part of the stem, until the period arrives for its passing into the other insect form, previously to which it gnaws its way out through the exterior bark. 'The disease is now almost beyond the power of remedies. The gall, increased in size, encircles the whole stem: the alburnum being so extensively destroyed, prevents the sap ascending; consequently, in dry weather, sufficient moisture is not supplied from the roots 
to counterbalance the transpiration of the leaves, and the diseased is very discernible amongst its healthy companions, by its pallid hue and flagging foliage. The disease now makes rapid progress, the swelling continues to increase, for the ressels of the alburnum and the bark continue to afford their juices faster than they can be conveyed away; moisture and air are admitted to the interior of the excrescence through the perforation made by the maggot; the wounded ressels ulcerate: putrefaction supervenes, and death concludes the stinted existence of the miserable plant. The tumour usually attains the size of a large hen's egg; has a rugged, ichorous, and even mouldy surface, smelling strong and offensively. The fibrous roots, besides being.generally thickened, are distorted and monstrous from swellings, that appear throughout their length, and which apparently arise from an effort of nature to form receptacles for the sap, deprived as it is of its natural spissation in the leaves. These swellings do not seem to arise immediately from the attacks of the weevil; for I have never observed them containing its larva.

Mr. Marshall very correctly describes the form which this disease assumes when it attacks the turnip. It is a large excrescence appearing below the bulb; growing to the size of botl hands, and as soon as the hard weather sets in, or it is by its own 
nature brought to maturity, becoming putrid, and smelling very offensively. On the last day of August, when the bulbs of the tumips were about the size of walnuts in the husk, the amburies were as big as a goose's egg. These were irregular and uncouth in their form, with inferior excrescences, resembling the races of ginger, hanging to them. On cutting them, their general appearance is that of a hard turnip; but on examining them through a magnifier, there are reins or string-like ressels, dispersed amongst the pulp. The smell and taste somewhat resemble those of turnips, but without their mildness, having an austere and somewhat disagreeable flavour resembling that of an old stringy turnip. The tops of those much affected turn yellow, and flag with the heat of the sun, so that, in the day-time, they are obriously distinguishable from those that are healthy. These distortions manifest themselves very early in the turnip's growth, even before the rough leaf is much developed. Observation seems to hare ascertained, that if the bulbs have attained the size of a walnut unaffected, they do not subsequently become diseased.

Mr. Spencer has already shewn, from established facts, that the ambury does not arise from any imperfection of the seed somn; for experience demonstrates, that, in the same field and crop, the attacks are very partial; and crops in two adjoining fields, 
sown with seed from the same growth, will one be diseased and the other healthy.

Secondly, It does not arise from an unfavourable time of sowing, or from dry unpropitious seasons during their aftergrowth; "for, on this supposition, we might expect that in all turnip districts the disease would occasionally make its appearance, in consequence of rariations in the period and mode of sowing, or from following droughts; jet we know that in many parts of the country it has never been heard of."

Thirdly, It does not arise from the quality of the soil ; for Sir Joseph Banks suffered from its infecting thin stapled sandy fields, whilst all Holderness, which is generally a strong loamy soil, was found equally liable to the disease. But a still more decisive evidence on this point is, that it makes its appearance at uncertain intervals upon the same soil ; the turnips upon it being in some jears greatly injured by the disease, and in other years entirely free.

Fourthly, Although it is certain from the observations of Sir Joseph Banks, and from general experience, that the disease occurs most frequently in soils tired of the crop, that is soils upon which it has been grown for a long course of years; yet, that this is not the immediate cause of the disease is proved by the fact, that often only patches in the same field are 
affected; and the same observers record, that it appears in soils that have not produced turnips for a long series of years. The diseased specimens examined by Mr. Marshall, were from an old orchard that had not borne turnips within the memory of man.

Mr. Spence concluded, that the disease is occasioned by the poisonous wound inflicted by some unascertained insect upon the turnip in an early stage of vegetation, or by its insinuating its egg into it, infusing at the same time a liquid, causing a morbid action in the sap ressels, and the consequent forming of excrescences. This correct opinion was afterwards confirmed by the actual discovery of the insect, and that there actually is a maggot generated from the egg, of which fact, at the time, he was entirely ignorant.

The maggot found in the turnip ambury, is the larva of a weevil called Curculio pleurostigma by Marsham, and Rhynchcenus sulcicollis by Gyllenhal. "I have bred this species of weevil " says Mr. Kirby, "from the knob-like galls on turnips, called the ambury, and I have little doubt that the same insects, or a species allied to them, canse the clubbing of the roots of cabbages ${ }^{2}$.

Marsham describes the parent as a cleopterous insect, of a dusky black colour, with the breast

${ }^{2}$ Kirby and Spence's Introduction to Entomology, i. 450. 
spotted with white, and the length of the body one line and two-thirds ${ }^{a}$.

The general experience of all the farmers and gardeners with whom I have conversed upon the subject, testified that the ambury of the turnip and cabbage usually attacks these crops when grown for successive years on the same soil. This is precisely what might be expected; for the parent insect always deposits her eggs in those situations where her progeny will find their appropriate food; and in the fragments of the roots of preceding crops, some of these embryo ravagers are to be expected. That they never attack the plants upon a fresh site is not asserted. Mr. Marshall's statement is evidence to the contrary; but it is advanced that the obnoxious weeril is most frequently to be observed in soils where the turnip, or cabbage, has recently and repeatedly been cultivated.

a He adds, subtus albido squamosus; inter thoracem et elytrorum basin puncto albo pectus notatur. Thorax utrinque obsoletè dentatus, postice et anticè fossulâ intermediâ exaratur. Femora omnia denticulata. Entomologia Brit. 282. A rery full description of this insect is in the "Insecta Suecica Descripta" of Gyllenhal, vol. iii. p. 229, under the name of Phynchonus sulcicollis. It is the Curculio affinis of Panzer's Faunæ Insectorum Germanicæ initia; the Curculio sulcicollis in Paykull's Suecica, the Falciger sulcicollis of De Jean's Catalogue des Cleoptères; and the Cryptorhynchus alanda of Germar's Insectorum species novæ, \&c. 
Another general result of experience is, that the ambury is most frequently observed in dry seasons. This is also what might be anticipated, for insects that inhabit the earth, just beneath its surface, are always restricted and checked in their movements by its abounding in moisture. Moreover, the plants actually affected by the ambury, are more able to contend against the injury inflicted by the larva of the weevil by the same copious supply. The developement of their parts, their growth, is more rapid; consequently the maggot has not to extend its ravages so extensively in search of food, as in drier seasons, when the stem is less juicy, and of smaller growth. In wet periods also the affected plants shew less the extent of the injury they have sustained; for their foliage does not flag, because their transpirations of watery particles are less, and their supply of nutriment from the soil is more free. In wet seasons I have, in a very few instances, known an infected cabbage plant produce fresh healthy roots above the swelling of the ambury.

These facts, being premised, better qualify us for the consideration of the best modes of preventing the occurrence of the disease and palliating its attacks. It is apparent that any addition to the soil that renders it disagreeable to the weevil, will prevent the visits of this insect. The gardener has 
this in his power with but little difficulty, for he can keep the ricinity of his cabbage, cauliflower, and brocoli plants soaked with water.

Mr. Smith, gardener to M. Bell, Esq., of Woolsington, in Northumberland, expresses his conviction after several years' experience, that charcoal-dust, spread about half an inch deep upon the surface, and just mixed with it by the point of a spade, effectually prevents the occurrence of this disease ${ }^{a}$. That this would be the case we might have surmised from analogy, for charcoal-dust is offensive to many insects; and is one of the most powerful preventives of putrefaction known. Soot, I have reason to believe, from a slight experience, is as effectual as charcoal dust. Judging from theoretical reasons, we might conclude that it would be more specifical, for in addition to its being like charcoal, finely divided carbon, it contains sulphur, to which insects have also a great antipathy.

Mr. Drurey, a practical farmer at Erpingham, in Norfolk, considered marl a certain preventive of this disease. He and sereral other judicious farmers also thought that teathing, that is, giving sheep and cattle their green food, turnips, \&c., upon the barleystubbles intended for turnips as the succeeding crop, would cause the ambury b. It is rery evident

a Trans. of London Horticultural Soc. vi. art. 2.

b Jarshall's Rural Economy of Norfolk, ii. 33-35. 
that it would mix fragments with the soil that would be liable to contain the eggs of the weevil. The marl approved by Mr. Drurey is probably the calcareous marl which occurs at Thorp Market, in the hundred of North Erpingham; but as there is a slight doubt owing to the deficiency of accuracy in the statement, it affords me an opportunity to impress upon cultivators in general the great importance of employing more certain terms than they usually do. What can be more indefinite than the statement, that marl is a certain preventive of the ambury? For the very first question suggested to the reader's mind is, what marl is intended? Is it a chalky-marl, or a clay-marl? Is it a mixture of chalk and clay, or of chalk and silicious sand? for all these varieties of marl are known. The want of a correct nomenclature is one of the drawbacks and deficiencies checking the improving progress of the soil's cultivation. Few have ever thought much upon this point, and still smaller is the number who duly appreciate its importance. Yet it is an incontrovertible fact, that no art or science can advance rapidly until its technical terms are fixed, terse, expressive, and generally understood. Chemistry attained a greater aid to its adrancement by the introduction of its new nomenclature by Lavoisier, than by any series of discoveries that 
have since been made on its rapid and brilliant progress. If a sulphate, an acid, or a metal is mentioned, a chemist immediately has a definite idea of the nature and properties of the substance alluded to, but if a loam or marl is spoken of, would any two cultivators of the soil agree in their idea of what description of earthy compound was intended? To make it well understood, a long detail must be added, and nothing checks the imparting of knowledge more than the person capable of imparting it being conscious that he must define every term as he goes on, and that even then it is doubtful whether he shall succeed in making himself intelligible. The rery name (ambury) usually applied to the disease which is the subject of our present consideration, is another proof of the necessity of a reformed horticultural and agricultural nomenclature; for, in Suffolk, the same title is given to another disease, which merely affects the leares of the turnip.

Sir Joseph Banks, Mr. Baker, of Norfolk, and others, agree that marl is the best preventive of ambury, and another evidence of the efficacy of applications to the soil, is afforded by a gentleman in Holderness, a Mr. Brigham, who had a highly manured clayey ridge, which he had levelled the year before, and which grew turnips entirely free from the disease, whilst, in the natural rich loam of the field, they were much infected. 
Francis Constable, Esq., of Burton Constable, had a field that had been in grass twenty years: this he pared, burned, and sowred with turnips, obtaining a crop perfectly free from the disease. Two white crops were then taken, after which turnips were again sown; and a considerable portion of the crop was then infected a.

I have myself tried the efficacy of common salt in preventing the occurrence of this disease. Its tendency to keep the soil moist, and to irritate the animal frame, certainly checks the inroads of the weevil, and its generally beneficial effects as a manure enables the plants better to sustain themselves under the reakening influence of the disease; but it is not a decisive preventive. The following results of one of my experiments was read to the Horticultural Society of London, October 16, 1821 :-

"Some cauliflowers were planted in a light siliceous soil, which had previously been manured with well putrefied stable manure; and over one-third of the allotted space was sown salt, at the rate of twenty bushels per acre; immediately before the planting, in the beginning of July, 1821, the previous crop had been brocoli; fifty-four plants were set on the two-thirds unsalted, and twenty-six on the one-third salted; the result has been, that of the fifty-four un-

${ }^{a}$ Spence's Observations on the Disease in Turnips, termed in Holderness, "Fingers and Toes." 
salted, fifteen have been diseased and unproductive, but of the twenty-six salted, only two.

"Some more cauliflowers were planted on a plot of ground which had previously borne a crop of saroys, and half of which ground had been sown with salt four months previous to planting; in this the unsalted and the salted were alike nearly destroyed, evincing that the salt was not present in a sufficient proportion to produce the desired effect.

"With regard to the use of salt as a cure for the disease, I am inclined to think, from the results of experiments which I have instituted, that unless the salt be applied very early it would be useless, for the root soon becomes so diseased as to be entirely past recovery." a

I have a strong opinion that a slight dressing of the surface soil, with a little of the dry hydro-sulphuret of lime, that may be now obtained so readily from the gas-works introduced through England, would prevent the occurrence of the disease, by driving the weevils from the soil. It would, probably, as effectually banish the turnip-fly or flea, if sprinkled over the surface immediately after the seed is sown. I entertain this opinion of its efficacy in preventing the occurrence of the ambury, from an instance when it was applied to some brocoli, ignorantly grown upon a bed, where cabbages had as

a C. W. Johnson's Essay on Salt, p. 136. 
ignorantly been endeavoured to be produced in successive crops. These had invariably failed, from the occurrence of the ambury; but the brocoli was uninfected. The only cause for this escape that I could trace was, that just previously to planting, a little of the hydro-sulphuret of lime had been dug in. This is a very fetid, powerful compound. Where dry lime purifiers are employed at gas works, it may be obtained in the state of a dry powder; but where a liquid mixture of lime and water is employed, the hydro-sulphuret can only be had as a thick cream. Of the dry hydro-sulphuret, I recommend eight bushels per acre to be spread regularly by hand upon the surface, after the turnip seed is sown, and before harrowing. If the liquid is employed, I recommend thirty gallons of it to be mised with a sufficient quantity of earth or ashes, to enable it to be spread over an acre in a similar manner.

For cabbages, twelve bushels or forty-seven gallons per acre, would not, probably, be too much, spread upon the surface, and turned in with the spade or last ploughing. To effect the banishment of the turnip flea, I should like a trial to be made of six or eight bushels of the dry, or from twenty-two to twenty-eight gallons of the liquid hydro-sulphuret being spread over the surface, immediately after the sowing, harrowing and rolling are finished. Although 
I specify these quantities as those I calculate to be the most correct, yet in all experiments it is best to try various proportions. Three or four bushels may be found sufficient, perhaps twelve, or even twenty may not be too much.

Frequent hoeing has been recommended as a preventive of this disease; but I believe this to be unsustained by either reason or practice. Hoeing, like any other stirring of the surface soil, assists the admission of the atmosphere to the incumbent plants, and so far promotes their general health; but I have never yet found, or even heard any one adrance, that a frequently hoed part of a crop was free from the ambury, which affected the more rarely hoed portion.

It would be fortunate if our white turnip crops could be sown as early as our Swedes, for they wonld then, probally, be as little liable to the ambury as these are. The reason of this seems to be, that the weevil does not emerge into that state in which it is capable of injuring the young plants until the summer is far adranced, and by that time the Swedish turnips have attained a size which secures their safety. I conclude this to be the case from my own slight, very slight, observations upon the habits of the insect; for, unfortunately, we are very deficient in knowledge upon this point. It is to be regretted, that entomologists are not more attentive to what may be termed the private and particular history of 
their study. 'To define and describe their specific characters is very useful; but it is chiefly so, because it is like a good index to an intricate volume. It is of far more utility to ascertain their habits, and their periods of gestation and transformation, because such knowledge is that which often affords us one of the best means of avoiding their ravages.

In cabbages, the ambury may usually be avoided by frequent transplantings, for this enables the workman to remove the excrescences upon their first appearance, and renders the plants altogether more robust and ligneous; the plant, in its tender, sappy stage of growth, being most open to the insect's attacks.

The sap of the turnip and cabbage thus diseased undergoes a considerable change. Its specific gravity is much increased, arising from an excess of mucilage, vegetable extract, and saline constituents, which it maturally contains, caused probably by its heing in a concentrated state; for it is very considerably reduced in quantity, compared with what the same plant contains when healthy. The increase of the saline components unquestionably exasperates the disease. They consist chiefly of chloride and (arbonate of potass, which, by the corroding power of the last-named, and the irritating qualities of both, must increase the sanious discharge, by stimulating the already lacerated and morbidly sensitive ressels. 
Probably the occasional application of diluted acids, such as the dregs of beer, would mitigate the symptoms, and check the progress of the ulceration; but the application could not be expected to effect a cure, nor is it available, even if proved to be a specific.

The warts or galls that may so frequently be 110 ticed on the bulbs of turnips, must not be mistaken for the ambury in a mitigated form. If these are opened, they will usually be found to contain a yellowish maggot, the larra, probably, of some species of cynips. This insect deposits its eggs in the tumip when of larger growth than that when it is attacked by the weevil, and the regetable, consequently, suffers less from the injury; but from slight observations, I am inclined to conclude, that the turnips thus infested suffer most from the frosts of winter, anil are the earliest in decay. This is what might be anticipated; for when the maggot has escaped from its cell, the hollow of this admits the exterior air to the wounded vessels, and forms a reservoir for moisture, agents which promote the progress of putrefaction, and assist the penetrating influence of the freezing temperature.

Canker. Whatever may be the disease under which a plant is suffering, it is too usual for the cultivator to confine his attention to the part immediately affected. It is looked upon as a strictly local derangement, and the remedies are as erroneously topical. 
To consider that because a bud, a branch, or a root is diseased, that the canse of the disorder is to be sought for there, is as sensible as to suppose that every local pain endured by the human frame arises from a disorganization of that part. On the contrary, we know that the diseases of animals arise almost universally from the stomach; and, as Addison remarked, "that physic is generally the substitute for temperance or exercise." The functions of the stomach, by whatever cause deranged, render digestion imperfect, and the secretions defective; the lile is superabumdant or deficient in quantity, and head-ache is the result; the liver is diseased, and it (auses a pain the most acute between the shoulders; the blood is ill elaborated, and eruptions are thrown out on the surface of the body. With plants it is the same. It may be laid down as an axiom, without exception, that all regetable diseases, unpreceded by external injury, arise from the unhealthy state of the sap-a state brought about conjointly or separately by the improper food imbibed, and the deranged digestive power of the leaves and other organs. That this is so will not appear strange, when we reflect, that from the sap all parts of the plant are formed, and are continually increased in number and size. The solid substance of the wood, and the temporary tender blossoms are alike extracted from that circulating fluid. If the constituents for these 
are ranting, or if improper components are introduced, disease is the necessary consequence. Disease, which in jouth and manhood usually arises from intemperance and over-excitement, risits old age as a consequence of its decayed vital powers; and, "if the silver cord has not been loosed," or " the golden bowl broken" by the short-sighted indulgence of early years, man gradually declines into the grave, as the rital organs cease to perform their offices, because the limit of existence natural to his species has been attained. Some diseases peculiar to old age are prematurely induced in the usually rigorous period of life by licentious indulgences, individual or hereditary. Ossification of the vascular system is an example. In the regetable part of the creation, the canker or ulcer, to which our apple, pear, elm, and other trees are subject, is a somewhat parallel instance. This disease is accompanied by different symptoms, according to the species of the tree which it infects. In some of those whose true sap contains a considerable quantity of free acid, as in the genus Pyrus, it is rarely accompanied by any discharge. To this dry form of the disease it would be well to confine the term cantier, and to give it the scientific name of Gangrana sicca. In other trees, whose sap is characterized by abounding in astringent or mucilaginous constituents, it is usually attended by a sanious discharge. In such instances, it might 
strictly be designated ulcer, or Gangrana saniosa. This disease has a considerable resemblance to the tendency to ossification which appears in most aged animals, arising from their marked appetency to secrete the calcareous saline compounds that chiefly constitute their skeletons. The consequence is an enlargement of the joints, and ossification of the circulatory vessels and other parts, phenomena very analogous to those attending the cankering of trees. As in animals, this tendency is general throughout their system; but, as is observed by Mr. Knight, " like the mortification in the limbs of elderly people," it may be determined as to its point of attack, by the irritability of that part of the system. This disease commences with an enlargement of the vessels of the bark of a branch, or of the stem. This swelling invariably attends the disease, when it attacks the apple tree. In the pear the enlargement is less, yet is always present. In the elm and the oak sometimes no swelling occurs; and in the peach I do not recollect to have seen any. I have never observed the disease in the cherry tree, nor in any of the pine tribe. The swelling is soon communicated to the wood, which, if laid open to view on its first appearance, by the removal of the bark, exhibits no marks of disease beyond the mere unnatural enlargement. In the course of a few years, less in number in proportion to the advanced age of the tree, and the un- 
favourable circumstances under which it is vegetating, the swelling is greatly increased in size, and the alburnum has become extensively dead; the superincumbent bark cracks, rises in discoloured scales, and decays even more rapidly than the wood beneath. If the caries is upon a moderately-sized branch, the decay soon completely encircles it, extending through the whole alburnum and bark. The circulation of the sap being thus entirely prevented, all the parts above the disease necessarily perish. In the apple and the pear the disease is accompanied by scarcely any discharge; but in the elm this is very abundant. The only chemists who have examined these morbid products are Sir H. Dary and Vauquelin; the former's observations being confined to the fact, that he often found carbonate of lime on the edges of the canker in apple-trees ${ }^{\mathrm{a}}$.

Vauquelin has examined the sanies discharged from the canker of an elm with much more precision. $\mathrm{He}$ found this liquor nearly as transparent as water, sometimes slightly coloured, at other times a blackish brown, but always tasting acrid and saline. From this liquor a soft matter, insoluble in water, is deposited upon the sides of the ulcer. The bark over which the transparent sanies flows attains the appearance of chalk, becoming white, friable, crystalline, alkaline, and effervescent with acids. A

a Elements of Agric. Chemistry, 2nd ed. p. 246. 
magnifier exhibits the crystals in the forms of rhomboids and four sided prisms. When the liquid is dark coloured, the bark appears blackish, and seems as if coated with varnish. It sometimes is discharged in such quantities as to hang from the bark like stalactites. The matter of which these are composed is alkaline, soluble in water, and with acids effervesces. The analysis of this dark slimy matter shews it to be compounded of carbonate of potass and ulmin, a product peculiar to the elm. The white matter deposited round the canker was composed of-

Vegetable matter . . . $\quad 60.5$

Carbonate of potass . . 34.2

Carbonate of lime . . $\quad 5.0$

Carbonate of magnesia . $\quad 0.3$

100.0

Vauquelin calculated from the quantity of this white matter that was found about the canker of an elm, that $500 \mathrm{lb}$. weight of its wood must have been destroyed ${ }^{a}$. There is no doubt that such a discharge is deeply injurious to the tree, but the above learned chemist appears to have largely erred, for he calculated from a knowledge of the amount of the saline constituents in the healthy sap, whereas in its diseased state these are much and umnaturally increased. I once was of opinion, that this disease

a Annales de Chimie, xxi. 30. 
does not arise from a general diseased state of the tree, but that it is brought on by some bruise or injury, exasperated by an unhealthy sap consequent to an unfarourable soil, situation, and culture: but more extensive and more accurate examinations convince me that the disease is in the tree's system; that its juices are vitiated; and that disease will continue to break out independent of any external injury, so long as these juices continue peccant and unaltered. This conclusion will be justified, I think, by the preceding facts, as well as by those distributed through the following pages.

The disease is not strictly confined to any particular period of the tree's age. I have repeatedly noticed it in some of our lately introduced rarieties that have not been grafted more than five or six years; and a writer in the Gardener's Magazine, rol. v. p. 3, states, that the trees in his orchard, though " only of four years' growth, are sadly troubled with the canker." Although young trees are liable to this disease, yet their old age is the period of existence most obnoxious to its attacks. It must be remembered, that that is not consequently a young tree which is lately grafted. If the tree from which the scion was taken be an old variety, it is only the multiplication of an aged individual. The scion may for a few years exhibit signs of increased rigour, owing to the extra stimulus of the more abundant 
quantity of healthy sap supplied by the stock; but the vessels of the scion will, after the lapse of that period, gradually become as decrepid as the parent tree. The unanimous experience of naturalists agrees in testifying that every organized creature has its limit of existence. In plants it varies from the scanty period of a few months, to the long expanse of as many centuries; but of all, the days are numbered; and although the gardener's,' like the physician's skill, may retard the onward pace of death, he will not be permanently delayed. In the last periods of life, plants shew every symptom that accompanies organization in old age,- -not only a cessation of growth, but a decay of former developement, a languid circulation, and diseased organs.

The canker, as already observed, attends especially the old age of some fruit trees, and of these the apple is most remarkably a sufferer. "I do not mean" says Mr. Knight, "to assert that there ever was a time when an apple tree did not canker on unfavourable soils, or that highly cultivated rarieties were not more subject to the disease than others, where the soil did not suit them. But I assert, from my own experience and observation within the last twenty years, that this disease becomes progressively more fatal to each variety, as the age of that variety, beyond a certain period, increases: that if an old worn-out orchard be replanted with fruit trees, 
the varieties of the apple which I have found in the catalogues of the middle of the seventeenth century, are unproductive of fruit, and in a state of debility and decay." a

Among the individuals particularly liable to be infected, are those which have been marked by an excessively vigorous growth in their early years. I had one in my garden at Great Totham, which for the first twelve years of its existence was remarkable for the unnaturally large size and abundance of its annual shoots. It then became grierously affected by canker which at length destroyed it.

Trees injudiciously pruned, or growing upon an ungenial soil, are more frequently attacked than those advancing under contrary circumstances. The oldest trees are always the first attacked of those similarly cultivated. The golden pippin, one of the oldest existing varieties of the apple, is more frequently and more seriously attacked than any other.

The soil has a very considerable influence in inducing the disease. If the subsoil be a ferruginous gravel, or if it is not well drained, and the soil be aluminous, and effective means are not adopted to free it of superabundant moisture-the eanker, under any one of these circumstances, is almost certain to make appearance amongst the trees they sustain,

${ }^{\text {a }}$ Some doubts as to the Efficacy of Mr. Forsyth's Plaster, by T. A. Knight, Esq. P. L. H. S., \&c., 1802. 
however young and rigorous they were when first planted.

How inductive of this disease is a wet retentive subsoil, if the roots penetrate it, appears from the statement of Mr. Watts, gardener to R. G. Pussell, Esq., of Chequer's Court, in Buckinghamshire. A border beneatle a south wall had a soil three feet and a half in depth, apparently of the most fertile staple, twice re-made under the direction of the late Mr. Lee, of the Vineyard, Hammersmith. In this the trees, peaches and nectarines, flourish for the next three or four years after they are planted, but are then rapidly destroyed by the canker and gum. The subsoil is a stiff sour clay, nearly approaching to a brick earth; and the disease occurs as soon as it is reached by the roots of the treesa. Mr. Forsyth concluded that the soil is not always the source of the disease, because it universally and invariably appears at first in the branches, and proceeds thence towards the roots of the tree. But this is certainly not a conclusion warranted by the premises, because the acridity of the sap, whatever may be its source, would be likely to injure and corrode, in the first instance, those parts where the vessels are the most weak and tender; now these, past dispute, are in the branches. Moreorer, we generally see the youngest branches the earliest sufferers.

${ }^{2}$ Gardener's Magazine, vi. $61 \%$. 
Pruning has a powerful influence in preventing the occurrence of the canker. I remember a standard russet apple tree, of not more than twenty years' growth, with a redundancy of ill-arranged branches, that was excessively attacked by this disease. I had two of its three main branches and the laterals of that remaining carefully thinned; all the infected parts being at the same time removed. The result was a total cure. The branches were annually regulated, and for six years the disease never reappeared. At the end of that time the tree had to be remored, as the ground it stood upon was required for another purpose. John Williams, Esq. of Pitmaston, from long experience, concludes that the golden pippin and other apples may be preserved from this disease, by pruning away every year that part of each shoot which is not perfectly ripened. By pursuing this method for six years, he brought a dwarf golden pippin tree to be as vigorous and as free from canker as any new varietya.

All these facts unite in assuring us that the canker arises from the tree's reakness, from a deficiency in its vital energy, and consequent inability to imbibe and elaborate the nourishment necessary to sustain its frame in rigour, and much less to supply the healthy developement of new parts. It matters not whether its energy be broken down by an unnatural rapidity of growth, by a disproportioned excess

a Trans. London Horticu'tural Society, ri. Art. 61. 
of branches over the mass of roots, by old age, or by the disorganization of the roots in an ungenial soil; they render the tree incapable of extracting sufficient nourishment from the soil, consequently incapable of dereloping a sufficient foliage a, and therefore unable to digest and elaborate eren the scanty sap that is supplied to them.

The reason of the sap becoming unnaturally saline appears to be, that in proportion as the vigour of any regetable declines, it loses the power of selecting by its roots the nourishment congenial to its nature. M. Saussure found in his experiments, that the roots of plants, growing in saline solutions, absorbed the most of those salts that were injurious to them, evidently because the declining plant lost the sensitiveness and energy necessary to select and to reject.

M. Saussure also found, that, if the extremities of the roots were removed, the plants absorbed all solutions indiscriminately ${ }^{\mathrm{b}}$.

An ungenial soil would have a debilitating influence upon the roots in a proportionate, though less violent, degree than the sulphate of copper, and as these consequently would absorb soluble bodies more freely, and without that discrimination so absolutely necessary for a healthy regetation, so the other

a No symptoms of a cankered tree is more invariable than a deficiency of leaves.

- Saussure's Recherches Chimiques sur la Vegetation, 260. 
most essential organs of nutrition, the leares of the weakened plant, would promote and accelerate the disease. These, reduced in number and size, do not properly elaborate the sap; and I have always found that, under such circumstances, these stunted organs exhale the aqueous particles of the sap very abundantly, whilst their power of absorption is greatly reduced. The sap, thus deficient in quantity, and increased in acridity, seems to corrode, and affect the rascular system of the tree in the manner already described.

These facts afford us most important guides in attaining the desired objects, the prevention and cure of the disease.

If superluxuriance threaten its introduction, the best remedy is for the cultivator to remore one of the main roots of the tree, and to be particularly careful not to add any fertile addition to the soil within their range. On the contrary, it will be well if the continued exuberant growth shews its necessity for the staple of the soil to be reduced in fertility by the admixture of one less fertile, or even of drift sand.

If there be an excess of branches, the saw and the pruning knife must be gradually applied. It can be only trees of very weak vital powers, such as is the golden pippin, that will bear the general cutting of the annual shoots, as pursued by Mr. 
Williams. A new vigorous variety would exhaust itself, the following year, in the production of fresh wood. Nothing beyond a general rule for the pruning can be laid down, and it amounts to no more than the direction to keep a considerable vacancy between every branch, both above and beneath it; and especially to provide, that not even two twigs shall chafe against each other. The greater the intensity of light, and the freer the circulation of air amongst the foliage of a tree, the better the chance for its lealthy vegetation.

If the disease be in a fruit tree, it is probably a premature senility, induced by injudicious management, for very few of our varieties are of an age that insure to it decrepitude. I have never yet known a tree, unless it was in the last stage of decay, that could not be recovered by giving it more air and light, by careful heading in, pruning, improvement of the soil, and cleansing the bark.

If the soil by its ungenial character induces the disease, the obvious and only remedy is its amelioration, and if the subsoil be the cause of the mischief, the roots must be prevented striking into it. In all cases, it is the best practice to remove the tap-loot. Many orchardists pave beneath each tree with tiles and broken bricks. If the trees are planted shallowly, as they ought to be, and the surface of the soil kept duly fertile, there is not much 
danger of the roots striking into the worse pasturage of the subsoil. On this point, the experience of $\mathrm{Mr}$. W. Nichol, the gardener at Newick Place, in Sussex, agrees with my own. He says that the canker may be avoided in most instances by paying proper attention to the soil in which the tree is planted. Canker, he thinks, will seldom occur if the surfacesoil is good, for in that case the roots will never descend into the prejudicial subsoil, but spread out their radicles near the surface, where they find food most abundant. If this is not kept up, the roots descend into the obnoxious substratum, and the disease assuredly follows a.

It remains for me to detail the course of treatment that I have always found successful in effecting a cure in any rariety not decrepit from age, if the canker has not spread to the roots.

Having completely headed down, if the canker is generally prevalent, or duly thinned the branches, entirely removed every small one that is in the least degree diseased, and cut away the decayed parts of the larger, so as not to leave a single speck of the decayed wood, I cover over the surface of each wound with a mixture, whilst in a melted state, of equal parts tar and rosin, applying it with a

3 Barter's Library of Agric. and Hortic. Knowledge, 3rd Edit. 22. 
hrush immediately after the amputations have been performed, taking care to select a dry day. I prefer this to any composition with a basis of cow-dung and clay, because the latter is always more or less absorbent of moisture and is liable to injury ly rain and frost, causing alternations of moisture and dryness to the wounds, that promote decay rather than their healing, by the formation of new wood and hark. The resinous plaster seldom or never requires renewal. Mr. Forsyth, the arch advocate of earthy and alkaline plasters, finding that they promoter decar, if applied to the wounds of autumn-pruned trees, recommends this important act of cultivation to be postponed to the spring. Such a procrastination is always liable to defer the pruning until bleeding is the consequence. If a resinous plaster be employed, it excludes the wet, and obviates the objection to autumnal pruning. Mr. Forsyth's treatment of the trunks and branches of trees, namely, scraping from them all the scaly, dry exuvia of the bark, is to be adopted in every instance. He recommends them to be brushed over with a thin liquid compound of fresh cow-dung, soap-suds, and urine; but I very much prefer a brine of commons salt. Each acts as a gentle stimulus, which is their chief cause of benefit; and the latter is more efficacious in destroying insects, and does not, like the other, obstruct 
the respiratory ressels of the tree. The brine is advantageously rubbed in with a scrubbing, or large painter's brush. Some persons recommend a liquid wash, containing, as prominent ingredients, quicklime and rood ashes, which, as the disease arises from an over-alkalescent state of the sap, cannot but prove injurious, and aggravate the disease. Mr. Forsyth, formerly gardener at Kensington Palace, made a considerable sensation at the close of the last, and at the commencement of the present century, by the wonderful effects produced upon trees, as he asserted, by the following composition, used as a plaster over the wounds from which the decared or cankered parts had been cut out:-

One bushel of fresh cow dung.

Half a bushel of lime rubbish; that from ceilings of rooms is preferable, or powdered chalk.

Half a bushel of wood ashes.

One sixteenth of a bushel of sand; the three last to be sifted fine. The whole to be mixed and beaten together until they form a fine plaster ${ }^{a}$.

Mr. Finight, in a very able and sarcastic pamphlet published in 1802, entitled "Some Doubts relative to the Efficacy of Mr. Forsyth's Plaster," fully exposed the quackery, perhaps falsehood may not be too harsh a term, of this horticulturist's statements.

a Forsyth's Observations on Fruit Trees, p. 68. 
Mr. Forsyth received a parliamentary grant of money for his discovery; but this, as Mr. Tnight observes, "afiords a much better proof that he was paid for an important discovery than that he made one."

"Should the public," continues this distinguished physiologist, "believe that an old dying tree can be restored to youth and vigour, merely by being plastered with lime, cow-dung, and wood ashes, and that a piece of such tree may by such means be made immortal, I think it would be a good speculation for some enterprising genius, in imitation of the quack doctors of the sixteenth century. to bring forward a nostrum to restore and perpetuate youth in the human subject. Should such a projector join Mr. Forsyth, and the one undertake the animal, and the other the regetable world. under Dr. Anderson's patronage, I will venture to predict that the success of each in the cures they perform will be eciual."

It has been rely ingeniously suggested, that, if a destruction of the bark by external violence, and consequently, likely to terminate in canker, has occurred, it would be a good plan to insert, as in ludding, a piece of living bark, exactly corresponding to the excision, from a less valuable tree.

In conclusion, I would enforce upon the orchardist's attention the importance of ubtaining his 
grafts or buds from trees not affected by the disease, because, apparently, it is hereditary; and, although after-culture may eradicate the malady, it is always far better to aroid the infection than to have to employ a specific.

Haring noticed the gangrene as it appears in various forms upon our trees, we may now turn to a few of the many instances where it occurs to our fruits and flowers, for it is not too much to say that scarcely a cultivated plant is within our enclosures that is not liable to its inroads. It assumes different aspects, and varies as to the organs it assails, yet still in some mode and in some of their parts all occasionally suffer, for it is the most common form of vegetable disease.

The canker in the auricula is of this nature, being a rapidly spreading ulcer, which, destroying the whole texture of the plant where it occurs, prevents the rise of the sap. Some gardeners believe it to be infectious, and therefore destroy the specimen in which it occurs, unless it be very valuable; but this I believe to be an erroneous opinion, the reason of its appearing to be infectious or epidemic, being that it occurs to many when they are subjected to the same injurious treatment which gires birth to the disease.

It appears to be caused by the application of too much water, especially if combined with superabundant nourishment. Therefore, although cutting out 
the decaying part when it first appears, and applying to the wound some finely powdered charcoal, will effect a cure if the disease has not penetrated too deeply, yet it will be liable to return immediately if a less forcing mode of culture be not adopted. No auricula will suffer from this disease if it be shifted ammally. and the tap-root at the time of moving be shortened, a thorough system of draining being adopted, either by using one of the pots siggested in a previous part of this work, or by having the pot used one-fourth filled with pebbles; and excessive damp during the winter being prevented by proper shelter.

Parsley grown in a poor soil is also liable to cantier in the winter. Mr. Barnes says he never found any application which eradicated this disease so effectually as a mixture in equal parts of soot and slacked lime sown over the plants. The cure is complete in a few days, and the vigour of the plants restored, indicating that this species of ulceration, like that which is found in the dwellings of the poor, arises from deficient nourishment.

The spot, as it is technically termed, occurring on the leaves of the pelargonium, is a dry gangrene, occasioned by an irregularity in the supply of moisture, and ricissitudes of temperature, but especially if one of the extremes is much below the legree of heat most favourable to the healthy growth of that plant. The reason of this is very obvious. 
If a pelargonium, or any other plant, be placed in a highly stimulating heat, and is abundantly supplied with root-moisture, it immediately increases its surface of leaf to elaborate and digest the large amount of sap forwarded from the roots. If this amount of sap is subsequently suddenly reduced, by lowering the temperature and adding water to the soil less freely. the increased surface of leaf is no longer required, and it is a law pervading all the vegetable creation, that the moment any of the parts of a plant are unnecessary to it, that moment it begins to decay. I placed a plant of the Marvel of Peru, or Heliotrope, in a high temperature, and supplied it abundantly with water until its leaves were much increased in size ; the temperature and moisture were then much reduced, and the leaves in a few days were completely decayed round their edges and in spots upon their surfaces. The extent of leaf was accommodated to the amount of sap to be elaborated.

The tubers of the potato also are liable to the speck, black spot, or dry gangrene; a disease which I once thought was occasioned by the calcareous earth (lime, or chalk) contained by the soil, but more lengthened observation has convinced me of my error; and having observed it in all soils, and in seasons characterized by opposite extremes of wetness and dryness, I am induced to consider that the disease arises from some defect in the sets employed; 
or to potatoes being grown too often on the same site. It is quite certain from my own experience, that in ground tired of potatoes, the disease invariably and most extensively appears. This suggests that it is occasioned by a deficiency of some constituent in the soil required by the tubers, a suggestion confirmed by the fact that in the fields of the market gardeners near London, which are supplied without stint with the most fertilizing manure, this disease of the potato comparatively is unknown.

The stems of succulent plants, such as the cacti, mesembryanthemums, and the balsam, as well as the fruit of the cucumber and melon, and the stalk of the grape, are all liable to moist gangrene; all requiring for the developement of the disease excessive moisture in the air, though the immediate cause of its outbreak is usually a sudden reduction of temperature.

Extrarasated Sap. - Under this general name I purpose to include the consideration of gumming, bleeding, and other injurious affections under which plants occasionally labour, on account of their sap) escaping from the properly containing vessels. The extrarasation proceeds either from the alburnum or from the inner bark, and may arise from five causes: 1. The acrid or alkaline state of the sap, which has been considered already, when treating of the canker. 2. From plethora, or excessive abundance 
of the sap efinused. 3. From the unnatural contraction of the circulatory vessels. 4. From wounds. 5 . Heat and dryness.

1. With regard to the alkaline state of the sap, it may be observed, additionally, that the excessive alkaline quality of the sap, imparting to it the power of destroying the fibre of its containing ressels, is placed on the basis of chemical experiment. A weak alkaline solution dissolves woody fibre, without alteration; and it may be thrown down again by means of an acid. By this property we are enabled to separate wood from most of the other regetable principles, as few of them are soluble in weak alkaline leys ${ }^{3}$. It is true that the vital principle may counteract powerfully this chemical action; but it will not control the corrosive effect of an active agent in excess, if repeated for any length of time. The blood of the human system contains, when in a healthy state, a portion of common salt; yet if this saline constituent is in excess, it induces inflammation and organic derangement.

2. Plethora is that state of a plant's excessive vigour, in which the sap is formed more rapidly than the circulatory ressels can convey it away. When this occurs, rupture must take place; for the force with which it is propelled during circulation, and consequently, the force acting to burst the ressels

${ }^{3}$ Thomson's System of Chemistry, vol. iv. p. 180. 6th ed. 
during any check, is very much greater than could have been expected, before Mr. Hales demonstrated it by experiment. This distinguished vegetable physiologist found, that in the rine this force was able to raise $19 \mathrm{lbs}$. weight. To the stem of a vine cut off about two feet and a half from the ground, he fixed a mercurial gauge, and luted it to the sides of the stem with mastic. The gauge was in the form of a syphon, so contrived, that the mercury might be made to rise in proportion to the pressure of the ascending sap. In this instance it raised the mercury to a height of thirty-eight inches ${ }^{\text {a }}$. The branch of an apple-tree was separated from the parent trunk, and placed in water. When the leaves were upon it, the force with which it propelled its sap, raised the mercury four inches, in a tube attached as to the vine; but a similar branch, deprived of its leaves, scarcely raised the mercury a quarter of an inch. The pear, quince, cherry, walnut, peach, gooseberry, and sycamore, had a power equal to elevating the mercury, varying from three to six inches. The elm, the oak, chesnut, hazel, sallow, and ash, elevated it variously from one to two inches. The laurustinus, laurel, and other evergreens, scarcely raised the mercury at all b.

The experiments made with a separated branch do

a Hale's Teget. Statics, rol. i. p. 107.

b Ibid. p. 114, \&c. 
not give the full amount of the parent tree's power. because the exhaustion incident to amputation necessarily diminishes the vigour, and every minute the power in the branch is reduced, because it is so much the nearer to death.

Now we know that a much less pressure than any of those above mentioned would be capable of bursting the delicate membranes of any of their exterior descending sap vessels; and it is in such outer ducts that the injury first occurs. When one exterior vessel is ruptured, that next beneath it, having the supporting pressure removed, is enabled to follow the same course at the same locality; and in proportion to the length of the time that the sap continues in excess, is the depth to which the mischief extends, and the quantity of sap extravasated.

If the extravasation proceeds from this cause, there is but one course of treatment to be pursued: sever one of the main roots, to afford the tree immediate relief, and reduce the staple of the soil, by removing some of it, and admixing less fertile earthy components, as sand or chalk. This must be done gradually, for the fibrous roots that are suited for the collection of food from a fertile soil, are not at once adapted for the introsusception of that from a less abundant pasturage.

Care must be taken not to apply the above remedies, before it is clearly ascertained that the cause is 
not an unnatural contraction of the sap ressels-because, in such case, the treatinent might be injurious rather than beneficial. I have always found it arising from an excessive production of sap, if the tree, when afflicted by extravasation, produces at the same time superluxuriant shoots.

3. Local contraction of the sap ressels. If the extravasation arises from this cause, there is usually a swelling of the bark immediately above the place of discharge.

I had a cherry tree in my garden, in Essex, of which the stock grew very much less freely than the graft. Consequently, just above the place of union, a swelling, resembing a wen, extended round the whole girth of the tree, from which swelling, gum was continually exuding. In the stem below it I never observed a single extravasation. In a case such as this, the cultivator's only resource is to reduce cantiously the amount of branches, if the bleeding threatens to be injuriously extensive, otherwise it is of but little consequence, acting like temporary discharges of blood from the human frame. as a relief to the system.

4. The extravasation of the sap from a wound is usually the most abundant, and therefore the most cxhausting; and as the wound, whether contused or cut, is liable to be a lodgement for water and other foreign bodies, opposed to the healing of the 
injured part, the discharge is often protracted. This is especially the case, if the wound be made in the spring, before the leaves are developed, as in performing the winter pruning of the vine later than is proper. In such case the vine is always weakened, and in some instances it has been destroyed. The quantity of sap which may be made to flow from some trees is astonishing, especially in tropical climates. Thus from a cocoa-nut palm, from three to fire pints of sap will flow during every daty for four or five successive weeks.

The best mode of checking such exudations, is by placing a piece of sponge dipped in a solution of sulphate of iron, upon the discharging place, covering the sponge with a piece of sheet lead, and binding it on firmly. The sulphate acts as a styptic, promoting the contraction of the mouths of the vessels; the sponge encourages cicatrization, and the lear excludes moisture.

5. Heat, attended by dryness of the soil, as during the drought of summer, is very liable to produce au unnatural exudation. This is especially noticeable upon the leaves of some plants, and is popularly known as honey-dew. It is somewhat analogous to that out-burst of blood which, in such seasons, is apt to occur to man, and arises from the increased action of the secretory and circulatory systems to which it affords relief. There is this great and 
essential difference, that in the case of the plants the extravasation is upon the surface of the leaves, and consequently, in proportion to the abundance of the extruded sap is their respiration and digestion impaired.

Azaleas sometimes, but rarely, have the impubes. rence on their leares, especially on their lower surface, beaded as it were with a resinous exudation. This can scarcely be called a disease. It is never found but upon plants that have been kept in a temperature too high, and in a soil too fertile. It is an effort to relieve the surcharged ressels, and occurs in various forms in other plants.

The honey-dew was noticed by the ancients and is mentioned by Pliny a by the fanciful designation of the "sweat of the hearens," and the "saliva of the stars," though he questioned whether it is a deposition from the air, purging it from some contracted impurity. More modern philosophers have been quite as erroneous and discordant in their opinions relative to the disease s nature. Some, with the most unmitigatable asperity declare that it is the excrement of aphides: others as exclusively maintain that it is an atmospheric deposit; and a third party consider that it arises from bleeding consequent to the wounds of insects. That there may be a glutinous, saccharine liquid found upon the leaves of plants arising from

a Ifist. Natur. xi. 12. 
the first and third named causes is probable, or rather certain, but this is by no means conclusive that there is not a similar liquid extravasated upon the surface of the leaves, owing to some unhealthy action of their ressels. It is with this description of honey.dew that we are here concerned. The error into which writers on this subject appear to have fallen, consists in their having endearoured to assign the origin of every kind of honey-dew to the same cause. Thus the Rer. Gilbert White seems (Naturalist's Calendar, 144) to have had a fanciful and comprehensive mode of accounting for the origin of honey-dew : he tells us, "June 4, 1783. Vast honeydews this week. The reason of this seems to be, that in hot days the effluvia of flowers are drawn up by a brisk evaporation, and then in the night fall down with the dews with which they are entangled."

The oljection urged to this theory by Curtis (Trans. Linn. Soc. vi. 82) is conclusive. "If it fell from the atmosphere, it would cover every thing on which it fell indiscriminately, whereas we never find it but on certain living plants and trees; we find it also on plants in stoves and green-houses covered with glass."

Curtis had convinced himself that the honey-dew was merely the excrement of the aphides; and he supported his theory with his usual ability, although he justly deemed it a little "wonderful extraordinary," that any insect should secrete, as excrementi- 
tious matter, sugar,-he even thought it possible that if the ants, wasps, and flies, could be prevented from devouring the honey dew "almost as fast as it was deposited," to collect it in considerable quantities and convert it into the "choicest sugar and sugar candy." The bees, however, he found totally disregarded the honey dew which came under his observation. With the opinion of Mr. Curtis I do not agree, any more than does the Abbé Boissier de Sauvages, who, in a memoir read before the Society of Sciences, at Montpelier, gives an account of "a shower of honey-dew," which he witnessed under a lime tree in the King's garden at Paris.

The various successful applications of liquids to plants, in order to prevent the occurrence of the honey-dew, and similar diseases, would seem to indicate that a morbid state of the sap is the chief cause of the honey-dew, for otherwise it would be difficult to explain the reason why the use of a solution of common salt in water, applied to the soil in which a plant is growing, can prevent the appearance of a disease caused by insects. But if we admit that the irregular action of the sap is the cause of the disorder, then we can understand that a portion of salt introduced into the juices of the plant rould naturally have a tendency to correct or vary any morbid tendency, either correcting the too rapid secretion of sap, stimulating it in promoting its 
regular formation, or preserving its fluidity. And that, by such a treatment, the honey-dew may be entirely prevented, I have myself often witnessed in my own garden, when experimentalizing with totally different objects. Thus I have seen plants of various kinds which have been treated with a weak solution of common salt and water totally escape the honeydew, where trees of the same kind, growing in the same plot of ground, not so treated, have been materially injured by its ravages. I think, however, that the solution which has been sometimes employed for this purpose is much too strong for watering plants. I have always preferred a weaker liquid, and am of opinion that one ounce of salt (chloride of sodium) to a gallon of water is quite powerful enough for the intended purpose. I am in doubt as to the correctness of Knight's opinion as to the mere water having any material influence in the composition of such a remedy, since I have noticed that standard fruit trees, around which, at a distance of six or eight feet from the stem, I had deposited, at a depth of twelve inches, a quantity of salt to promote the general health and fruitfulness of the tree, according to the manner formerly adopted to some extent in the cyder counties for the apple orchards ; that these escaped the honey-dew (which infected adjacent trees) just as well as those which had been watered with salt and water. It is with much diffidence that I 
doubt the correctness of any of the opinions of such a man as the late lamented President of the Horticultural Society, for to him is vegetable phrsiology most deeply indebted for many highly scientific, arcurate, and interesting researches: he seemed, too, on all occasions, to introduce into his experiments an elegance of research and ingenious management, worthy of the great class of organized substances to which he devoted his raluable life. Will not something be done towards shewing the gratitude of his contemporaries? Cannot some nook be found at Westminster for his tablet? 


\section{CHAPTER IX.}

DEATH AND DECOMPOSITIOY.

As in the animal creation the period of life varies from a few hours in the ephemeron, to hundreds of years in the tortoise, so among the regetable tribes, though it is circumscribed to a few months in some of our annuals, yet it extends to centuries in the oak, the chestnut, and the adansonia. But however varied in space, each has its limit of existence; and death. though its inroad may be delayed, finally effects a conquest over all.

Now, what is the death of a plant:- -and though this query admits of the ready answer that it is a want of the porrer to regetate, though the requisites for vegetation are present-yet one question more difficult of solution follows upon this reply-what is that power of which death is the negation?-and although neither the chemist nor the physiologist have ever succeeded-probably never will succeedin penetrating further than to an acquaintance with the phenomena of that power, yet these we have already seen are intimately connected with the gardener's art, and the phenomena attending its absence are not less worthy of his study. 
The phenomena of that power-which is justly called regetable life-liave been traced in previous pages from germination through all the stages of growth, the developement of parts, the circulation of the sap, the mysteries of the impregnation and the maturing of the fruit; and we will now trace the phenomena of the plant's decline and final decar.

The first symptom of that decline is a deficiency of the usual annual developement of parts. A permanently lessened production of shoots, or leares, or fruit-or of all these-becomes apparent; and this non-production arises from a diminished power in the roots to imbibe, and of the ressels of the stem and branches to impel, the sap.

Thus Hales always found that the two, three, and four years' old branches of trees imbibed water with much greater force than those of greater age; and that young vigorous rines usually exuded their sap with much greater force than the older and less robust. So I have found that our annuals, such as the dwarf kidney bean, mignionette, clarkias, and others, imbibed water with more than twofold rapidity when in full bloom, than other plants of the same species and size did in the autumn, though they were still growing and rerdant.

Now, what is the cause of this deficient powerthis decline of vigour?-'To me there appears little 
doubt that it is the exhaustion consequent upon the production of seed. Scarcely an annual exists which usually dies at the close of the season, after ripening its seed, but may be made to retain a vigorous existence if its inflorescence be removed as speedily is formed. Mignionette is a very familiar example, for this may be allowed to bloom, but if its flower stalks be cut down before the seed-ressels are perfected, it becomes woody and shrubby, and will live and bloom for three or more successive jears. If allowed to ripen its seed, it dies the same autumn. The common nasturtium is an annual, but the double nasturtium, says M. De Candolle, has become a perennial, because its flowers, deprived of the faculty of producing seeds, do not exhaust the plant, and it is probable that erery annual, rendered double by cultivation, will become a perennial.

This explains why fruit trees are weakened, or rendered temporarily unproductive, and even killed, by being allowed to ripen too large a crop of fruit, or to "orerbear themselres," as it is emphatically termed by the gardener.

The thinning of fruit is, consequently, one of the most important operations of the garden, though one of the least generally practised. On the weaker branches of the nectarine and peach, an arerage space of nine inches should be between each brace of fruit, and on the most rigorous wood 
of the most healthy trees, they should not be nearer than six inches. This enforcement of the importance of thimning fruit, is not intended to be confined to the two trees specified; it is equally important to be attended to in all other fruit-bearers, but especially the vine, apricot, apple, and pear. It should be done with a bold, fearless hand-and the perfection of that which is allowed to remain will amply reward the grower in the harvest time for the apparent sacrifice now made. But he will not reap his reward only in this year; for the trees thus kept unweakened by orer-production, will be able to ripen their wood and deposit that store of inspissated sap in their vessels, so absolutely necessary for their fruitfulness next season.

The berries of the grape-vine are best thimned from the branches with a sharp-pointed pair of scissors, care being taken to remove the smallest berries. This increases the weight and excellence of the bunches, for two berries will always outweigh four grown on the same branchlet of a bunch, besides being far handsomer, and having more juice as compared with the skins. The average weight of the bunches on a vine may be taken, when ripe, at half a pound each, and with this data it is easy to carry into practice Mr. Clement Hoare's excellent rule for proportioning the crop to the size of the vine. 
If its stem, measured just above the ground, be three inches in circumference, it may bear five pounds weight of grapes.

$$
\begin{aligned}
& 3 \frac{1}{2} \text { inches . . . . } 10 \text { lbs. } \\
& 4 \text {. . . . . . } 15 \\
& 4 \frac{1}{2} \text {. . . . . . . . } 20 \\
& 5 \text {. . . . . . } 25
\end{aligned}
$$

And so five pounds additional for every half inch of increased circumference.

Although fruit bearing is the most influential curtailer of a plant's longevity, there are others of scarcely less fatal efficiency, among which are improper supplies of moisture, obnoxious soils, deleterious food, uncongenial temperatures, and deficient light. These all tend to shorten a plant's existence, or even at once to destroy it if administered in a violent or protracted degree.

Excessive moisture induces that over succulency which is ever attended by weakness, unnatural growth, and early decay. Such plants more than any others are sufferers by sudden vicissitudes, in the hygrometric state of the atmosphere, and are still more fatally risited if exposed to low reductions of temperature.

Soils containing obnoxious ingredients are certain introducers of disease and premature death. An excess of oxide of iron, as when the roots of the 
apple and pear get into an irony red, gravelly subsoil, always causes canker to supervene. In the neighbourhood of copper-smelting furnaces not only are cattle subjected to swollen joints, and other unusual diseases, causing decrepitude and death, but the plants also around are subject to sudden risitations-to irregular growths, and to unwarned destruction; and a crop once rigorous will suddenly wither as if swept orer by a blast. There is no doubt of this arising from the salts of copper which impregnate the soil irregularly as the winds may have borne them sublimed from the furnaces, and the experiments of Sennebier have shewn, that of all salts those of copper are the most fatal to plants.

That they can be poisoned, and by many of those substances, narcotic as well as corrosive, which are fatal to animals, has been shewn by the experiments of M. F. Marcet. The metallic poisons being absorbed are conveyed to the different parts of the plant, and alter or destroy its tissue. The regetable poisons, such as opium, strychnia, prussic acid, belladonna, alcohol, and oxalic acid, which act fatally upon the nerrous system of animals, also cause the death of plants. Does not this farour the opinion of those who believe that there is something in plants analogous to the nerves in animals? is the naturally suggested inquiry made 
by Dr. Thomson, the Glasgow Regius Professor of Chemistry.

The poisonous substance is absorbed into the plant's system, and proves injurious when merely applied to its branches or stem, almost as much as if placed in contact with the roots. Ulcerations and canker are exasperated if lime be put upon the wounds : and when Dr. Hales made a golden rennet apple tree absorb a quart of camphorated spirits of wine through one of its branches, one half of the tree was destroyed.

An uncongenial heat is as pernicious to regetables as to animals. Every plant has a particular temperature, without which its functions cease, but the majority of them luxuriate most in a climate of which the extreme temperatures do not much exceed $32^{\circ}$ and $90^{\circ}$. No seed will regetate, no sap will circulate, at a temperature at or below the freezing point of water, yet the juices of the plant are not congealed even at a temperature far more depressed, and I know of no other more satisfactory proof, that like a cold-blooded animal, the frog and the leech for example, it becomes torpid though life is not extinct, unless excited by a genial temperature. No cultiration will render plants, natires of the torrid zone, capable of bearing the rigours of our winters, although their offspring raised from seed may be 
rendered much more hardy than their parents. When a new plant arrives from such tropical latitudes, it is desirable to use every precaution to avoid its loss, but so soon as it has been propagated from, and the danger of such loss is remored, from that moment ought experiments to commence, to ascertain whether its acclimatization is attainable. That this should be done is self-evident; for the nearer such a desirable point can be attained, the cheaper will be its cultivation, and consequently the greater will be the number of those who will be able to derive pleasure from its growth. Hence, it is very desirable that an extended series of experiments should be instituted, to ascertain decisively whether many of our present green-house and stove plants would not endure exposure to our winters, if but slightly or not at all protected. It may be laid down as a rule, that all Japan plants will do so in the souther'n coast counties of England, but it remains unascertained to what degree of northern latitude in our islands this general power of endurance extends. "Foregone conclusions" should hare nothing to do with this matter. Experiment, and experiment only, ought to be relied upon; for we know that the larch was once kept in a green-house : and within these few months, such South American plants as Tropaoleum pentaphyllum and Gesnera 
Douglasii hare been found to survive our winters in our garden borders; the first in Scotland and Suffolk, and the second in Herefordshire ${ }^{a}$.

Another fact is, that many tropical plants of every order and species have been found to require much less heat, both during the day and during the night, than gardeners of a previous century believed. Other plants than those already noticed have passed from the tropics to our parterres, and even to those of higher northern latitudes. The horse chestnut is a native of the tropics, but it endures uninjured the stern climate of Sweden. Aucuba Japonica, Paonia Moutan, we all remember to have passed from our stores to the green-house, and now they are in our open gardens.

Every year renders us acquainted with instances of plants being acclimatized; and, in addition to those already noticed, we find that Mr. Buchan, Lord Bagot's gardener, at Blithfield House, in Staffordshire, has an old cinnamon tree (Laurus Cinnamonum) under his care, which ripens seed: from these many plants hare been raised that endure our winters in a conservatory without any artificial heat ${ }^{b}$. Then, again, there is no doubt that all the coniferce of Mexico, which flourish there at an eleration of more than 8000 feet abore the sea's lerel, will survive our winters in the open air.

a Gard. Chron. 824.

b Iond. Hort. Soc. Trans. 
Among these are Pinus Llareana, P. Teocote, P. patula, P. Hartwegii, Cupressus thurifera, Juniperus flaccida, Abies religiosa, and some others ${ }^{a}$.

Closely connected with the consideration of acclimatization of plants is the fact that they retain habits long after their removal to situations in which these habits are unsuitable. Thus the hyacinth, a native of Southern Asia, begins to shew symptoms of vegetation here in autumn, which answers to the spring of its long-left native clime. So the fuchsia, although it accommodates itself to our hemisphere, and submitting to remain dormant during the winter, will revive in the spring, yet the season during which it will grow most rigorously, if placed in a suitable temperature, is the wmter, for this is the spring-time of its native country, Chili. This. I consider, is the rationale of what Mr. Ayres justly calls the whole secret of fuchsia management ${ }^{b}$. It should be placed at the end of December, in a suitable temperature, and duly supplied with moisture and manure, and it will have attained a growth in April far larger than it would during twice the number of months, if the growth were not permitted to commence until the spring.

In the next place, let us consider what circumstances render a plant most liable to suffer from frost, and let it be observed once for all, that

${ }^{a}$ Gard. Chron. 315, sce.

b Gard. Chron. \$21. 
to aroid such circumstances, is by so much to render plants capable of enduring our climate.

First. Moisture renders a plant susceptible of cold. Every gardener knows this. If the air of his green-house be dry, the plants within may be submitted to a temperature of $3: 0$ without injury, provided the retum to a higher temperature be gradual.

Secondly. Gradual decrements of temperature are scarcely felt. A myrtle may be forced, and subsequently passed to the conservatory, cold pit, and even thence to an open border, if in the south of England, without enduring any injury from the cold of winter, but it would be killed if passed at once from the hot-house to the border.

Thirdly. The more saline are the juices of a plant, the less liable are they to congelation by frost. "Salt preserves vegetables from injury by sudden transitions in the temperature of the atmosphere. That salted soils freeze with more reluctance than before the salt is applied is well known, and that crops of turnips, cabbages, cauliflowers, \&c., are similarly preserved, is equally well established a.

Fourthly. Absence of motion enables plants to endure a lower degree of temperature. Water may be cooled down to below $32^{\circ}$ without freezing, but it solidifies the moment it is agitated.

${ }^{a}$ Cuthbert Johnson on Fertilizers, 381. 
Some plants like some animals are able to endure a very high degree of temperature. Sir Joseph Banks and others hare breathed for many minutes in an atmosphere hot enough to cook eggs, and I have myself travelled in Bengal breathing air without inconrenience, which rendered the silver mountings of my green spectacles too hot to be borne without their occasional remoral. So do certain plants flourish in hot water springs of which the temperature varies between the scalding heats of from $150^{\circ}$ to $180^{\circ}$ of Fahrenheit's thermometer, and others have been found growing freely on the edge of rolcanoes in an atmosphere heated above the boiling point of water. Incleed it is quite certain that most plants will better bear for a short time an elevated temperature which, if long continued, would destroy them, than they can a low temperature. Thus a temperature much above the freezing point of water to orchidaceous and other tropical plants is generally fatal if endured by them for only a few minutes, whereas a considerable elevation above a salutary temperature is rarely injurious to plants. But this is not universally the case, for the elegant Primula marginata is so impatient of heat, that although just about to bloom, it never opens a bud if lrought into a room in which there is a fire.

Plants, generally, have the power of preventing their sap attaining to the umnatural elevation of 
temperature of the atmosphere around them. This in some degree may depend upon the bark and wood being bad conductors of heat, but they have a power of resisting heat quite independent from that; for the pine apple, though growing for months in a minimum temperature of $60^{\circ}$, never has that of its flesh, whilst growing, elevated abore 50\%. Now the worst of conductors would have convered heat through them in that time. This is only analogous to what occurs in the animal economy. Sir Joseph Banks, Sir Charles Blagden, and Dr. Solander, in the case already alluded to, remained several minutes in a room heated to $212^{\circ}$, the boiling point of water. and though unpleasant sensations were produced, yet the air was easily borne, and the temperature of the body was very little elevated. If they breathed on the thermometer it sank several degrees; every expiration was cool to the nostrils, previously heated by the air inspired; the body felt cold as a corpse to the touch of the fingers, and the heat of the skin under the tongue was only 98. A dog was exposed to a temperature of $220^{\circ}$ for ten minutes, but its body's heat did not rise above $110^{\circ}$, being only nine degrees above its natural warmth. In these rooms an egg was cooked quite hard in twenty minutes.

But though plants have the power of preserving an internal temperature, differing from that of the external air in which they are regetating, yet they have 
no more power than have animals to escape from the injurious excitement occasioned by being compelled to live for any protracted time in a temperature uncongenially elerated. In such a temperature, youthful and growing animals are stimulated to an excessive rapidity of growth, so attenuating, that nothing but removal to a colder climate can preserve them from premature death; and the same phenomena attend upon plants. These, over-excited by heat, acquire rapidly an unnaturally elongated growth, attended by a weakness of texture, that hastens them to decay, unless checked by a gradual reduction of temperature. The roots in such a heat absorb water with unnatural rapidity, and this is commensurately hurried through the sap vessels of the stem and branches, so that the over watery sap arrives at the leaves much too fast for them to elaborate it sufficiently, though an extra effort is made by preternaturally enlarging the leaves. The water transpired is excessive, but very little carbonic acid is inhaled, and consequently the quantity of carbon assimilated is very deficient. The whole structure of the plant is therefore watery and weak; and if a supply of water to the roots is withheld but for a few hours, the leaves wither and shrivel past revival. These organs not only lose the power to decompose carbonic acid, but also to decompose water, though the light to which they are exposed be the brightest sunshine; and 
CH. IX.] DEATH AND DECOMPOSITION.

thus deficient of carbon and hydrogen, the chief constituents of their colouring matter, they become unnaturally pale.

It must not be omitted to be observed, that all plants have a great power to resist the reduction, as well as the elevation, of their internal temperature, however low may be that of the air which surrounds them. In the polar regions, and even in those of less northern latitudes, they have to endure a temperature ten and more degrees below the freezing point of water-yet their sap is never known to freeze. If water does congeal in the texture of a plant it rifts it, but this never occurs unless extraneous moisture has penetrated through some wound or decayed part. Ihave seen trees so torn, but never without finding a mass of ice within the trunk or branch traceable to some outward fissure. This is entirely in accordance with the the experiments of Mr. John Hunter; and other experiments which I have tried, confirm me in acceding to the conclusion to which that distinguished anatomist, as well as Sprengel, Schluber, and others have arrived, that the sap of healthy plants never congeals, however low the temperature to which they are exposed. Even in a temperature fifteen degrees below that at which the sap, if taken from the tree, would freeze, jet, in the living plant, it remains uncongealed. This has been tried upon the rine, walnut, elm, and red pine. 
These experiments also determine that plants have but a slight power of generating heat; for the thermometer, placed within their stems, in winter sinks gradually nearly to the temperature of the exterior air; and in the spring or summer, that instrument so placed does not follow implicity the atmospheric variations, but this is not merely because wood is a bad conductor of heat. It is erident that a living plant has the power of preventing the congelation of its juices, and it is impossible to account for this phenomenon without connecting it with the plant's vitality; and I see no reason for concluding that plants, differing from animals, do not, during their respiratory function, convert oxygen into carbonic acid, set free its latent heat. and thus preserve their temperature. It is beyond a doubt, that, by this chemical change, some plants at one period of their vegetation generate a considerable degree of heat. The stamens of Arum cordifolium emit so much heat at the time they shed their pollen. that twelve of them placed by M. Hubert round a thermometer raised the mercury from $79^{\circ}$ to $143^{\circ}$. Under similar circumstances, M. Sennebier obserred the stamens of the Arum maculatum were nearly $16^{\circ}$ hotter than the surrounding air. The flowers of Caladium pinnatifulum, when emitting a strong ammoniacal smell, were obserred by Dr. Schultz to be as hot as $81^{\circ}$, though the atmospheric temperature 
was but $61.25^{\circ}$. The stamens of the "Pompion, Bignonia radicans, and Polyanthus tuberosa have also been observed to elevate the mercury at the time of shedding their pollen, but in a much slighter degree. In every instance this evolution of heat is occasioned by a proportionate absorption of oxygen gas by the stamens and pistils at the instant of fecundation. The stamens of the Arum maculatum, for instance, have been shewn by MI. Saussure to absorb at that time 200 times their bulk of oxygen gas, converting it into carbonic acid. But, although some plants thus cause a great extrication of heat, and others are capable of resisting the greatest known cold to which they can be exposed, yet all have degrees of temperature most congenial to them, and if subjected to lower temperatures are less or more injured proportionately to the intensity of that reduction. If the reduction of temperature be only slightly below that which is congenial, it only causes the growth of the plant to diminish, and its colour to become more pale; this effect being now produced by the plant's torpidity or want of excitement to perform the requisite elaboration of the sap, as it is by over excitement when made to regetate in a temperature which is too elevated. If blossoms are produced at all, they are unfertile, and the entire aspect of the plant betrays that its secretions are not healthy, and its functions are deadened. Mr. Knight says, that 
melon and cucumber plants, if grown in a temperature too low, produce an excess of female blossoms; but if the temperature be too high, blossoms of the opposite sex are by far too profuse.

If a plant be frozen, and though some defy the attacks of frost, others are very liable to its fatal influence, death is bronght upon them as it is in the animal frame, by a complete breaking down of their tissue, their vessels are ruptured, and putrefaction supervenes with umusual rapidity. As already observed, when considering the means of acclimatizing plants, the more abundant is the water present in their vessels, the more apt are they to be injured by frosts, whence the young shoots are often destroyed, whilst the older branches remain uninjured, and crops on ill-drained soils suffer more sererely in winter than those where the drainage is more perfect.

Deficiency of light is auother contingency most influential in promoting the decline and death of plants. In proportion as they are deprived of this stimulus, they become mable to elaborate their juices, and, deficient in colour, weak, and of umatural height, they die prematurely, and decompose more rapidly than those whose fibres, more firm and robust, are less combined with an excess of watery sap.

Finally, the unhealthy vicissitudes to which plants, in common with all other organized forms, are ex- 
posed, inevitably bring upon them death; and it would be mere waste of time to argue against those physiologists who maintain that, in farourable circumstances, the life of plants may be prolonged indefinitely. Those who choose to surmise that some plants would endure throughout all time, if unfailingly preserved from all things offensive, and supplied without failure with all things agreeable, amuse themselves with imagining what would occur under circumstances of impossible attainment.

A plant must be subjected to unfarourable contingencies, and the greater the amount and frequency of their occurrence, the more speedily do they bring its life to a close-for the more do they aid chemical affinities in breaking down that resistance of their efforts, which is the chief characteristic of vitality.

So long as a plant lives, it triumphs over those affinities. Its roots overcome the affinity of the soil and take from it its moisture; its leares overcome the affinity of the atmosphere, and deprive it of the watery vapour it has in solution; the internal vessels orercome numerous affinities, and, by the decomposition of carbonic acid and water, perform within their simple tubes that which can only be effected by the chemist's most powerful agents. These triumphs orer chemical affinities-and that most characteristic of triumphs, its avoidance of pu- 
trefaction, endure in the same individual, often fur centuries of years; it is the most marked of the triumphs of vitality; its prime distinction as a creature, capable, for a time, of defying the laws which doom all organic matters to return to the dust from which they were created; for no sooner does that vitality cease, than the lieat, the moisture, and the gases which vitality compelled to minister to the plant's luxuriance and health, now triumph in their turn, and serve to destroy that form which they had aided to sustain.

That heat is necessary to putrefaction appears from the fact, that no regetable matter kept at the freezing temperature of water will decay. Adrantage of which is taken by the gardener occasionally to preserve his summer fruits and regetables in the ice-house; and apples, pears, and grapes are borne unchanged half round the globe in the ice ships which annually visit India from North America.

That dryness effectually prevents regetable putrefaction we see every day, in the fact, that our furniture does not decay; and the gardener knows that moisture is fatal to his stores in the fruitroom.

Putrefaction is also prevented by the exclusion of the atmospheric air, or if it proceeds, it is by very slow degrees. An example of this is familiarly presented in a very effective mode adopted to pre- 
serve green peas. These are put into dry glass bottles, and the bottles placed in water, then gradually made to boil. The chief part of the air is thus driven from the bottles and they are corked down tightly, and the cork rosined over whilst thus heated. What little oxygen remains in the bottles is absorbed by the peas, and these remain green and unaltered for months, requiring only the addition of a little soda to the water in which they are boiled, to be as tender nearly as when first gathered.

When a temperature of $45^{\circ}$, moisture, and atmospheric air occur to dead vegetable matters, they absorb large quantities of oxygen, evolving also an equal rolume of carbonic acid. If composed of carbon, hydrogen, and oxygen only, the fumes they emit are not offensive; but if, as in the case of onions and the cabbage tribe, they contain a considerable portion of azote, the smells emitted are disgusting.

As in all other instances where vegetable substances absorb oxygen gas in large quantities, much heat is evolved by them when putrefying; and advantage is taken of this by employing leaves, stable litter, and tan, as well known sources of heat in the gardener's forcing department.

When the putrefactive process of plants is completed, there remains a soft black mass, known as vegetable mould, or humus. One hundred parts of the humus of wheat straw have of extractive or 
apotheme, rather more than twenty-six parts, and the residue is lime, peroxide of iron, phosphate of lime, and carbonaceous matter. This apotheme is identical with the humic acid of Liebig, the ulmic acid of Braconnot, and the geic acid of Berzelius. It contains

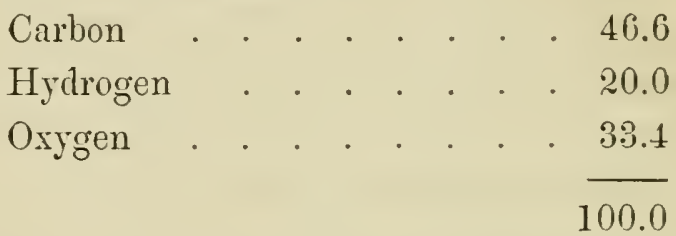

It was once believed, indeed is still believed, by a few men of science, that this apotheme is the immediate fertilizing component of organic manures, heing soluble under some circumstances, and entering at once into the roots of plants dissolved in the moisture of the soil. But every relative research of more modern chemistry is against this conclusion, and it is now tolerably certain that a chief nutritive portion of regetable manures are their carbon converted into carbonic acid, absorbed, either in solution with the earth's moisture, or in a gaseous form, by the roots. Apotheme is only one of the products formed during the progress of putrefaction, and is in its turn a source of carbonic acid. Carbonic acid has been long since shewn to be beneficial if applied to a plant's roots. It abounds in the sap of all vegetables, though this be drawn from 
their rery lowest parts, whereas apotheme is injurious to them if they are grown in a solution of it, and the minutest analyzers hare failed to detect it eren within the extreme ressels of roots.

Acids are antiseptic, and retard the decay of regetable matters, which explains why the woody fibre in peat soils remains so long unchanged, for those soils abound in gallic and other acids.

Alkalies, on the other hand, accelerate vegetable decomposition; and these being present in calcareous soils, is one reason that manures are sooner exhausted in them than in any other. Another reason for this rapid consumption is, that in calcareous and siliceous soils, the air easily penetrates, and the rapid progress of decay depends in a great measure upon the free access of oxygen gas. Such access is less easy to manures buried in clayey soils; and, as a consequence, manures in them are much more perrnanent.

Such is the progress, such the phenomena, attendant upon the death of plants; and but one more relative question remains for our consideration-Can death be arerted from plants? Can they be made, by man's devices, an exception to that decree of limited existence, which extends over all other organized creatures?

Those who assert that grafting completely renovates the scion, maintain the affirmative. From these I totally differ; for though it is happily true that 
grafting upon a young and rigorous stock imparts to the scion a supply of sap of which the parent stem is incapable, yet this failure is only premonitory of the departure of power which will, after a transient increase of strength, occur to its removed member. Every subsequent scion, howerer frequently. and whilst in apparent health, removed to another youthful stock. will be found to have a period of renewed vigour and productiveness of shorter duration than its predecessor. The golden pippin is occasionally quoted as a contrary proof: but this example has no such weight; for, supposing that this fruit yet exists, still it has not passed the age beyond which the period of unproductiveness and death in the apple-tree may be delayed by grafting; for we have no mention of this fruit that at all justifies the conclusion. that the golden pippin existed much more than three centuries ago. A pearmain apple is mentioned in records as old as King Joln (A. D. 1205); but the pippin is not noticed by any authority earlier than the reign of Henry the Eighth (1509). Lambard mentions that Tenham in Kent, famous for its cherrygardens and apple-orchards, was the place where Richarl Hiarris, or Haines, that king s fruiterer, first planted cherries, pippins, and the golden renate.

Supposing, then; that the golden pippin of our days is a genuine portion of the Tenham trees, handed down to us by successive graftings, yet still, 
though in extreme decrepitude, it has not exceeded the age assigned by naturalists as that beyond which the life of the apple does not extend. But then another question will arise, supnosing our golden pippin does appear to survive the allotted period.Who will undertake to demonstrate that the golden pippin of Tenham still exists? It is quite certain that a majority of the apples for which the title of golden pippin is claimed have no pretensions to the distinction, and more than one old person with whom it was once a farourite fruit now declare that it is no longer obtainable.

$\mathrm{Be}$ this as it may, eren if the tree in question has not already departed, yet even those who maintain that it is still to be found lingering in our fruit gardens, acknowledge that it is in the last stage of decrepitude and decay; it is following the universal law of nature, no organized creature shall endure through all time. Grafting may postpone the arrival of death, as the transfusion of blood will revive for a while the sinking animal, but the postponement cannot be for a time indefinite: the day must come in both the animal and the scion, when its vessels shall be without the energy to propel or to assimilate the vital fluid, though afforded to it from the most youthful and most vigorous source. 



\section{N D E X.}

Abroma augusta, 194

Absorbent power of soils, 63 power of manures, 101

Acacia lophanta, 17

Acclimatizing plants, 316

319

Acids antiseptic, 331

Acridity of sap, 281, 299

Adaptation to circumstances, 171

Adhesion of soils, 63

Agrostis, 119

Alburnum, 131

Alkalies promote putrefaction, 331

Alopecurus agrestis, 119

Alumina, 84

$$
\text { in soils, \&c., } 80
$$

Amaryllis formosissima, 192

Ammonia in rain, \&c., 31 from gas works, 35 formed during germina-

tion, 36

to roots, \&c., 105

Anæthum foniculum, 119

Angle for hot-house glass, 235

Animal manures, 91

Apocynum androssæmifolium, 105

Apotheme, 330

Apple, 213, 332

- trees, canker in, 284

A pricot, derivation of, 202

A renaria rubra, 120

Aristolochia clematis, 193

Artichoke, to enlarge, 166
Arum cordifolium, 324

- maculatum, 325

Association of plants, 54

Atmosphere, its components, 35

Auricula ulcers, 295

Autumn tints, 149

Azalea cross with rhododendron, 201

$\longrightarrow$, disease of, 301

Bachelor's buttons, 204

Backward soils, 85

Bacon, 4

Bark of plants, 125,127

Barren soils, characteristics of, 112

Beaton's theory of double flowers, 210

Bees honey-seeking, 193

Berberris vulgaris, 192

Berry, 213

Betula alba, 118, 127

Bignonia radicans, 325

Birch, 118, 127

Black grass, 119

Blackthorn-winter, 223

Blanching, 147

Blind cabbages, 184

Bones, 96

Borders, flooring, 181

Bottom-heat, 22

Brake, 113

Branches of plants, 125

Brine destroys moss, 129

Broad-leaved plants, soil for, 83 
Broad-leaved plants, water for, 75 Broom, 117

Budding, 165, 175

Buds, to promote, 167

_.., their convertibility, 206

Bulbous roots, 137

Burning weeds wasteful, $10 \mathrm{~S}$

Cabbages, blind, $1 £ 4$

Calyx, 185

- -, its use, 1ST

Cambium, 165

Canker, 27T

Capsule, 213

Carbon, abundant in seeds, 40

in plants, $\$ 2$

Carbonic acid beneficial to plants, $93,107,111$

erolved by the stem and branches, 130

_-... quantity consumed

by plants, 147

L exhaled by flowers,

190

red colours, 191

Carduus arrensis, $11 \mathrm{~s}$

Cellular integument, 12 T

Chalk, St

Charcoal, its ralue as fuel, 226

Charlock, 39

Chlorine promotes germination, 31 , 37

Cinnamon tree, $31 \tau$

Clay, 81

Clarer soils, why germination slow in, 46

Club-root, 137

Coal, relative ralue of, 225

--, its heating power, 226

Cnal-ashes, 18, 22, 107

Coffce, sced of, 9

Cold, to preserre plants from, 319

- plants can exclude, 323

Colour of soils, 18, 120
Colour of leaves, 135, $1 \pm 9$

- - of fiowers, 190

- - of fruit, consequences, 223

- - of walls, 223

Coltsfoot, 119

Compost, 109

Cone, 213

Coniferæ of Mexico, 317

Contortions, how cured, 132

Contraction of sap resscls, 302

Cooling, laws of, 218

Corn-mint, 119

Corolla, 185

--, its use, 1ST

Cortical layers, 128

Creeping roots, useful, $6 \mathrm{~S}$

- bent, 119

Crops affect different soils, $\$ 6$

Cross-breeding, 195

Cucunber blossoms, 325

Curl in potatoes, 256

Cuttings, 179

Death of plants, 309

Decline, symptoms of, 310

Decomposing matters absorb moisture, 56

Decomposition of dead plants, $30 \mathrm{~s}$

Depths for sowing, 39, 47

Digging, labour required by, 61

Dionæa muscipula, 104

Diseases of plants, 243

Double flowers most enduring, 1SS

$$
20 \mathrm{~S}
$$

to obtain, 199, 204, theory of, 210

Drainage, how nccessary, 30,71

D water, 123

Draining, expense of, 71

Drilling, 59

Drupe, 213

Dungs, \$9, 105

Early and late crops, soil for, $8 T$

Earths, their influence, 82 
Earth-worms, 79

Eleocharis crespitosa, 119

Elm, 117

- ulcerous discharge from, 281

Empedocles, 3

Endemics of plants, 254

Epidermis of plants, 125, $25 \pm$

Erica, 116

Etiolation, 147

Evergreens transpire little, 137

Excrements of plants, 52

Exercise of plants, 105

Exhalation, most when the air is agitated, 222

Experiments, how to try, 100

Extrarasated sap. 298

Fair maid of France, 204

Fallowing, $\overline{5} 3,60$

Female flowers, to produce, $326^{\circ}$

Fennel, 119

Fern, 113

Fertile soil, 82, 84

Filbert pruning, 175

Fingers and toes, 137

Fish as manure, 90

Flower, the, $18 \tilde{5}$

___ its organization, 156

___ its uses, $18 \mathrm{~T}$

_ ausorbs oxygen, 189

Flues, 228

Fogs, cause of, 24

— on undrained suil, 123

Food of plants, thuid, 68, 330

Fork preferable for digging, 62

Form of plants accommodated to circumstances, 171

Forsyth's plaster for trees, 293

Forward soils, 85

Freezing soils, its effect, $6 \bar{J}$

- plants, its effect, 326

Frost, to prevent its being injurious, 318

_- its effect on rose seed, 15
Frost, depth it penetrates, 20

Fruit, 212.

_ process of ripening, 214

_ influence of its colour, 22.23

_- influence of its skin, 224

- influence of moisture, 237

— why it cracks, 238 storing, 239

Fruitfulness, to promote, 166

Fuchsia growing, 315

Fuel, comparative value of, 225

-___ heating power of, 226 should be dry, 227

Full flowers, 204

Furze, 115

Gangræena sicca, 279

___ saniosa, 250

Gardening defined, 1

Gases applied to roots, 81

Gathering fruit, 239

Geic acid, 330.

Germination, essentials for, 8

- heat required, 13

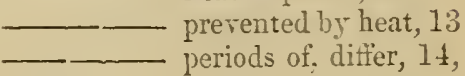

42

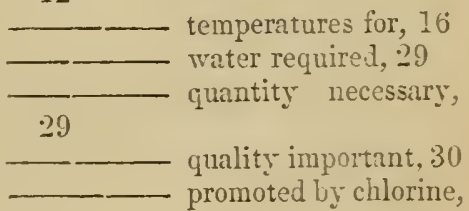

31

31

some liquids, 31

changes, 32 injured by some salts, does not occur in injured by sudden requires oxygen, 35 in the light, 11 not to be checked, 42

46 evolves carbonic acid, 
Glass should be double, 237

— why best to be used, 207

Golden pippin, 332

—- renate, 332

Gooseberries, to grow large, 238

Grafting, 176

—— to hasten fertility, 158

- wax, 175

$\frac{177}{17}$ not done indiscriminately, by the ancients, 177 on different organs 187 does it prolong life? 331

Grapes, shanking in, 298 thinning, 312

Grasses for sands, 68

Gravitation does not guide roots, 44 Grew, 4

Groundsel, 13

Growing time of plants, 164

Gum, 94

- its components, 215

Gypsum, 81, 96

Habits, plants acquire, 318

Haw thorn seed, 15

Heading down, its effects, 170

Heat, effects of its excess, 13,315 , 320,325

- effects of its reduction, 325

— endured by plants, 142,320

- plants have the power to exclude, 321

— plants produce, 324

— its radiation, 218

— required for germination, 13 ripening fruit, 218

the agent to arouse life, 16

Heaths, 116

Hedysarum gyrans, 105

Height of plants, how influenced, 132

Helleborus niger, 189

Hide-bound, 126

Hilum of seed, 42
Hoeing, 58, 64

Honey-dew, 303

Horse chestnut, 317

Hot-beds, cause of their heat, 329

Hot-houses, proper angle for their glass, 235

— why needed, 225 their ventilation, 145

Hot water for heating, 228

House plants, when to put out, 29

Humic acid, 330

Humus, 329

Hunt's pots, 72

Hyacinth, 318

Hybridizing, 195

- influence of parents in, 196 modes of, 197

Hybrids, parents of some, 204

Hydro-sulphuret of lime as a remedy, 273

Impregnation, 191

- symptoms of, 199

Inarching, 178 produces heat, 324

Insects aid impregnation, 193

- to destroy, 108, 128

Iron in soils, \&c., 81

Iry injures trees, 130

Japan plants will endure our climate, 316

Kidney beans, 9 .

- rule for sowing, 25

Knight (T. A.), 2, 6, 308

Knot-grass, 119

Lavoisier, 6

Leafing, time of, 27

Leaves, 135

___ absorb moisture, 144

cause of colour, 135

- influence of light oul, 135

their functions, 136 
Leaves, transpiration how influenced by, 139, $2 \$ 9$

_ - transpire water, 137

— to be cleansed, 139

140 their pores or stromates, absorb carbonic acid, 144 their colours in decay, 149 - direction, 151

170 in excess prerent flowers,

required by fruit, 178

- propagating by, 183

- expand, when light is deficient, 207

Legume, 213

Liber, 128

Life, regetable, what is, 309

conquers chemical affinities, $32 \pi$

- can it be prolonged indefinitely, 331

Light, influence on germination, 41 _- influence over colour, 135, 149

206,326

231 252

Lime, $71,108,109,110$

Lime in soils, \&c., 80

Magnesia in soils, \&c., 80 when injurious, 110

Male flowers, to produce, 325

Malpighi, 4

Manganese in soils, \&c., 81

Manures, why useful, 81,88 decay, 93

fresh, economical, 94

- how to try, 100
Manures absorb moisture, 101

- - retain moisture, 103

- rules for inserting, 43,87

stimulate plants, 104

vield gases, 106 destroy vermin, 108 promote decay, 109 influence a soil's tempera-

ture, 109

Marl, 111

Marvel of Peru, decay of its leares, 297

Medulla, 133

Melon seed, 9

blossoms, 326

Nentha piperita, 183 - arrensis, 119

Mexican coniferæ, 317

Mimosa sensitiva, 105

Mists, cause of, 24

- on undrained soil, 123

Moisture required by fruit, 237

- excessive, injurious, 313 renders a plant susceptible

of cold, 319

Morphology, 170, 206

Moss, to destroy, 129

Motion aids cold to be injurious, 319

Nules produced by intermixing species, 202

MInltiplicate-flowers, 205

Myrica-gale, 120

Nectarine thinning, 311

Nerves? Have plants, 314

Netting, why useful, 219

- which best, 220

Nettle, 117

Night temperature, 162

Nitrate of potass, 81

Nitrogen in seeds, 9,11 tion, 36

Nymphoa alba, 209 
()ak. 118

Oil injurious to trees, 12 ?

()ily secds, 12

Onions, soil for, 83

Ononis, 117

O vart, 212

Orer-production, its consequences, 311

Oxalis s॰nsitiva, 105

Oxide of iron, its effect on roots, 313

Oxycen required for germination, 35 41,45 proportions necessary, 36 , appli d to roots, 55

- moist earth absorbs, 55

- quantity alssorbed, $56^{\circ}$ absorbed by roots, 60 inhaled by the stem and branches, 130 essential to flowers, 189 quantity they absorh, 190

Packing seed, 33

Papaver rhneas, 120

Parenchyma, 127

Parsley seed, 14

—__ canker, 296

Parsnip, S7

Peach, stocks for, 15S, 161

- - thinning, 311

Pearmain, 332

Peas, early, 16

--_ to preserve, 328

Peat, its ralue as fuel, 226

- soil, 331

Peculiar juices, 165

Peirese, 4

Pelargonium spotting, 296

Peony seed, 15

Pericarp, 185, 212

Petals, 185

- - their use, 187

Phounix dactilifera, 191
Phospliate of lime, 97

Phrsiology, its progress, 4

Pistils, 185

Pith, 133

Plants, their nature, 245

constitusnts, $21 \%$

functions, 249

proofs of sensation in, 104,

252

Plethora in plants, 299

Poa annua, 13, 50

Pod, 213

Poisons, their effect on plants, 313

Pollen, 185

_- - its use, 192

- - quantity necessary, 199

- - time it continus good. 193

- - analysis of, 200

- - essential to fertility, 191

Polvanthus tuberosa, $32 \%$

Polygonum aviculare, 11:

Pome, 213

Pomona's ring, 16 -

Poppr, 120

Potato, autumin planting, 21

Potatoes, deprived of hlossom, 52

- ulcers in. 297

Pot-culture, 75

Potherbs, drying, 143

Pots, their form, 72

Primula marginata, 320

Proliferous tlowers, 205

Pruning, 174

Prunus, various species of, 201

Pteris aquilina, 113

Pulp, 127

Putrefaction, 327

- of manures, 92

- causes heat, 329

Pyrrhine in rain, 34 its requisites, 241)

Pythagoras, 3

Rabbits' urine, 117 
Radiation, to prevent, $21 \mathrm{~S}$

Rain water to be preferred, 33 - ammonia in, $3 t$

Rain in England, 81, 114

Raking, $4 \bar{\tau}, 6 \pm$

Rendles system of heating, 229

Rest-harrow, 11i

Retentire power of manures, 103

Rhododendron. cross with azalea, -201

Pice,, ?

Ridging, its beneits, $55,59,65$

Ring of Pomona, 167

Ripening wood, 132, 162

Ronm plants, their culture, 75

Rooms, their tmperature, $7 T$

Ronts, temperature they like, 22

23.73

_- effects of salts on, 30

why they descend, 43

- their duration, 49

_ - most abundant in poor soils,

50

- how to guide, 50

- - excess of, checks the production of seed, 52

- oxygen to, 55

- why to be near the surface,

$5 \mathrm{~S}$

- - their power of selection, 107

their extremities, 66

renewed annually, 67

their extent, 67

require a certain supply of

water, 74

a plant's own best, 155

- - to promote produce of, 167

Rosa perpetuosissima, 200

Rose, increasing its fragrance, 54

- seed 15

Rotation of crops, 53

Salt (common), 81, 109
Salt, as a remedy, $2-3,30-319$

Saltpetre, $\mathrm{SI}$

Salts as manures,,-5

- in plants, $9 \delta$

— when to be used, 90

— their effect on rosts. 30

Sand, St

Sandr soils, grasses for, $6 \varepsilon$

Sap, 152

- power with which it rises, 153,300

_- its elaboration, 154

- its descent, 15

- checking its return, 166

— required by fruit, 217

- checking its ascent, 217

— extravasated, 298

Saw-wort, 118

Scar of seed, 42

Science of Gardening, 2

Scion, how influenced by the stock, $151-160$

-___ and stock must be related, 17

Seedlings, time before they hear, 197

Seed-packing, 33

Seed-producing shortens the life of a plant, 49

Seed-ressel, its office, 214

Seeds, 212

- time they retain ritality, 9 , 11

- containing nitrogen, 9, 11

- oil, 1?

differ in excitability, 13

ing, 14 time of germinat-

- some bear great heat, 16

- their germination accele-

rated, 31 depths to bury, 39,47

abound with carbon, 40

why buried in the soil, 41

time germinating. 42

how fertilized, 191 
Seeds, sap they require, 217

- - ripening, 242

Sensation in plants, 104,252

Shanking of grapes, 24, 298

heltering, laws of, 218

Shoots, to promote, 167

Silica, 84

- - in soils, \&c., 80

Siliqua, 213

Skin of fruit, its influence, 224

Small-foliaged plants, soil for, 83

Smell of soil, 121

Smithia sensitiva, 105

Snow useful as a shelter, 221

Soil in pots, 78

-- poisonous components of, 313

- temperature of, 17

- influence of colour, 18

- - rate of heating, 18, 55 cooling, 19, 85

- depth it is frozen, 20

-- wet and cold, 24

- when moist absorbs oxygen, 55

stirring beneficial, 55,64

—— - how regulated, 57

_._- force required to dig, 63

63,122 with which it adheres,

-- composition, 82

- fertile, 82

- relation to moisture, 83

-- will not grow some crops, 86

- - for early and late crops, 87

- its soluble matters, 95 .

- - specific gravity, 121

- - smell, 121

- - feel, 122

Solandra grandiflora, 171

Soluble matter in soil, 95

Sowing, 8

_

- proper depths for, 39

rule for, 47
Spartium scoparium, 117

Spiked rush, 119

Spinach, soil for, 83

Specific gravity of soils, 121

- heat of water and air, 227

Speck in potatoes, 297

Spot in pelargonium, 296

Sprit, 120

Stable manure, its components, 89

Stamens, 185 absorb oxygen, 189

Standards produce best fruit, 133

Stean as a source of hent, 230

Steeping seed, 31, 111

Stem of plants, 125

- pores of the, 130

- absorbent, 130

_- not essential, 133

Stems, why they rise out of the soil, 45

Sterile soils, their characters, 112

Sterility, $\$ 6$

Stillness preserres a plant from injury by cold, 319

Stimulating manures, 104

Stock, its influence orer the scion, $154-160$

Storing fruit, 239

— room, 241

Strawberries, 53

Strobile, 213

Subsoils, 83

Sugar, 94

- - its formation, 215

Sulphate of lime, 81, 96

Sulphurous acid destroys colour of flowers, 191

Superfnetation, 200

Sweet-gale, 120

Synchronisms of nature, 25

Tank system of heating, 228

Tap-rooted regetables, to grow fine, 51 
Tartaric acid, its components, 215 Temperature for cuttings, 181

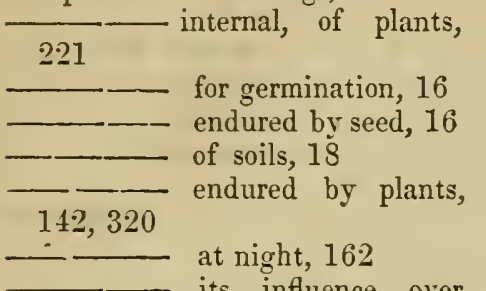
transpiration, 139, 164

Theophrasta latifolia, 183

Thinning fruit, its importance, 311

Tipula pennicornis, 194

Tobacco seed, 15

Training, 174 the sap, 217

Transformations, 173

Transpired matter, 198

that imbibed, 138 proportioned to decreases with the temperature, 139,164

the dryness of air, 141

Transplanting, its effects, 50

Trenching, 51, 58, 86

Tropical plants which endure our climate, 316

Truffle, 49

Tuberous roots, 137

Tulip pollen, 200

Turnip flea or fly, 273

- - warts, 277

Turnips secured from the Hy by - early sowing, 275

Tussilago farfara, 110
Ulcers, 279

_- - analysis of discharge from, 282

Ulex europæus, 115

Ulmus campestris, 117

Urtica urens, 117

Varieties, raising, 196

Vegetable manures, 91

- mould, 329

Ventilation, why needed, 145

Vine, increase of its leaves, 208

__ training vigorous, 217

- when it grows, 164

Vines, their roots when forced, 73

Viola tricolor, 192

Vital power of plants, 309-333

Wall fruit, sheltering, 219

Warts on turnips, 277

Water required for germination, 29

- quality important, 30,33

- not sole food of plants, 69 ,

81

- salts in, 70

313 not to be in excess, 70 ,

- whell to be applied, 74

Wax for budding and grafting, 175

Way-thistle, 118

White-washing, how injurious, 146

Wind, why cooling, 222

- _ - periodical, 223

Wood, its construction, 130

- promotion of its growth, 131

162

- promoting its ripening, 132 ,

- value of as fuel, 226

Woody fibre, 94

Wounds of plants, 302 


\section{PUBLISHED BY ROBEIT BALDTIN.}

GUIDE to the CONSEFVATORY; being a cuncise Treatise on the Hanagement of the Hot-house and Green-house; the Forcing of Bulbs, Shrubs, \&c.; and the best mode of keeping a succession of bloom through every month of the year; exemplified in a select list of the most admirable plants of the present day, under the arrangement both of Jussieu and Linnæus; including their native country, propagation, and the soil adapted to each. BY KICHARD BAINBRIDGE, Flower Gardener to the Right Hon. Lord Wenlock. From Notes of the Author's daily practice, and communications furnished by liberal eminent Floriculturists. In $12 \mathrm{mo}$, price 5s. cloth lettered.

** The peculiar characteristic of this work is the means of obtaining a constant and large supply of flowers. It includes a very extensive List of Orchidacea, with their cultivation as pursued by the most eminent practitioners.

A TREATISE ON MANURES; their Nature, Preparation, and Application; with a Description and Application of the most approved British Grasses. To which is added, a Miscellaneous Article on Farming, with an Estimate and Description of an Example Farm of 300 acres, illustrated with Plans of Farm Buildings. By JoHs Donalinson, Professor at the Agricultural College at Hoddesdon. In 8ro, price 12s. cloth.

\section{A GRANDMOTHER'S ADVICE to YOUNG} MOTHERS, on the Physical Education of Children. By M. J., late Countess of Mountcashell. A new Edition, Price 6s. cloth.

*** "This book is the proluction of many years' experience, and much reflection; and the Author trusts that it will be of use to those for whom it is designed-the anxious mother, the attentive governess, and the careful nurse."Preface.

A GUIDE to the FRENCH LANGUAGE, especinlly devised for Persons who wish to study the Elements of that Language without the Assistance of a Teacher. By J.J. P. LE Bretilos. The Tenth Edition, Sro. Price 12s.

A KEY to the EXERCISES in the above Work, by means of which any person of a mature understanding may acquire the elements of the French Language piactically, as surely as if a professed teacher were sitting by his side; and, with a very superficial knowledge of it, mis teach it to others. Directions are giren in the Key to parents nut accustomed to teach languiges, who wish to instruct their children, with the assistance of this book, how they must proceed. Price $S_{s}$.

G. Woodfall and Son, Printers, Angel Court, skinner Street, London. 





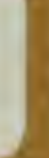

\section{UNIVERSITY OF ILUNOIS-URBANA

1

.

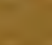

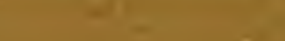

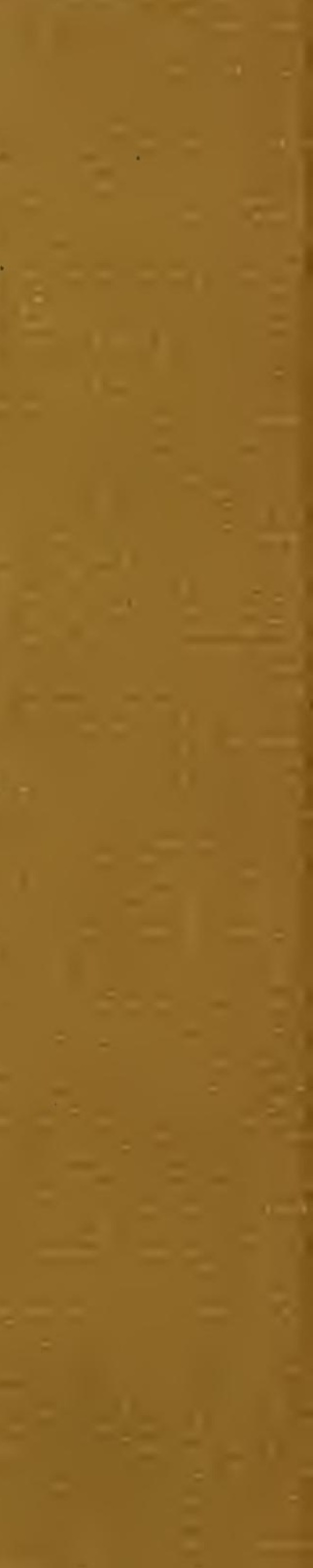

